\title{
Die Bedeutung von Idolen für Jugendliche der Dresdner Gothic-Szene
}

\section{Sandra Lehmann}

\section{Zusammenfassung}

Die Autorin untersucht in einer qualitativen Studie die Aneignung von medialen Bezugspersonen im Jugendalter mit Fokus auf die Einbindung von Musikidolen in die Lebenswelt junger Gothics. Ihre These ist, dass bei Gothics im Unterschied zu Fans von Mainstream-Musikern der Populärkultur übergreifende Wert- und Lebensstilorientierungen vorliegen. In ihrem theoretischen Überblick über das Forschungsfeld geht die Autorin auch auf Aneignungsmodi und die individuellen Funktionen von Stars für die Bewältigung von Entwicklungsaufgaben im Jugendalter insbesondere für die Identitätsbildung ein. Nach einer schriftlichen Befragung zur Sondierung des Feldes wird die Hauptstudie vorgestellt, die ausführliche Interpretation eines qualitativen Interviews mit einem Jugendlichen der Dresdner Gothic-Szene. Diese Fallstudie ist nicht nur wegen der biografischen Besonderheiten und schwierigen Lebensumstände des Jugendlichen aufschlussreich - es gelingt der Autorin auch, ihre These einer ganzheitlichen Verwendung von Musik-Idolen bei Gothics beispielhaft aufzuzeigen.

\section{Kontakt}

Sandra Lehmann M.A. frl.lehmann@web.de 


\section{Inhalt}

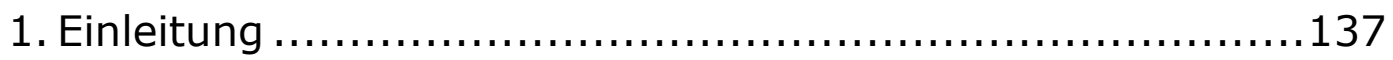

2. Vorbild, Star, Idol......................................... 143

2.1 Vorbilder ............................................... 144

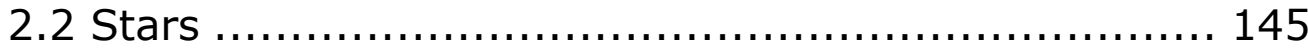

2.3 Idole ..................................................... 146

2.4 Zusammenfassung...................................... 150

3. Die Rolle von Idolen im Jugendalter und für die Identitätsbildung.......................................... 152

3.1 Entwicklungsaufgaben im Jugendalter ................. 152

3.2 Identitätsbildung im Jugendalter....................... 153

3.3 Bedeutung und Funktion von Idolen im Jugendalter... 155

4. Modi der Aneignung von Idolen ..............................160

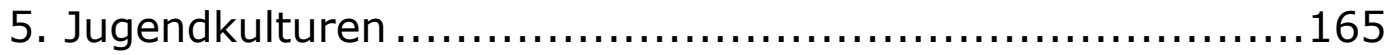

5.1 Jugendkultur, Subkultur und Szene ..................... 165

5.2 Jugendliche und Musik................................... 167

5.3 Schwarze Szene ......................................... 169

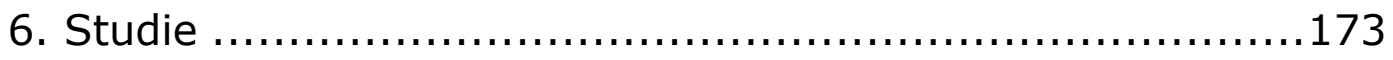

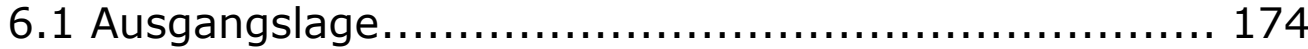

6.2 Schriftliche Befragung ............................... 177

6.2.1 Konzeption und Inhalt des Fragebogens ............. 177

6.2.2 Auswertung der Fragebogendaten .................... 181

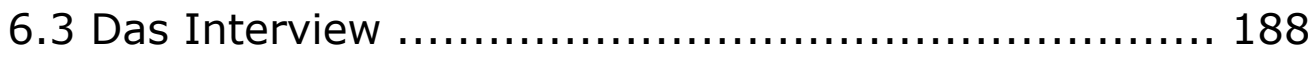

6.3.1 Leitfadenkonzeption und Methode ................... 188

6.3.2 Portrait des Idols ...................................... 190

6.3.3 Inhaltsanalyse des Interviews mit Chris (16 Jahre, Idol: Tilo Wolff) ....................................... 192 
6.3.3.1 Interviewsituation und persönlicher Lebenshintergrund .................................. 193

6.3.3.2 Soziale Kontakte und Freizeitbeschäftigungen ..... 198

6.3.3.3 Fangeschichte.................................... 200

6.3.3.4 Faszination und Funktion der Musik ................ 202

6.3.3.5 Persönliche Deutung und Bedeutung des Idols und Aneignungsmodi .................................. 205

6.3.3.6 Persönliche Werte und Zukunftspläne................ 219

7. Zusammenfassung und Fazit.................................221

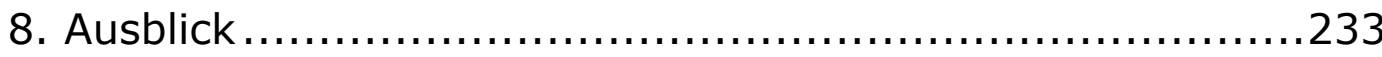

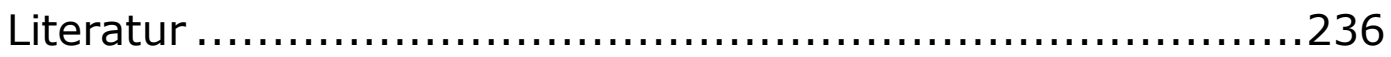




\section{Einleitung}

Die vorliegende Arbeit beschäftigt sich mit der Rolle von MusikIdolen im Alltag Jugendlicher - speziell der Dresdner GothicSzene. Jeder Mensch hat Vorbilder, Personen welche Eigenschaften besitzen, die er bewundernswert findet oder mit denen er sich identifizieren kann. Menschen, die Dinge leisten, die man selbst gerne erreichen würde, einen Lebensstil pflegen, den man selbst anstrebt oder ein Lebensgefühl verkörpern, das dem eigenen entspricht, so dass man sich mit ihnen verbunden fühlt. Diese Personen können aus der Nahwelt kommen, oder aus dem Fernbereich - Bekannte, Familienmitglieder, Freunde sein oder unerreichbare Medienpersonen. Im Jugendalter sind sie von besonderer Bedeutung für die eigene Entwicklung, um sich selbst zu reflektierten, herauszufinden wer man ist und sein möchte, Anregungen für den eigenen Lebensweg zu finden und ein Zugehörigkeitsgefühl zu bekommen, feste Wertvorstellungen und Verhaltensweisen, um sich Halt in sich selbst geben zu können. Diese Bezugsperson leistet also Orientierung bei der Suche nach der eigenen Identität und kann dadurch sinnstiftend wirken. Daher ist naheliegend, dass eine Beziehung zu einem Vorbild, Star oder Idol in der Jugend viel intensiver gelebt wird als im späteren Leben.

Neuere Studien haben gezeigt, dass die Rolle von Vorbildern, speziell aus dem Medienbereich, in den letzten Jahren wieder zugenommen hat, da Medien einen großen Teil der Freizeitaktivitäten Jugendlicher einnehmen und ein enormes Angebot an potentiellen Identifikationsfiguren offerieren. Die 13. Shell-Jugendstudie spricht von einem Supermarkt an Orientierungen, inflationär werden Stars und Wertorientierungen produziert und es gibt rund 400 Subkulturen, denen sich ein junger Mensch anschließen kann. Die Stars der Jugendlichen kommen überwiegend aus den Bereichen Musik, sowie Film und Fernsehen. Auch Sportler sind oft vertreten. Weniger nennen junge Leute dagegen Politiker oder Wissenschaftler. Unter den von 1400 Kindern und Jugendlichen zwischen sechs und 19 Jahren meistgenannten Idolen waren in einer repräsentativen Befragung von iconkids \& youth im März 2007 Sportler wie Michael Ballack oder Lukas Podolski und Musiker wie Tokio Hotel und Robbie Williams, aber auch der Moderator Stefan Raab oder Modell Heidi Klum haben für viele Vorbildfunktion. 
Sich in dieser Untersuchung auf Musikidole zu beschränken, erschien sinnvoll, da dadurch zum einen Vergleichbarkeit der Ergebnisse gegeben ist. Zum anderen spielt Musik für die meisten Jugendlichen eine wichtige Rolle im Alltag, da sie gerade auch in der Pubertät wichtige Funktionen erfüllt.

Gegenüber einer breiten Forschung zu ganzen Fankulturen gibt es wenige Studien zum Medienhandeln des Einzelnen mit seiner medialen Bezugsperson. Wegener (2008) untersuchte deshalb die Rolle von Stars im Alltag jugendlicher Fans - insbesondere die damit verbundenen Prozesse der Aneignung, sowie die Bedeutung dieser Medienbeziehung für die Identitätsbildung, die im Jugendalter als wesentliche Entwicklungsaufgabe gilt. Neben einer Onlinebefragung wurden Einzelinterviews mit Jugendlichen zwischen 14 und 17 Jahren geführt, die sich als Fans verschiedener Musiker der Populärkultur bezeichnen - konkret von Robbie Williams, Jeannette Biedermann, Eminem und Britney Spears. Es ging nicht um die Erforschung von bestimmten Fangruppen, sondern vorrangig um die Analyse der subjektiven Lesarten und Aneignungsweisen der Fans vor dem Hintergrund ihrer ganz persönlichen Geschichte und aktuellen Identitätsthemen, sowie die sich daraus ergebenden Funktionen, welche durch die Beziehung zu einer Medienfigur erfüllt werden. So individuell wie der einzelne Mensch und seine $\mathrm{Bi}-$ ografie sind auch die jeweilige Bedeutung der Stars für ihre Anhänger und die Entwicklungs- und Identitätsthemen, die sie mit ihrer Hilfe zu bearbeiten suchen.

Adoleszente entwickeln noch ihre Persönlichkeit, sie sind auf der Suche nach ihrem eigenen Wesen, entdecken ihre individuellen Bedürfnisse und wollen ihren eigenen Weg finden, sich auszudrücken und ihr Leben zu gestalten. Identitätsbildung steht in der Jugendphase im Vordergrund, da hier zum ersten Mal im Leben Eigenständigkeit im Wollen und Handeln gefordert wird. Das Thema begleitet einen jeden auch in weiteren Lebensphasen. Man ist in der heutigen Zeit gezwungen, sich ständig weiterzuentwickeln, wird mit Veränderungen konfrontiert, die eine Anpassung der eigenen Handlungsweisen und Einstellungen erfordern. Deshalb ist Identitätsbildung niemals abgeschlossen, jedoch ist sie später vielleicht nicht mehr so zentral wie noch im zweiten und dritten Lebensjahrzehnt, weil Grundpfeiler der Persönlichkeit und das 
Wissen über sich selbst eine gewisse Stabilität erlangt haben und dann auch nur noch in Grenzen wandelbar sind. Eng genommen werden nur Menschen im Alter zwischen zwölf und höchstens 20 Jahren der Jugendphase zugerechnet. Durch verlängerte Ausbildungszeiten und die Möglichkeit und Notwendigkeit von beruflichen Umorientierungen hat sich der Zeitpunkt, zu dem ein junger Mensch sesshaft wird, einen Beruf ausübt und eine Familie gründet, nach hinten, oft auf das vierte Lebensjahrzent, verschoben. Zudem haben sich diese einstigen Kennzeichen des Erwachsenenstatus zeitlich entkoppelt und sind sogar optional geworden. Deshalb gelten heute auch 20- bis 30-Jährige als jugendlich. Diese verlängerte Phase wird als Postadoleszenz bezeichnet. Kennzeichnend für diese jungen Menschen ist, dass sie kulturell selbstständig sind, eine eigene Wohnung besitzen oder in Wohngemeinschaften leben, sie haben eine Ausbildung abgeschlossen oder befinden sich noch in Ausbildung, beginnen aber noch nicht, eine eigene Familie zu gründen und befinden sich nicht in einem Beruf, der ihre materielle Subsistenz sichert (vgl. Baacke 2004, S. 134). Häufig wird der Lebensunterhalt aus verschiedenen Quellen bestritten. Aufgrund dessen und da auch das Phänomen Fan-sein und die dadurch erfüllten Funktionen nicht auf die mittlere Jugendzeit beschränkt sind, wurden die Postadoleszenten nicht aus meiner Erhebung ausgegrenzt. Zudem handelt es sich gerade bei den Gothics um eine Jugendkultur, die viele über 25 -jährige beherbergt.

Angesichts des Konzeptes der Patchworkidentitäten (Keupp 1988) - nach dem die Identität eines Menschen flexibel angelegt ist, viele Facetten besitzt, bedingt durch die Struktur der modernen Gesellschaft, so dass je nach den Rollenanforderungen in einer spezifischen Situation unterschiedliche Personenanteile in den Vordergrund treten - war im Hinblick auf die Ergebnisse dieser Arbeit auch interessant, wie ganzheitlich ein Star angenommen wird - ob es das Idol für einen Jugendlichen gibt oder eher immer mehrere Stars leitend sind, von denen dann jeweils spezifische Aspekte herausgegriffen und genutzt werden.

Die Sichtweise dieser Arbeit ist subjektorientiert, denn nicht die Analyse der Stars steht hier im Vordergrund oder eine Gruppe von 
Fans, sondern der Jugendliche, der sich sein Idol individuell nutzbar macht. Der Wahl einer solchen Leitfigur liegt eine persönliche Struktur zugrunde, die Ausdruck der eigenen Biografie und Lebenslage ist. Aus der individuellen sozialen Situation, Bedürfnissen und Rollenmustern ergeben sich spezielle Themen und Entwicklungsaufgaben, die auch mit Hilfe dieses Vorbilds zu bearbeiten versucht werden. Vor diesem Hintergrund ist eine Diskussion um falsche oder richtige Vorbilder und deren Notwendigkeit überflüssig. Denn eine Gefährdung durch ,ungünstige' Vorbilder ist nicht zu erwarten. Wenn eine solche vorliegt, dann ist dies eher in den Problemlagen des Jugendlichen begründet und nicht der Medienperson geschuldet. Bevor Erwachsene den Einfluss der Stars auf ihre Kinder kritisieren, sollten sie dahinter schauen und verstehen, welche Erfahrungen und Identitätsthemen diese mit deren Verehrung be- und verarbeiten. Die Informationen, die junge Menschen über ihre Idole und ihre persönliche Bedeutung geben, sind nützlich, um etwas über sie selbst zu erfahren, um ihre inneren Themen und Auseinandersetzungen zu verstehen. Man muss die Perspektive der Jugendlichen einnehmen, sich mit ihren Bedürfnissen auseinandersetzen, um ihre Problemlagen und Ziele nachzuvollziehen und sie in ihrer Entwicklung besser unterstützen zu können.

Für diese Arbeit war von besonderem Interesse, wie junge Menschen, die sich einer Subkultur zugehörig fühlen, ihre Stars nutzen. Ein Jugendlicher wählt ein Idol, das eigene Werte vertritt oder solche, die ihm attraktiv erscheinen. Weichen diese vom Durchschnittsbürger ab, dann könnte die persönliche Beziehung zu dieser speziellen Person sich umso intensiver gestalten, weil sie Identifikation ermöglicht, die im nahen Umfeld oder mit den meisten anderen Menschen nicht möglich ist. Durch die Bestätigung der eigenen, besonderen Weltsicht ist das Gefühl der Zugehörigkeit zu diesem Star sehr stark und die Medienbeziehung umso bedeutender für den Fan. Dadurch war zu erhoffen, dass sich Aneignungsweisen und generell die Funktionen, die das Idol im Leben dieses jungen Menschen erfüllt, umso deutlicher aufzeigen lassen. Die diesbezüglichen Ergebnisse sollten sich dann aber trotzdem auf andere Jugendliche übertragen lassen, da anzunehmen ist, dass prinzipiell die gleichen Mechanismen wirken, die hier nur stärker ausgeprägt sind. Dennoch ist natürlich nicht auszuschließen, dass 
es Differenzen zu Fans von Mainstream-Musikern gibt - bezüglich Aneignung, Bedeutung, Nutzung ihrer Stars und genereller Einbindung in den Lebensalltag. Da Gothics eine spezielle Gruppe von Jugendlichen sind, die sich von der Masse abheben, sind auch ihre Idole speziell, wodurch die damit verbundenen Aufgaben, Mechanismen und Funktionen vielleicht anders gelagert sind. Auch dieser Frage galt es durch die hier vorgestellte Befragung nachzugehen.

Die Wahl einer Szene, der man sich zugehörig fühlt, hängt eng mit persönlichen Lebenserfahrungen und Einstellungen zusammen. Die Annahme war, dass viele Jugendliche, die sich der Gothic-Kultur anschließen, spezielle biografische Erfahrungen gemacht haben und auch spezielle Einstellungen und Werte besitzen. Niemand wird einfach so "Gruftie'. „Isolation, fehlende Zuwendung und Kommunikation, Identitätsprobleme und fehlende Beziehungen zu Freunden oder Eltern zeichnen den Gothic aus"(Behr 2007, S. 134, Hervorhebung im Original). Angehörige von Jugend(sub)kulturen können aber nicht generell mit dem Etikett sozialer Benachteiligung versehen werden. Die Mehrheit dieser Jugendlichen kommen aus intakten Familien und leben ein ganz ,normales' Teenager-Dasein. Sie haben lediglich spezielle musikalische Vorlieben und Lebensanschauungen. Dennoch war zu vermuten, dass sich innerhalb dieser Szene viele junge Menschen mit diesen besonderen Problemlagen finden würden, bei denen dadurch die typischen Spannungen des Jugendalters noch verschärft werden. Auch dieser Aspekt könnte die Beziehung zu einem Vorbild intensivieren, wodurch wiederum die Hoffnung bestand, die Funktionen die es im Alltag und für die persönliche Entwicklung erfüllt, deutlich aufzeigen zu können und zudem exemplarisch die Möglichkeiten aufzudecken, die sich - im positiven Sinne - mit der Verehrung eines Idols ergeben. Denn befindet sich ein Mensch in einer schwierigen sozialen Situation und fehlen ihm brauchbare Identifikationsfiguren im realen Leben, kann ein Idol vielleicht kompensierend wirken und teilweise Ersatz leisten.

Die eigene Untersuchung, die hier vorgestellt werden soll, beinhaltet eine schriftliche Befragung mittels Pen\&Paper-Fragebögen. Darüber hinaus wurden drei Einzelinterviews geführt, zunächst mit 
dem Ziel mehrere Fälle vergleichen zu können und eine breite Palette bezüglich Bedeutung und Funktionen der Idole aufzeigen zu können. Ich beschränkte mich letztlich jedoch auf die Darlegung eines einzelnen Falles, da dieser einen pubertierenden 16-jährigen Jugendlichen zeigt, der sich bereits seit sieben Jahren der GothicSzene zurechnet, zudem sein Idol stark verehrt und es wichtige Bedeutung im Alltag, für sein Selbstbild, sowie seine Identitätsentwicklung besitzt. Bei diesem Jungen handelt es sich um einen Spezialfall, da er zum einen aus schwierigen familiären Verhältnissen stammt und zum anderen eine Borderline-Persönlichkeitsstörung bei inm diagnostiziert wurde, wegen der er auch in stationärer Behandlung war. Diese Krankheit zeigt sich in Abweichungen der emotionalen Wahrnehmung und bestimmten Verhaltensweisen, so dass sich die Beziehungen zu anderen Menschen speziell gestalten und sich dadurch möglicherweise auch die Ausprägung der Funktionen und Mechanismen in einer Medienbeziehung verstärkt. Aus diesem Grund und weil dieser Junge zudem derzeit relativ isoliert von Freunden und Familie leben muss, bekommt sein Idol einen besonderen Platz in seinem Leben. Dieser Fall vermag alle Facetten der Aneignung von Idolen aufzuzeigen, wie es bei keinem der anderen interviewten Jugendlichen möglich war und gibt ausreichend Material, um mögliche Funktionen von Vorbildern, Stars und Idolen aufzuzeigen.

Somit kann als wesentliche Fragestellung für die Analyse dieses Einzelfalles gelten, welche Rolle ein Idol im Leben eines Adoleszenten in einer schwierigen Lebenslage spielt, im Hinblick auf die Bewältigung typischer Aufgaben im Jugendalter - zu denen die Entwicklung einer eigenen Identität, die Akzeptanz der eigenen Person und die Ausgestaltung der Beziehungen zu Freunden und Familie gehören, ebenso wie die Entwicklung von Lebensentwürfen und Zielen. Dabei erlaubt ein solch besonderer Fall, dessen Lebenssituation und psychische Verfassung zusätzlich spezielle Problematiken provoziert, noch weniger als ohnehin schon Einzelfälle, keine Generalisierung der Ergebnisse auf andere Jugendliche. Dennoch wirken m.E. dieselben Mechanismen bei der Aneignung und Nutzung von Idolen, vermutlich aber in ausgeprägterer Form, denn die Tiefe der Auseinandersetzung und Funktionalität der Beziehung des Jungen zu seinem Star ist gesteigert, wodurch die Mechanismen aber - wie bereits betont - erst deutlich sichtbar 
werden, und dieser Fall deshalb für eine wissenschaftliche Analyse gut geeignet erscheint.

Im Folgenden sollen zunächst die Begriffe Vorbild, Star und Idol näher erläutert werden, da diese zwar oft parallel verwendet werden, jedoch analytisch betrachtet im Grunde unterschiedliche Aspekte eines Phänomens beschreiben und auch subjektiv durch den Einzelnen mit verschiedenen Bedeutungen besetzt sind. Im darauffolgenden Kapitel geht es um die Spezifika des Jugendalters, typische Entwicklungsaufgaben, mit besonderer Beachtung der Identitätsbildung als zentralem Aspekt, der eng mit der Aneignung und Nutzung von Vorbildern im Zusammenhang steht. Zudem sollen Forschungsergebnisse zum Stellenwert und den Funktionen von Idolen im Jugendalter vorgestellt werden. Ein weiterer Abschnitt der Arbeit wird auf Modi der Aneignung von Stars und Idolen eingehen, die einen wichtigen Schwerpunkt der Untersuchung darstellen. Das letzte Kapitel der theoretischen Abhandlung setzt sich mit Jugendkulturen auseinander, insbesondere der Gothicszene, sowie den Funktionen, die Musik, als ein konstituierendes Merkmal solcher Gruppierungen, im Jugendalter einnimmt. Im zweiten, praktischen Teil der Arbeit wird die eigene Untersuchung vorgestellt, wobei zunächst die Vorgehensweise und theoretische Ausgangslage erläutert wird. Darauf folgt die Zusammenfassung und Deutung der Ergebnisse der Fragebogen-Erhebung und anschließend die ausführliche Analyse des qualitativen Interviews mit dem 16-jährigen Chris. Den Abschluss bilden eine Zusammenfassung der wesentlichen Ergebnisse, das Fazit der Arbeit, sowie ein Ausblick für die weitere Forschung.

\section{Vorbild, Star, Idol}

Der Titel dieser Arbeit spricht von Idolen und ihrer Bedeutung für Jugendliche. Synonym wären auch die Begriffe Vorbild oder Star möglich gewesen. Es geht um personale Leitbilder für junge Menschen, hier Personen in den Medien, speziell Musiker. Das Anliegen war, Jugendliche zu finden, die nicht nur über einen Star sprechen, den sie neben anderen auch mögen, sondern über eine Person, die sie in erster Linie und umfassend verehren, die eine bedeu- 
tende Rolle in ihrem Leben spielt. Der Begriff ,Idol' erschien ausdrucksstark genug, um genau die Jugendlichen zu finden, die ihrem Lieblingsmusiker diesen Status einräumen. Denn die Bedeutung und Funktionen für die Identitätsbildung und im Alltag eines Menschen in aller Deutlichkeit aufzeigen zu können, wird m.E. erleichtert, wenn die Identifikation mit dem Star und seine Verehrung ausreichend groß sind und eine intensive Beziehung gelebt wird. Die Assoziationen, die Jugendliche zu den Bezeichnungen haben, können ganz unterschiedlich sein und auch ob sie diese für sich akzeptieren, ist einstellungsabhängig. Unabhängig von der subjektiven Interpretation, ist es jedoch sinnvoll, die drei Begriffe zumindest analytisch zu trennen, da sie unterschiedliche Seiten eines Phänomens beschreiben. Im Folgenden sollen ,Vorbild', ,Star' und ,Idol' deshalb kurz näher definiert werden.

\subsection{Vorbilder}

Vorbilder können Menschen aus dem Familien- und Bekanntenkreis sein oder auch Personen aus Geschichte und Gegenwart, an denen sich andere orientieren. Sie sind Leitbilder, die zur Identifikation und Nachahmung anregen. Dabei muss die Person nicht allumfassend bewundert werden, sondern auch einzelne Eigenschaften können herausgegriffen werden (vgl. Janke 1997, S.19). Laut der IBM-Jugendstudie von 1995 sind die wichtigsten Merkmale, die Jugendliche an ihren Vorbildern schätzen, konkurrenzbetonende wie Durchsetzungsvermögen, Zielstrebigkeit und Konsequenz vor moralischen Eigenschaften wie Ehrlichkeit, Aufrichtigkeit und Toleranz. Die hohe Bewertung dieser Charaktermerkmale durch Jugendliche, verweist auf das Klima unserer Gesellschaft, die Leistung und Erfolg fordert und gar zum obersten Wert erhebt.

Der Vorbild-Begriff ist traditionell dem Pädagogischen zuzuordnen, den Bereichen Moral, Intellekt und Leistung (vgl. Wegener, S. 20). Da Erwachsene befürchten, Kinder könnten - in ihren Augen falschen Vorbildern nacheifern, sind sie oft bemüht, ihnen brauchbare vorzusetzen. Gerade dies führt zu einem negativen Image des Begriffes, da die Jugendlichen inn mit Zwang und Verordnung assoziieren. Vermutlich führt deshalb die Frage nach Vorbildern bei jungen Leuten in Umfragen oft zu einer Abwehrhaltung. Die 
Verwendung der Begriffe Star, Idol, Kultfigur o.ä. sind dagegen vielleicht weniger negativ besetzt und bewegen daher möglicherweise eher dazu, sich zu einer Leitfigur zu bekennen.

Grundlegend gilt, dass Personen zwar als potentielle Vorbilder angeboten werden können, aber die tatsächliche Wahl trifft jeder Einzelne nach individuellen Kriterien. Welcher Mensch wirklichen Orientierungscharakter bekommt, ist von vielen persönlichen Faktoren abhängig und daher nicht vorherzusehen oder vorsetzbar. Es hat immer auch mit der eigenen Persönlichkeit, den bedeutenden (Entwicklungs-)Themen, Problemlagen, Bedürfnissen und Zielen im Leben zu tun. Sicher ist jedoch, dass von jeher in jedem Leben andere Menschen, ob bewusst oder unbewusst, als Orientierung eine wichtige Rolle spielen.

\subsection{Stars}

Ein Star ist eine prominente Persönlichkeit. Zumeist handelt es sich um Schauspieler, Musiker oder Sportler. Auch Wissenschaftler oder Politiker können Starstatus bekommen. Wesentlich ist, dass die Person eine relativ große Fangemeinschaft hat, die ihr ein gewisses Maß an Bewunderung zuteilwerden lässt. Der Star wird erst durch den Fan ${ }^{1}$ erschaffen, er steht inm notwendig gegenüber.

Beim Star geht es nicht vorrangig um Leistung und Moral, wie beim Vorbild, sondern bei inm stehen Image und Aura im Mittelpunkt - er muss unverwechselbar und unerreichbar sein (vgl. Wegener, S. 20). Ein Mensch in den Medien wird immer auf eine bestimmte Art dargestellt. Um inn wird ein Mysterium errichtet, er wird inszeniert und tut dies selbst. Der Mensch hinter dieser Fassade ist nie ganz erkennbar, was Spekulationen und Phantasien darüber anregt, inn geheimnisvoll macht und dadurch eine besondere Faszination bewirkt. Der langfristige Erfolg einer Figur ist nicht vorhersehbar und damit auch nicht konstruierbar. Dies zeigen die unzähligen Prominenten, die die Unterhaltungsindustrie regelmäßig neu produziert, aber die auch ebenso schnell wieder in der Versenkung verschwinden. Echte Starqualitäten, Unverwechselbarkeit und Charisma können nicht einfach erworben werden.

${ }^{1}$ Der Fan ist als begeisterter Anhänger einer Person oder Sache definiert (vgl. Duden (Fremdwörterbuch), 1997, S. 254). 
Man kann versuchen, jemanden so zu inszenieren, dass er ein breites Publikum anspricht, aber ob er sich langfristig behauptet, liegt nicht in den Händen der Produzenten. Wie das Image eines Stars vom Einzelnen wahrgenommen und interpretiert wird, ist dabei wiederum subjektiv geprägt, denn es hängt von den eigenen Hintergründen und Lebensthemen ab.

\subsection{Idole}

Etymologisch ist Idol abgeleitet vom griechischen, eidolon' und hat die Bedeutungen Gestalt, Bild, Götzenbild oder Abgott. Es handelt sich in diesem Fall also um eine Person, die von den Menschen übermäßig geliebt oder vergöttert wird.

Ein Star kann zum Idol werden, wenn die Faszination noch eine Steigerung erfährt: „Das Idol braucht den Himmel, das Geheimnis der Ewigkeit, die Überschreitung der Zeit. Es ist kein Zufall, dass geheimnisumwitterter, unnatürlicher Tod hier so häufig vorkommt. Er ist Teil des Mythos. Stars werden bewundert, Idole verehrt. Idole sind Göttinnen und Götter im Himmel einer verweltlichten Religion. Idole können nicht industriell erzeugt werden; die Ewigkeit wird nicht durch die Industrie verliehen" (Biermann et al. 1997, S.1).

Idole sind grundsätzlich unerreichbar und wie bei den Stars handelt es sich um Musiker, Schauspieler, Sportler oder seltener auch um Wissenschaftler oder Politiker. Prototypen sind früh und tragisch verstorbene Kultfiguren wie beispielsweise Elvis Presley, James Dean, Jim Morrisson oder Kurt Cobain, aber auch Führer politischer Bewegungen, wie Rudi Dutschke oder Che Guevara, Wissenschaftler wie Albert Einstein und Politiker wie John F. Kennedy. Während der Star Mensch bleibt, der für sein Talent und die Leistungen auf seinem Gebiet gewürdigt wird, gilt dem Idol die Verehrung als Gesamtbild - Privatperson und Rollen-Image sind nicht getrennt. Er wird über die Normalsterblichen herausgehoben, weil er einen spezifischen Mythos verkörpert (vgl. Sommer 1997, S.115). Oft wird einem Star erst nach seinem Tod der Idolstatus zugesprochen. Der Kult wird noch verstärkt, wenn er auf dem Gipfel seines Erfolges ablebt, da damit seine Jugendlichkeit und der Glanz des Ruhms verewigt werden und weil auch die mögliche Entdeckung von menschlichen Schwächen dieses Bild nicht mehr 
zerstören können. Anhänger von Idolen weisen Parallelen zu religiösen Eiferern auf - Fans idealisieren ihr Idol, leugnen unangenehme Enthüllungen, pilgern zu Wohnsitz oder Grabstätte oder bestreiten sogar den leiblichen Tod desjenigen (vgl. Janke 1997, S.21). Dieses Phänomen war zum Beispiel erst kürzlich nach dem Ableben Michael Jacksons zu beobachten.

Die Überzeugungskraft von Idolen ist abhängig davon, ob sie eine Geschichte anbieten, die als Projektionsfläche für eigene Sehnsüchte, Hoffnungen und Erwartungen dienen kann und ob sie Lösungen für die eigene Situation eröffnet. Kennzeichnend für den Umgang mit Idolen ist die Gleichzeitigkeit von Distanz und Nähe. Über bestimmte Objekte oder Praktiken ist das Idol fest im Alltag verankert, aber der Zugang ist - wie auch bei den Stars - nur über Medien möglich, die ersehnte Informationen über deren Leben liefern (vgl. Waldmann 2000, S.2).

Nach Krüger und Richard (1997) haben seit der Nachkriegszeit drei traditionelle Idoltypen bestand:

Das tragische Idol symbolisiert das Zerbrechen der Individualität und den gescheiterten Versuch in die Erwachsenenwelt einzutreten, was bis zum Selbstmord führen kann. Diese Menschen zerbrechen an den Umständen ihres Lebens, an der gegebenen Welt, die ihre Gefühle nicht versteht und achtet. Das eingestandene Scheitern wird zum Kult. Beispiele sind tragisch verstorbene Stars wie James Dean, Kurt Cobain, River Phoenix oder Ian Curtis. Letzterer ist ein Idol der Gothic-Punk-Szene, eine hypersensible Seele, die sich 1980 vermutlich aus unerfüllter Liebe, der Überforderung durch den aufkeimenden Ruhm und aus der Ohnmacht gegenüber seiner Epilepsie-Erkrankung das Leben nahm. Jugendlichen, die oft an einer ähnlichen Zerrissenheit bezüglich eigener Gefühle, Persönlichkeit und Lebenszielen leiden, kann die Anteilnahme am Schicksal ihrer tragischen Idole helfen, eigene Schwierigkeiten in konstruktiver Weise - zu bewältigen.

Das konservative Ido/ steht für Konformität und schnellen, erfolgreichen Aufstieg in die Erwachsenenwelt. Im Rahmen der akzeptierten Normen haben sie es zu Erfolg gebracht und werden als Vorbilder kollektiv verehrt. Beispiele sind angepasste und leis- 
tungsorientierte Sportidole, z.B. Michael Ballack, Stefan Kretzschmar oder Michael Jordan. Einen eigenen Stil zu entwickeln ist hier nicht ausschlaggebend.

Das rebellische Idol steht für zielloses, aggressives Aufbegehren gegen Normen und Tabus. Es geht um das Leben des eigenen Stils, ohne Angst vor Konsequenzen. Beispiele sind Marlon Brando oder Jim Morrisson. In einem gesellschaftlich begrenzten Freiraum führen sie alles aus, was, normalen' Jugendlichen versagt bleibt. Der Kultstatus wird durch frühen Tod noch verstärkt.

Seit den 80ern hat sich ein neuer Typus von Idolen im musikalischen Bereich herausgebildet, den Krüger und Richard (1997) das geklonte posthumane Idol nennen. Charakteristisch sind multiple, künstlich hergestellte Identitäten und Körper. Bezeichnend ist das wechselnde Schlüpfen in Rollen, das Spiel mit Maskeraden, Kleidungsstilen und Androgynie. Beispiele sind Michael Jackson, Madonna oder Prince.

Das Idol bedarf der einstimmigen Verehrung vieler. Idole brauchen die Masse, weil sie ein selbstverstärkendes Moment darstellt - immer weitere Fans werden dadurch angezogen (vgl. Janke 1997, S. 21). In Zeiten der Pluralisierung und Individualisierung, durch Differenzierung der Gesellschaft in immer kleinere Gruppen, sind jedoch große verbindende Idole am Aussterben. Es kommt eher zur vereinzelten Hinwendung zu ganz unterschiedlichen Stars, die kaum noch überindividuelle Geltungskraft haben (vgl. Wegener 2008, S. 28). Grundlegend ist aber, welchen Status eine Medienperson für das Individuum hat. Zunächst zählt der Grad der ganz persönlichen Würdigung. Prinzipiell kann eine Figur auch sehr stark verehrt werden, wenn keine Masse hinter ihr steht. Gerade in einer Zeit, in der Individualität großgeschrieben wird, kann es Jugendlichen ein gutes Gefühl geben, ein ,eigenes' Idol zu haben, beziehungsweise eines, dass verhältnismäßig wenige mit ihm teilen. Die Masse ist letztlich aber doch notwendig dafür, dass eine Medienperson subjektiv als Idol betrachtet wird, denn zum einen wird sie erst bekannt und erfolgreich, wenn sie genügend Verehrer gefunden hat und zum anderen ist immer anzunehmen, dass eine Person die eine solche Faszination bei einem Menschen bewirken kann, auch viele andere mit dieser Aura erreicht und beeindruckt. Die entstehende Massenbewegung verstärkt dann den Kult um die 
Person. Trotz Differenzierung der Gesellschaft ermöglicht die Globalisierung letztlich auch die internationale Vernetzung von Fans, so dass zwar nicht im näheren Umfeld eine große Fangemeinde vorhanden sein muss, doch aber weltweit. Über das Internet, Fanclubs, Foren, Homepages etc. haben Fans die Möglichkeit, ihre Leidenschaft, Wünsche und Fantasien mit anderen zu teilen - so wird dem Einzelnen doch wieder das Gefühl einer verstärkenden Masse gegeben.

Auch viele der großen Idole früherer Zeiten, üben noch heute ihre Faszination aus. Der 1994 verstorbene Ausnahmekünstler Kurt Cobain - Sänger der Grunge-Band Nirvana - findet noch immer treue Anhänger. Und Ian Curtis - Sänger der Postpunk-Band Joy Division -, der sich bereits 1980 das Leben nahm, vermag junge Leute in seinen Bann zu ziehen, die zum Zeitpunkt seines Todes nicht einmal geboren waren. Möglich ist dies durch die fortlaufende Widerbelebung des Kults durch die Industrie. So erschienen in den letzten Jahren eine Autobiografie seiner Witwe und ein filmisches Portrait des Sängers von dem Star-Fotografen und Regisseur Anton Corbijn. Die Musik von Joy Division war wegweisend in der Entstehungszeit der Gothic-Szene. Wer sich dieser Szene anschließt, kommt nicht an Ian Curtis und seiner Verehrung vorbei.

Idole werden auch heute noch geboren. Der im Juni 2009 verstorbene ,Pop-King' Michael Jackson führte zur massenhaften Mobilisierung von Fans aus aller Welt, die seine Neverland-Ranch zur wahren Pilgerstätte auf erheben. Wenn er nicht schon zu Lebzeiten als Idol gelten konnte, ist er es spätestens jetzt geworden. Auch der Schauspieler Heath Ledger, der 2008 im Alter von 28 Jahren an einer Überdosis Tabletten verstarb, bekam, Idol-typisch verstärkt durch seinen frühen Tod, Kultcharakter.

Jeder musikalische Stil hat seine Idole, selbst solche die sie ablehnen. Zum Beispiel hat die Punkbewegung in den 70er Jahren welche die Parole , kill your Idols' feierte - mindestens ein Idol hervorgebracht, namentlich Sid Vicious, den Sänger der Sex Pistols. Und auch die Technobewegung, die in den 80ern entstanden ist und einzig die Musik in den Vordergrund stellen wollte, macht ihre DJs letztlich zu Stars. Das Hervortreten einzelner Personen innerhalb einer (musikalischen) Bewegung, scheint unvermeidliches Gesetz zu sein, weil die Jugend diese sucht und braucht. 
Besonders Jugendliche haben tiefe Sehnsüchte und Unsicherheiten auszustehen, die der Beistand von Idolen oder Stars, als Übermenschen, erleichtert. Gerade im Zeitalter der Individualisierung und Vereinzelung, bei dem gleichzeitigen - weil menschlichem Bedürfnis nach Zugehörigkeit, dürften verbindende Idole und Ideale eine wesentliche Rolle spielen. Denn, wenn auch unter Wahrung einer besonderen Ausrichtung, wie durch die Zugehörigkeit zu einer bestimmten Subkultur, können sie Halt und Orientierung geben. Die Ganzheitlichkeit der Ausrichtung an einem Idol, also ob die Person leitend für alle Identitätsthemen gleichzeitig zu sehen ist, kann angezweifelt werden, ist aber auch nicht notwendig dafür, wichtige Funktionen für die Selbstbildung zu übernehmen.

\subsection{Zusammenfassung}

Resümierend kann festgehalten werden, dass die Begriffe Vorbild, Star und Idol analytisch auseinandergehalten werden müssen, da sie unterschiedliche Facetten eines Phänomens beschreiben. Jedoch übernehmen sie letztlich alle dieselben Funktionen für eine Person, nur auf anderen Ebenen und für andere Bereiche des Denkens und Fühlens. Sie stehen jeweils für einen bestimmten Lebensentwurf, von denen sich ein Mensch, begründet in der eigenen Struktur, angezogen fühlen kann oder eben nicht.

Das Vorbild appelliert an intellektuelle und moralische Vorstellungen, der Star appelliert an Gefühle und Leidenschaften und das Idol bindet ins irrationale weisende Energien - letzteres macht das Phänomen daher zum rätselhaftesten der drei (vgl. Janke 1997, S.21). Wie bereits erwähnt, zielte diese Arbeit auch aus diesem Grund auf die Idol-Thematik ab. Es bestand die Hoffnung, in der Gothic-Szene Anhänger solcher teils bereits verstorbenen Kultfiguren zu finden, oder zumindest Fans, die ihrem Musiker den IdolStatus einräumen und inn stark und umfassend verehren. Denn die Analyse einer solchen Medienbeziehung würde interessante, deutliche und reichhaltige Ergebnisse versprechen. Zudem zielte die Untersuchung auf Jugendliche, die in schwierigen Verhältnissen leben, womit genau diese jungen Menschen gefunden wären, für die eine Gefährdung ihrer persönlichen Entwicklung durch die übermäßige Verehrung von Medienpersonen am ehesten ange- 
nommen wird. Die Erforschung der Beziehung, die diese Jugendlichen zu ihren Idolen pflegen, könnte diese Befürchtungen ausräumen.

Wegener (2008) nutzte die neutrale Bezeichnung ,mediale Bezugsperson', um sich nicht vorab auf einen der Begriffe und ihre Bedeutung festzulegen, da diese eine einseitige Richtung der Aneignung implizieren und die spezifische Ausdeutung und Transformation der Figur durch das Subjekt außer Acht lassen (vgl. ebd., S. 32). Der Begriff sollte individuell erst nach Analyse des Rezeptionsprozesses präzisiert werden. Wie bereits erwähnt, haben Jugendliche oft ihre eigenen Interpretationen und Assoziationen zu den Begriffen. Weshalb der tatsächliche Status, den eine Medienperson für einen Menschen bekommt, tatsächlich erst nachvollzogen werden kann, wenn man sich intensiv mit dem Fan auseinander gesetzt hat.

In der schriftlichen Befragung der hier vorgestellten Untersuchung wurde der Begriff ,Vorbild' bewusst vermieden, um keine Abwehrhaltung bei den Jugendlichen zu erzeugen. Da diejenigen erreicht werden sollten, die eine Person ausschließlich und sehr stark verehren, bat sich die Bezeichnung ,Idol' an, wodurch dieser Aspekt in aller Deutlichkeit zum Ausdruck kommt. Später in den Interviews lehnten die Befragten aber im Allgemeinen auch den IdolBegriff ab, da sie damit eine Person assoziieren, die jemand uneingeschränkt positiv sieht und versucht zu kopieren. Dies passt nicht zu den zentralen Werten der heutigen Jugend - zu denen Einzigartigkeit, Individualität und Authentizität gehören. Es gestaltet sich also schwierig mit einer begrifflichen Formulierung den Nerv der Jugend zu treffen, um ein Phänomen zu beschreiben, dass zweifelsohne existiert. Die Jugendlichen bewerten die entsprechenden Bezeichnungen individuell und nehmen sie dementsprechend an oder lehnen sie ab. "Mediale Bezugsperson" (Wegener 2008) klingt zu steif und konstruiert um Jugendliche damit direkt ansprechen zu können. Es handelt sich dadurch immer um einen schmalen Grad und eingeschränkte Vergleichbarkeit in einer solchen Untersuchung. Trotz der Kenntnis um die wissenschaftliche Definition und Abgrenzung der Begriffe Vorbild, Star und Idol, werden die Bezeichnungen nachfolgend, zur besseren Lesbarkeit des Textes, auch synonym verwendet. 


\section{Die Rolle von Idolen im Jugendalter und für die Identitätsbildung}

\subsection{Entwicklungsaufgaben im Jugendalter}

Die Jugend ist eine Zeit der Orientierung und Sinnsuche. Jugendliche sind in der Pubertät mit einer Vielzahl an Aufgaben konfrontiert. Havighurst (1972) und daran anschließend Dreher \& Dreher (1985) haben ein Konzept von Entwicklungsaufgaben im Jugendalter entwickelt.

Zunächst sind erhebliche Veränderungen des eigenen Körpers zu sehen, die akzeptiert werden müssen. Daran knüpft sich auch die Auseinandersetzung mit und die Annahme der eigenen $\mathrm{Ge}$ schlechtsrolle. Der Heranwachsende muss seine Abhängigkeit von den Eltern lösen und tiefere Beziehungen zu Gleichaltrigen aufbauen. Auch erste Erfahrungen mit Liebesbeziehungen werden gesammelt. Der Jugendliche muss lernen selbstständig zu sein, zu denken und eigenständig Pläne für die mittlere Zukunft entwickeln - bezüglich Berufswunsch, Familiengründung und Lebensform. Er muss sich über seine Gefühle und Bedürfnisse bewusst werden, einen Weg finden, sie in Eintracht mit anderen zu leben. Es gilt eine eigene Identität auszubilden, wobei die Balance zwischen Anpassung und Individualität gefunden werden muss. Der junge Mensch steht damit oft im Dilemma zwischen verschiedenen Ansprüchen, nämlich den Erwartungen der Umwelt, der Schule und der Erwachsenen allgemein gegenüber den eigenen Wünschen und den Vorstellungen, wie man sein möchte und welchen Lebensstil man für sich beanspruchen möchte. Die Situation der Jugendlichen ist dabei oft paradox, denn auf der einen Seite wird ihnen Mündigkeit und Entscheidungsfähigkeit abverlangt, andererseits werden aber Möglichkeiten vorenthalten, sie zu realisieren. Will er selbstständig handeln, wird er oft kontrolliert und gemaßregelt, verzichtet er auf eigene Entscheidungen, wird ihm auch das vorgeworfen (vgl. Baacke 2004, S. 256). Zudem werden eigene Wertvorstellungen und eine Moral entwickelt, wobei durch die Masse an Identifikationsangeboten und möglichen Lebensentwürfen in der heutigen Zeit ein relativ großer und damit auch verwirrender Spielraum existiert. Nahezu jede Norm oder Konvention darf heute hinterfragt werden. 
Die potentiellen Wahlmöglichkeiten für den Lebenslauf führen auch zu der Qual Entscheidungen treffen zu müssen, deren Reichweite noch nicht ab- und einschätzbar ist (vgl. Liebau 1997, S. 24). Zudem kann diese Freiheit als unbefriedigend erlebt werden, weil eine Entscheidung letztlich immer mit dem Unsicherheitsgefühl verbunden ist, andere, womöglich bessere, Möglichkeiten verpasst oder ausgelassen zu haben. Die Wahlfreiheit für den Lebenslauf ist letztlich auch nur eine Illusion, denn real hat nicht jeder alle Kompetenzen und Ressourcen, um jedes Ziel zu verwirklichen. Nicht jedem ist gegeben, ein hohes formales Bildungsniveau zu erreichen und damit den Ausbildungs- oder Studienplatz zu bekommen, den er sich wünscht. Hierfür benötigt er neben Ehrgeiz und Intelligenz auch die soziale und finanzielle Unterstützung seiner Familie. Jemand kann auch anstreben ein bekannter Musiker zu werden und alles dafür tun, der Erfolg muss aber auch dann nicht eintreten, wenn er durchaus das Potential dazu hätte. Und selbst wenn einem Menschen gegeben ist, den gewünschten Berufsweg einzuschlagen, sind der Erfolg in Ausbildung beziehungsweise Studium und der Verlauf der beruflichen Karriere von vielen vom Individuum nicht beeinflussbaren Faktoren abhängig. Jugendliche haben folglich oft das Gefühl schlechter Zukunftsaussichten und weniger Sicherheiten, Leben daher für den Augenblick und pflegen einen eher hedonistisch-genussreichen Lebensstil (vgl. Ferchhoff 2007, S. 319).

Das Forschungskonzept der Entwicklungsaufgaben geht von einer klar definierbaren Übergangsphase aus. Tatsächlich sind aber heute die Statusübergänge zeitlich verschoben und zudem optional. Beispielsweise wird der Jugendliche relativ früh finanziell selbstständig, aber gründet eine Familie, wenn überhaupt, erst sehr viel später. Jugendlichkeit ist darüber hinaus auch kein bloßer Übergang mehr, sondern ein Wert, den auch Erwachsene heute anstreben.

\subsection{Identitätsbildung im Jugendalter}

Das Konzept der Identität und Identitätsbildung ist eng mit dem Namen Erikson verbunden. Sein von der Psychoanalyse beeinflusstes entwicklungspsychologisches Modell thematisiert Jugend 
als Krise im Lebenslauf und setzt dabei einen normativen Zielpunkt der Jugendentwicklung voraus - eine gelungene Ich-Identität herauszubilden (vgl. Ferchhoff 2007, S.101). Identität bezeichnet bei Erikson die Kontinuität des Selbsterlebens. Dabei ist wesentlich, dass das Gefühl persönlicher Identität zum einen die eigene Kontinuität des Erlebens voraussetzt, als auch die Wahrnehmung dieser selbsterlebten Gleichheit und Stabilität durch andere (vgl. Erikson 1966, S. 18). Nach Erikson ist Identitätsbildung ein lebenslanger Prozess, der in bestimmten aufeinander aufbauenden Lebensphasen jedoch mit spezifischen Aufgaben verbunden ist, die zwar das ganze Leben lang bestehen, aber in der jeweiligen Phase zentral sind und gelöst werden müssen, um in das jeweils nächste Stadium einzutreten und schließlich im Erwachsenalter eine stabile Identität zu entwickeln.

Im Jugendalter gilt es für jeden seine soziale Rolle zu finden und zu festigen, eigene Fähigkeiten und Rollen zur Identität zu integrieren, was bei Überforderung, im Konflikt zwischen Rollen und Anforderungen, zu Identitätsverwirrung führen kann. Der Bewältigung dieser Thematik kann auch die Orientierung an Leitbildern dienlich sein.

Anschließend an Erikson spricht Marcia (1993) von einem Moratorium - einem von vier Identitätszuständen - in dem sich Jugendliche befinden. Dies ist eine experimentelle, krisenhafte Periode, aus der sich bestenfalls eine erarbeitete Identität mit eigenem stabilem Standpunkt entwickelt. Die unreflektierte Übernahme von Rollen und Werten führt zur übernommenen Identität und bei Orientierungslosigkeit, Desinteresse, mangelnden Überzeugungen und wenig Bestreben diese zu erlangen, kommt es zu Identitätsdiffusion. Nicht jeder entwickelt im Laufe seines Lebens eine erarbeitete Identität.

Fan zu sein, wird oft als der Jugendphase zugehörig angesehen. Gerade weil Jugendliche noch auf der Suche nach der eigenen Identität sind und ihr Zugehörigkeitsgefühl zu einem Star, einer Musik oder Lebensanschauung besonders nach außen sichtbar machen. Es gibt aber auch erwachsene Fans, was darauf hinweist, dass die Funktionen des Fan-seins nicht allein auf die Jugendphase begrenzt sind. 
Es ist anzuzweifeln, dass Identität noch im Sinne von Kontinuität und Eindeutigkeit zu verstehen ist und zu einem bestimmten Zeitpunkt im Erwachsenenalter als abgeschlossen gelten kann. Sie besitzt keinen konsistenten und essentiellen Wesenskern im Sinne eines eindeutigen und stabilen Sinnmittelpunkts, sondern scheint heute vielmehr fragmentarische Teil-, Augenblicks-, Situations- oder Patchworkidentität zu sein, die den Eindeutigkeitszwang transzendiert (vgl. Keupp 2005, S. 87). Identitätsbildende Prozesse spielen in jeder Lebensphase eine Rolle. Mit der Schnelllebigkeit der heutigen Zeit, in der Pluralität konstitutionell ist, die Notwendigkeit besteht, flexibel und individuell zu sein, sowie der Einzelne ständigen Unsicherheiten und beruflichem wie privatem Wandel unterworfen ist, gibt es im Verlauf des Lebens immer wieder Ereignisse und neue Rollen, die in die Persönlichkeit integriert werden müssen. Somit ist auch das Selbst einem ständigen Wandel unterworfen, Entwicklung gibt es daher in jeder Lebensphase. Die Suche nach Identität endet nie. Die Jugendphase hat trotzdem einen Sonderstatus, da hier erstmals eine eigene Identität konstruiert wird.

\subsection{Bedeutung und Funktion von Idolen im Jugendalter}

Jugendlicher zu sein, bedeutet auch Sehnsucht. "Sehnsucht ist der Hunger der Seele, der sich auf das "Andere" richtet, auf das was die Person nicht ist und nicht hat, was nicht um sie oder bei inr ist" (Liebau 1997, S. 24). Der Pubertierende sehnt sich nach einem schönen, fertigen Körper, nach glücklicher Liebe, nach guten Freundschaften, nach der eigenen Aufgabe im Leben und einer klaren Haltung.

Aufgrund der Pluralität an Möglichkeiten und teilweisen Paradoxien, bei mangelnder Orientierung, kann es zu Überforderung und Ratlosigkeit kommen. "Die für viele als nicht aushaltbar erlebte Sinnzerissenheit und ontologische Bodenlosigkeit kann wiederum die Sehnsucht nach mehr Lebenswärme, nach mehr Sicherheit, nach mehr Gewissheit, nach mehr (Lebens-)Sinn und meditativer Spiritualität, nach mehr sozialer Verortung und Heimat, nach mehr Bindung u. Gemeinschaft und nach (vermeintlich) stabilen und eindeutigen Identitätsangeboten fördern" (Ferchhoff 2007, S. 289). Bei allem Bestreben nach Einzigartigkeit und dem eigenen 
Weg in der heutigen Zeit, bleiben Gemeinschaftsgefühl, Verbundenheit und Halt auf der Strecke, die der Jugendliche aber unbedingt braucht, um sich nicht verloren zu fühlen. Stars, Idole oder Vorbilder können diese Sehnsucht stillen, sie können vorübergehend Orientierung, Sinn und Halt geben und das Gefühl von Zugehörigkeit - zu Gleichgesinnten, zu einem Werteschema und Lebensstil.

Baacke beschreibt Identität als Beziehungsleistung, die durch Imitation, Identifikation und Vergleich mit anderen entsteht. "[...] [J]emand erkennt sich als geworden und nunmehr in gewisser Weise gleichbleibend und wiedererkennbar; geworden und wiedererkennbar ist er mit Hilfe der Interaktionen mit anderen, deren Eigenschaften, Interessen und Motive er einerseits teilt, andererseits aber für sich differenziert - denn nur auf diese Weise wird seine Identität von der anderer abgrenzbar" (Baacke 2004, S.254, Auslassung und Anpassung: S.L.). Jugendliche können sich in ihren Stars spiegeln, sich reflektieren, wiederfinden oder inspirieren lassen. Die Auseinandersetzung mit ihrer Bezugsperson unterstützt sie bei der Arbeit am Selbst- und Weltbild und der Bewusstwerdung ihrer eigenen Persönlichkeit. Der Jugendliche wählt sich sein Idol selbst, definiert sich damit und grenzt sich auch gleichzeitig zu anderen $a b$.

Angesichts der großen Unsicherheiten des Lebens in der heutigen Gesellschaft und dem Wunsch nach Orientierung ist naheliegend, dass Idole, Vorbilder oder Stars als Bezugspunkte heute wieder zunehmend eine wichtige Rolle im Leben der Jugendlichen einnehmen. Diese Tendenz ist tatsächlich aus der Shell-Jugendstudie zu entnehmen, welche alle drei bis vier Jahre die Relevanz von Vorbildern für Jugendliche erfragt. Seit den 50ern wurde ein Rückgang festgestellt. Es schien die Zahl derer, die sich zu einem personalen Vorbild bekennen, trendförmig zu schwinden ( $\mathrm{vgl}$. 12. Shell-Jugendstudie 1997, S. 358). 1955 gaben noch 44 Prozent der 15-24-jährigen an, ein Vorbild zu haben, diese Zahl sank 1984 auf 19 Prozent, 1996 sind es nur noch 16 Prozent. Diese Entwicklung wurde mit zunehmendem Individualisierungsdruck- und Wille erklärt, so dass eher die Abgrenzung von anderen Personen und damit das Finden individueller Identität im Vordergrund steht. In der folgenden Shell-Studie von 1999 wurde deshalb nicht mehr 
differenziert auf Vorbilder eingegangen, was sich aber als voreilig erwies. Denn plötzlich gab es einen sprunghaften Anstieg der Jugendlichen zw. 15-29 Jahren, die sich zu einem Vorbild bekennen, auf 29 Prozent. Das entspricht einer Steigerung um 13 Prozent seit 1996. Neben der tatsächlichen verstärkten Orientierung an Erwachsenen könnten die Gründe für dieses Ergebnis in der Fragebogenstruktur begründet sein, da die Vorbildfrage auf die nach zurzeit wichtigen Personen für Jugendliche folgte. Es kann auch einen Verständniswandel bezüglich des Vorbild-Begriffes gegeben haben. Jedoch wird die Zahl von einem Drittel der Jugendlichen, die sich zu einem personalen Vorbild bekennen, seitdem durch andere Untersuchungen bestätigt - so auch die Studie ,Medienhandeln Jugendlicher' (Treumann et al. 2007), die aber speziell nach Personen aus den Medien fragte, die diese Funktion erfüllen. Insgesamt bekennen sich mehr Jungen als Mädchen zu einem Vorbild, mehr Jüngere als Ältere, mehr Jugendliche mit formal geringerer Bildung und Ausländer (vgl. 13. Shell-Jugendstudie 2000, S.217f). Die Shell-Studie von 1997 zeigte auch eine weitere Tendenz, nämlich die Verschiebung der Vorbildpräferenzen vom Nahbereich in den Fernbereich - was sich bereits seit den 50ern abzeichnet. 1955 wählten noch 74 Prozent der Jugendlichen Personen aus dem näheren Umfeld, 1996 waren es nur noch 36 Prozent. Demgegenüber sind Vorbilder aus dem Fernbereich von 25 auf 67 Prozent gestiegen. Jungen wählen eher Sportler, Mädchen eher Filmschauspieler und Künstler, beide Geschlechter begeistern sich kaum für Politiker (vgl. 12. Shell-Jugendstudie 1997, S. 359). Auch Treumanns Studie (2007) bestätigt, dass es sich bei den Stars überwiegend um Sportler, Musiker oder Schauspieler handelt. Mädchen wählen eher Personen fiktionaler Sparten, Jungen eher nicht-fiktionale. Neben Sportlern sind dabei auch Moderatoren wie Stefan Raab und Günther Jauch sehr beliebt. Vermutlich orientieren sich Jungen eher an Leistung, Erfolg und Engagement, während Mädchen eher den Ausgleich zur Realität suchen ( $\mathrm{vgl}$. Wegener 2008, S. 95). Deutlich wird in jedem Fall, dass großes Interesse der Jugend an Film-, Fernseh- und Musikstars besteht. Die Palette der genannten Vorbilder ist groß, was darauf hinweist, dass es nicht mehr das, die Massen vereinende, Idol der Populärkultur gibt. Stattdessen gibt es eine Vielzahl an potentiellen Bezugspersonen. Die beiden letzten Shell-Studien 2002 und 2006 sind nicht mehr auf die Vorbild-Frage eingegangen. Dass es sich 
tatsächlich um einen Trend zunehmender Orientierung an Erwachsenen, vor allem aus dem Fernbereich, handelt, ist aber plausibel, da Medien als Sozialisationsinstanz und ihre zahlreichen Offerten bezüglich dem Programmangebot und damit verbunden auch an potentiellen Vorbildern einen immer größeren Stellenwert bekommen.

Zur subjektiven Bedeutung von Medienpersonen im Jugendalter gibt es wenig empirisch abgesicherte Daten. Für das Kindesalter liegen dagegen mehrere Forschungsarbeiten vor (z.B. Paus-Haase 1998, Theunert 1993). Diesem Umstand trug Wegener (2008) mit ihrer Studie Rechnung, in der sie die Relevanz medialer Bezugspersonen im Alltag Jugendlicher untersuchte. Es ging dabei nicht um die Untersuchung von Fan-Gruppen im Sinne der Cultural Studies. Die umfangreiche Forschung zum Fanverhalten stellt kulturelle Identitäten in den Mittelpunkt, mit der Grundannahme, der Rezipient sei determiniert durch strukturelle, gesellschaftliche und kulturelle Bedingungen. Angesichts der Pluralisierung von Lebenslagen und -stilen, wodurch stärker individualistische statt kollektiver Formen der Identitätsbildung hervorgebracht werden, stellt Wegener dagegen personelle Aspekte, die Medienhandeln bestimmen, die Integration von Medienthemen in das individuelle Denken und Handeln und die subjektive Deutung der Medienbeziehung durch den Fan, in den Vordergrund (vgl. Wegener 2008, S.74). Es ging also um die ganz persönliche Beziehung eines Jugendlichen Fans zu seinem Star. Im Fokus stand hierbei die individuelle Aneignung, subjektive Deutung und Funktion eines medialen Vorbilds, die vor dem Hintergrund individueller Identitätsthemen und Prozessen der Identitätsbildung zu sehen ist.

Wegener hat in ihrer Studie quantitative und qualitative Daten erhoben und ausgewertet. Grundlage waren die Inhaltsanalyse der Zeitschrift Bravo, eine Online-Befragung und qualitative Interviews. Die Ergebnisse bestätigen die These, dass ein Idol im Zeitalter der Pluralisierung und Bastel-Mentalität nicht mehr ganzheitlich verwendet wird. Das heißt, der Jugendliche greift sich bei einer Person nur einige, für inn relevante Eigenschaften heraus, die er anzunehmen versucht. Meist werden nicht alle Identitätsbereiche, zum Beispiel Abbild für Ausformulierung beruflicher Ziele und Ide- 
ale, Gestaltung sozialer Beziehungen sowie Entwicklung individueller Werte und Normen, gleichermaßen an einer Person bearbeitet (vgl. Wegener 2008, S. 380). Auch wenn ein Jugendlicher sich meist nicht nur auf eine einzige mediale Bezugsperson fixiert, sind es aber dennoch meist mehrere Themen, die ein Idol anspricht.

Ein interessantes Ergebnis der Studie war auch, dass jugendliche Fans keine Außenseiter sind, die mit ihren medialen Bezugspersonen lediglich soziale Beziehungen kompensieren. Dagegen sind sie sozial integriert, aufgeschlossen und engagiert. Die mediale Bezugsperson ergänzt dann nur das Repertoire an sozialer Orientierung (vgl. ebd., S. 379). So nutzen Fans Medien auch häufiger als Kommunikationsanlass, sind aktiver und kreativer in ihren Freizeitaktivitäten, sowie etwas leistungsbezogener und zielstrebiger. Zudem scheinen Fans, was die eigene Person angeht, reflektierter und kritischer zu sein, sie stellen auch hohe Ansprüche an sich selbst, weshalb sie Angebote der Medien eher wahrnehmen, um sie zur Ausgestaltung der eigenen Identität zu nutzen (vgl. ebd., S. 115). Die mediale Bezugsperson spiegelt persönliche Interessen und vertieft sie, repräsentiert damit Bedürfnisse und Lebenslagen und hilft bei der konstruktiven Bearbeitung der eigenen Persönlichkeit.

Bezüglich der Werte, die die Jugendlichen - zumindest solche mit Idolen der Populärkultur - an ihren Bezugspersonen schätzen, war auffallend, dass eher individuelle Merkmale, wie Aussehen, Verhalten und Sprüche eine Rolle spielen als Werte von gesamtgesellschaftlichem Interesse, wie Lebensstil, Image, soziales Engagement und gegen den Strom schwimmen (vgl. Wegener 2008, S. 103). Dabei wird mit zunehmendem Alter Querdenken, Einstellung und soziales Engagement wichtiger. Meine Vermutung ist, dass Jugendliche in Subkulturen, also auch die in dieser Arbeit betrachteten Gothics, häufiger auch übergeordnete Werte angeben, die sie an ihren Musikern schätzen, da eine Subkultur-Zugehörigkeit oft an ein von der Norm abweichendes Weltbild mit entsprechender Gesellschaftskritik gebunden ist, die unter Gleichgesinnten zum Thema gemacht wird. Die Jugendlichen finden Unterstützer ihrer eigenen Wertvorstellungen und entwickeln auch durch die Auseinandersetzung mit ihrem Idol individuelle Normen, die sie dann performativ nach außen tragen (vgl. ebd., S. 114). 
Ganz allgemein treffen Idole, Vorbilder und Stars Bedürfnisse vor allem im Jugendalter, sie entlassen aus der Realität und bieten die Möglichkeit in Träume und Vorstellungen einzutauchen. Zudem können sie Zukunftsperspektiven eröffnen oder zumindest handlungsanleitend oder bestätigend wirken. In jedem Fall geben sie Impulse für die Persönlichkeitsentwicklung. Entscheidend ist dabei aber, dass die Funktion von Vorbildern, Idolen und Stars für Jugendliche immer vor dem individuellen Hintergrund gesehen werden müssen. Von Bedeutung sind biografische Erfahrungen, aktuelle Problemlagen und Entwicklungsthemen ebenso wie Lebenslage, Herkunftsmilieu, Geschlecht und kulturelle Zugehörigkeit (vgl. Waldmann 2000, S. 2).

\section{Modi der Aneignung von Idolen}

Derselbe Star kann für verschiedene Fans unterschiedliche Bedeutungen haben, gedeutet werden und damit andere Funktionen erfüllen. Denn Medienrezeption bedeutet nicht, dass jeder Mensch eine Vorlage in gleicher Weise für sich deutet und nutzt. Nach Hall (1999) gibt es drei Lesarten, mit denen ein medialer Text durch den Rezipienten entschlüsselt wird. Zum einen die Vorzugslesart, das heißt der Inhalt wird gänzlich so interpretiert, wie es vom Produzenten intendiert ist. Bei der ausgehandelten Lesart wird die nahegelegte Bedeutung zwar akzeptiert, jedoch führt der subjektive Hintergrund des Rezipienten zu einer eigenständigen abweichenden Interpretation. Zuletzt gibt es die oppositionelle Lesart, wobei die intendierte Deutung zwar verstanden, jedoch abgelehnt und vollständig alternativ interpretiert wird. Für die Erfassung der Lesart, mit der ein Fan seinen Star wahrnimmt, muss zunächst die Darstellung des Stars in den Medien - also die Vorzugslesart ermittelt und schließlich mit der Wahrnehmung des Fans verglichen werden. In meiner Untersuchung war das nur bedingt möglich, da generell wenig Informationen über die Idole der interviewten Jugendlichen in den Medien zu finden waren. Da das Wissen der Fans über ihre Musiker aber im Wesentlichen auch nicht darüber hinaus ging, konnte auch dieses nur schwach gezeichnete Bild seinen Zweck erfüllen. 
Bei Medienaneignung geht es um die Verarbeitung der Inhalte während und nach der Rezeption. Ein Star wird niemals nur einseitig und kritiklos imitiert. Aneignungsmodi sind Formen und Prozesse der Medienaneignung, in denen individuelle Themen mit Medienthemen verbunden und in wechselseitigem Abgleich strukturiert werden (vgl. Wegener 2008, S. 58). Dies geschieht mittels interkommunikativer, intrakommunikativer und performativer Prozesse. Bezüglich des Idols als Medieninhalt meint Ersteres die Kommunikation mit Anderen über die Thematik, intrakommunikativ betrifft dagegen die selbstreflexive innere Auseinandersetzung mit der medialen Bezugsperson. Performative Medienaneignung ist als symbolischer Selbstausdruck zu verstehen. Es geht um die Selbstinszenierung einer Person als Ausdruck der Reflexion, Auseinandersetzung und Identifikation mit dem Idol - in Habitus, Kleidung und durch die Gestaltung der persönlichen Umgebung, wie das eigene Zimmer mit Postern und Fanartikeln - so dass die Zugehörigkeit zu einem Star also nach außen sichtbar wird, damit sowohl Ausdruck intrakommunikativer Prozesse ist, als auch auf interkommunikative Akte zielt, wenn das Verhalten Anstoß zum Austausch mit anderen Personen wird (vgl. Wegener 2008, S. 56).

Wie bei Hall (1999) zum Ausdruck kam, wird die Lesart der Fans zwar auch, aber nicht allein durch die Vorlage bestimmt. Medieninhalte werden nicht einfach übernommen, sondern aktiv und individuell von Jugendlichen bearbeitet. Die Interpretation von Medientexten steht immer im Zusammenhang mit den gesellschaftlichen und individuellen Bezügen einer Person. So wird die Deutung durch subjektive Wertvorstellungen bestimmt, die eng mit der eigenen Biografie und dem Lebenskontext zusammenhängen. Aktuelle Themen und spezifische Interessen des Rezipienten spielen eine Rolle. Bei der Aneignung kommt es zu bewussten oder unbewussten Deutungsmustern, in denen sich die Selbst- und Weltsicht ausbilden - damit tragen sie auch zur Orientierung bei (vgl. Wegener 2008, S. 58). Um den Umgang mit Medien und die Bedeutung ihres Idols für Jugendliche verstehen zu können, ist es also unabdingbar, sich zum einen mit der Medienperson auseinanderzusetzen, aber auch mit der spezifischen Disposition des Jugendlichen. 
Wegener (2008) beschreibt drei Haupt-Aneignungsmodi: Identifikation und Projektion, parasoziale Interaktion und diskursive Konstruktion und soziale Unterstützung.

Bei Identifikation geht es darum, so sein zu wollen wie die Medienperson. Eigene Emotionen, Wertvorstellungen und Verhaltensweisen werden mit denen der Medienperson verglichen und anhand dessen überprüft oder aber man setzt sich in die Figur hinein und erlebt so dessen situativen Erlebnisse und Verhaltensweisen mit. Grundsätzlich ist Identifikation das subjektive Wahrnehmen von Gemeinsamkeiten. Das Gegenüber wird als gleich erlebt. Dabei werden entweder eigene Eigenschaften wiederentdeckt, wodurch der Fan Selbstbestätigung bekommt, oder aber die Medienperson zeigt andere vielleicht gegenteilige Verhaltensweisen und Einstellungen, die dann dazu führen, dass man eigene überdenkt und die zunächst fremden integriert. Möglich ist auch, dass zu einem Thema noch kein eigener Standpunkt existiert und der Fan durch die Auseinandersetzung erst zur Annahme einer Sichtweise angeregt wird - wobei nicht bloß übernommen, sondern mit anderen eigenen Einstellungen abgeglichen und darin eingepasst wird. Projektion meint, dass eigene Eigenschaften der Medienperson zugeschrieben werden, wodurch möglicherweise das Zugehörigkeitsgefühl und vor allem das eigene Selbstwertgefühl verstärkt werden. Der Aneignungsmodus Identifikation und Projektion drückt sich zum Beispiel in dem Wunsch aus, einen Beruf wie der Star ergreifen zu wollen, was über 60 Prozent der Jugendlichen angaben. Laut Wegener geht es hier aber nur um Identitätsentwürfe, die nicht auf tatsächliche Realisierung angelegt sind. Eher die Annehmlichkeiten die mit dem Beruf des Schauspielers, Musikers oder Spitzensportlers verbunden sind, Ruhm, Geld und Privilegien seien ausschlaggebend für die Faszination ( $\mathrm{vgl}$. Wegener 2008, S. 114). Vermutlich ist die Notwendigkeit in unserer Gesellschaft, Leistung zu bringen und Erfolg zu haben, ein Faktor, warum diese Berufsziele nicht zu dem tatsächlichen Bestreben führen, sie zu verfolgen. Sicher können nicht alle Jugendlichen einen Künstlerberuf ausüben, aber das Risiko zu scheitern und in der Gesellschaft nicht überlebensfähig und akzeptiert zu sein, hindert eventuell daran, seinem Herzenswunsch nachzugehen. Wäre dieser Faktor, ökonomischer Sicherheit und greifbaren Erfolges we- 
niger gefordert, würden vielleicht viel mehr Jugendliche - vorausgesetzt sie besitzen das nötige Talent - tatsächlich eine Musikkarriere anstreben und damit ihren Identitätsentwurf in ein reales Projekt verwandeln. Es geht ja um die innersten Wünsche und nicht um die Umdeutung und Verwerfung von Bedürfnissen und Zielen aufgrund äußerer Erfordernisse. Über 20 Prozent und signifikant mehr Mädchen als Jungen geben an, genauso aussehen zu wollen wie ihre Bezugsperson, diese Orientierung nimmt aber mit dem Alter $a b$, wenn ihre diesbezügliche Identität gefestigter und selbstbewusster wird (vgl. Wegener 2008, S. 101). Ebenso sinkt die Häufigkeit der Angabe, genauso sein zu wollen wie die Person, die bei durchschnittlich fast 40 Prozent liegt, mit dem Alter, was mit einer zunehmend realistischeren Positionierung in der realen Lebenswelt in Beziehung gesetzt werden kann (vgl. ebd., S. 102). Mit zunehmendem Alter sind Zukunftsvorstellungen und -pläne allmählich Beschränkungen unterworfen, da die Breite der Optionen geringer wird. Ohne Studienberechtigung wird es nicht möglich sein, zu studieren und ein berühmter Wissenschaftler zu werden und ohne jahrelanges Training rückt auch der Traum vom Profisportler in die Ferne. Ebenso führt die Feststellung, dass zum Beispiel gesangliche Qualitäten nicht ausreichen, zu der Einsicht, eine Musikkarriere ad acta zu legen.

Der nächste Schritt, das performative Tragen der Identifikation nach außen zeigt sich zum Beispiel in dem mit Postern gestalteten Zimmer, wodurch ein eigenes Territorium abgegrenzt wird, in der der Jugendliche selbstbestimmt ist und das starke Zugehörigkeitsgefühl des Fans zu seinem Star für den Betrachter deutlich wird. Das gilt auch für Kleidung und das eigene Styling, wenn sie an das Idol angelehnt sind. Durch diese performativen Handlungen wird Identität nicht nur sichtbar, sondern auch erst konstruiert.

Parasoziale Interaktion bedeutet grundlegend den Wunsch einer persönlichen Beziehung mit der Medienperson (vgl. Horton \& Wohl 1956). Dies wird letztlich in der Fantasie auch ausgelebt und zeigt sich in einer einseitigen Kommunikation des Rezipienten mit seinem Star. Der Fan bekommt mit der Zeit das Gefühl das mediale Gegenüber zu kennen oder sieht es gar als Freund. Er macht sich vielleicht auch Gedanken über die Person und stellt Vermutungen 
über dessen zukünftige Handlungen an. Durch regelmäßige Medienpräsenz ist die Person immer verfügbar und kann so einen festen Platz im Alltag einnehmen. Dem Fan ist es möglich, je nach Art der Beziehung, die er zu seinem Star entwirft, entsprechend seinen Bedürfnissen verschiedene Rollen auszuprobieren. 70 Prozent der befragten Jugendlichen gaben zum Beispiel den Wunsch an, gern mit der Person befreundet zu sein. Der Star wird auch als guter Freund betrachtet. Mädchen wählen für parasoziale Beziehungen häufiger gegengeschlechtliche Idole, was auf die Relevanz von ersten Liebesbeziehungen hinweist. Eine Paarbeziehung wird fantasiert und die entsprechenden Vorstellungen imaginär ausgelebt.

Bei diskursiver Konstruktion und sozialer Unterstützung geht es um interkommunikative Prozesse, in denen Medienpersonen zum Anlass realer Kommunikationsprozesse werden, sich Jugendliche zum Beispiel mit anderen über ihren Musiker unterhalten und auch allgemein um die soziale Einbindung der Medienbeziehung ( $\mathrm{vgl}$. Wegener 2008, S. 66). Beispielsweise kann die Diskussion über die Art oder Lautstärke der Musik mit den Eltern Grenzen austesten, Autonomie und Selbstdurchsetzung erproben sowie Macht aushandeln, wobei das Idol als symbolischer Unterstützer fungiert. In diesem Zusammenhang kann der Star auch Anlass für Vergemeinschaftung mit anderen Jugendlichen sein. Die gemeinsame Verehrung ist Kommunikationsanlass und ermöglicht die Basis für neue Bekanntschaften und Freundschaften. Tatsächlich gaben aber nur rund 20 Prozent der Jugendlichen an, sich häufig mit anderen Fans zu treffen, eine größere Rolle könnten dagegen Aktivitäten in Internetforen- und Communitys spielen, sodass der Vergemeinschaftungsaspekt doch wieder relevant wird (vgl. ebd., S. 161).

Die Aneignungsmuster der Fans haben gezeigt, dass mediale Bezugspersonen grundsätzliche Funktionen im Lebensalltag Jugendlicher übernehmen. Diese betreffen die Vorbildfunktion für die berufliche Identität und den Wunsch nach Freundschaft. Darüber hinaus wird im Abgleich mit der Medienperson die eigene Identität konstruiert und gedeutet, individuelle Werte entwickelt und performativ nach außen getragen. Kurz gesagt, werden Vorbilder, Idole und Stars für die Lebensbewältigung im Jugendalter genutzt. 
Der Sinn der subjektiven Medienaneignung unterliegt dabei einem fortlaufenden Prozess. Mit den Themen die im Leben des Jugendlichen im Vordergrund stehen, kann sich auch die Bedeutung und Funktion der medialen Bezugsperson ändern.

\section{Jugendkulturen}

Vorliegende Arbeit beschäftigt sich mit Jugendlichen einer Subkultur, speziell der schwarzen Szene und insbesondere mit der Beziehung zu deren Musikstars. Deshalb folgt zunächst eine knappe Definition der Begriffe Jugendkultur, Subkultur und Szene. Ein weiterer Abschnitt wird kurz auf die Bedeutung und Funktionen von Musik im Jugendalter eingehen und abschließend wird die hier im Fokus stehende Jugendkultur der Gothics in wesentlichen Punkten vorgestellt.

\subsection{Jugendkultur, Subkultur und Szene}

Jede neue Generation hat den Wunsch sich auf eigene Art zu entfalten und selbst zu verwirklichen. Auch wenn Jugendliche grundlegend die gleichen Werte für ihr Leben schätzen wie die Erwachsenen, zählen für sie doch weniger Konformität und Leistungsstreben. Freundschaften und Partnerschaften werden oft höher bewertet als die Familie. Auch stehen das Ausleben ihrer Bedürfnisse, Kreativität und allgemein der Lebensgenuss stärker im Vordergrund als für ihre Eltern. „Jugend ist das Abbild der jeweiligen Gesellschaft. Sie versucht sich von den gängigen Konventionen der älteren Generationen zu lösen und definiert somit neue Lebensstile" (Behr 2007, S. 22). Jugendliche suchen Orientierung, wollen sich abgrenzen und ihre eigene Identität finden. Sie neigen dazu, sich in Peergroups zusammenzuschließen. Sie sind dort gerne unter sich, weil sie so einen sozialen Status erreichen und ihre eigentliche Persönlichkeit entdecken können. Dieser Zusammenschluss in Gleichaltrigengruppen bildet den Grundstein für die Herausbildung von Jugendkulturen. Die 50er der BRD „[...] haben für die Entwicklung des jugendlichen Lebens und Aufwachsens einen bemerkenswerten Beitrag geleistet: in ihnen fand [...] die gesellschaftliche Produktion des "Teenagers" [statt] und damit hatten die Heranwachsenden zwischen 13 und 19 Jahren Anschluss 
gefunden an Lebensstil und Lebensformen der westlichen Demokratien, vor allem der USA und Englands" (Baacke 2004, S. 9, Auslassung und Umstellung: S.L.). Es bildeten sich die ersten Jugendkulturen, bedingt durch den beginnenden Wohlstand in Deutschland. Das jugendliche Leben wurde in Jugendgruppen umstrukturiert. Beispiele für Jugendkulturen oder Jugend-Subkulturen sind die Beatniks der 50er, die Hippies in den 60ern, sowie die Punks und Gothics seit den 80ern.

Eine Jugendkultur kann als Teilkultur der Gesellschaft definiert werden, in der Gemeinsamkeiten unter den Mitgliedern - in Weltanschauung, Aktivitäten, Kleidung, symbolischen Handlungen, Sprache und anderen Elemente eines Lebensstils - ein Zugehörigkeitsgefühl bewirken, das nicht örtlich gebunden ist ( $\mathrm{vgl}$. Schröder; Leonhardt 1998, S. 17). Die Angehörigen einer solchen Gruppe verfügen auch über ähnliche Deutungsmuster, was ebenso Orientierung und Bestätigung gibt.

Der Begriff ,Subkultur' meint prinzipiell das Gleiche wie ,Jugendkultur', wird aber heute weniger verwandt. Dieser Umstand hängt damit zusammen, dass ,Subkultur' "[...] den Unterschied zwischen der herrschenden Kultur und den jugendkulturellen Strömungen [betont], die sich explizit von der Normalität absetzen, abweichendes Verhalten praktizieren und von $>>$ unten $<<$ her Widerstand und Veränderung in Gang setzen" (Schröder; Leonhardt 1998, S. 17, Umstellung: S.L.). Diese widerständigen Elemente sind jedoch heute nur noch selten vorzufinden. Häufig wird die eigene Kultur auch lediglich in der Freizeit gelebt. Der Begriff Subkultur suggeriert also nicht (mehr) gültige Elemente von Jugendkulturen, weshalb die Vorsilbe ,sub' heute meist weggelassen wird (vgl. Baacke; Ferchhoff 1995; Vollbrecht 1997). Ich werde im Folgenden aus Gründen der Lesbarkeit trotzdem beide Begriffe verwenden.

Die Jugendkulturen haben eigene Interessen, Werte, Verhaltensweisen und eigene Musik, die ihre Mitglieder gegenseitig bestärken und von anderen abgrenzen. Sie haben zudem gesellschaftsverändernde Potenz, denn die gegen das Konventionelle rebellierenden Werte, Moden und Lebensstile, die Subkulturen und ihre Stars verkörpern, werden meist irgendwann - wenn auch abgeschwächt - vom Mainstream übernommen, wie das beispielsweise 
bei der Punk- und Gothic-Mode zu beobachten war. Trotz alternativem Lebensstil und Wertmaßstab sind in allen diesen Kulturen Mechanismen der normalen Welt wiederzufinden. So muss sich ein Jugendlicher auch innerhalb seiner Gruppe an Normen und Regeln anpassen. Für den Jugendlichen ist das jedoch ein selbstgewählter Regelkatalog, der mit seinen Bedürfnissen in Einklang steht und daher nicht als aufgezwungen erlebt wird. Jugendkulturen leisten auch einen wichtigen Beitrag für die Identitätsentwicklung, da sie klare Orientierungspunkte geben, einen Rahmen, um probeweise verschiedene Rollen und Identitäten auszuleben und eine eigene zu entwickeln - und dies außerhalb der konventionellen Normen und Erwartungen der Erwachsenenwelt.

Den jeweiligen Lebensstil einer Jugendkultur praktizieren Jugendliche in entsprechenden Szenen. Jugendkulturelle Szene bezeichnet Anhänger eines Lebensstils in einem regional begrenzten Raum (vgl. Schröder; Leonhardt 1998, S. 18). Die Mitglieder müssen sich dabei nicht persönlich kennen, jedoch ist die Anzahl überschaubar.

\subsection{Jugendliche und Musik}

Jugendkulturen bauen auf unterschiedlichen Musikstilen auf. Musik ist wesentliches Kennzeichen der Abgrenzung zwischen den verschiedenen Gruppen und ist ein Kriterium, über das sich Szenen definieren. Ich habe mich thematisch für die Rolle von MusikIdolen im Jugendalter entschieden. Sicherlich können auch Personen anderer Bereiche, wie des Sports, Films, der Wissenschaft oder humanitäre Persönlichkeiten von Bedeutung sein, jedoch macht die Begrenzung auf eine spezifische Gruppe von potentiellen Leitfiguren einen Vergleich der Beziehung Jugendlicher zu ihren Idolen einfacher. Die Bedeutung und Funktion der Musik im Jugendalter ist ein eigenständiges, sehr komplexes Thema, dem in diesem Rahmen nicht gerecht zu werden ist, weshalb hier nur grob auf die entsprechenden Mechanismen eingegangen wird ${ }^{2}$.

2 Viele Autoren haben sich eingehend mit der Thematik Jugend und Musik beschäftigt, auf die an dieser Stelle nur verwiesen werden soll, z.B.: Baacke 1993, Behne 1986, Breuer 1998, Gembris 1990, Müller 1990. 
Die Beschäftigung mit Musik ist eine der wichtigsten Freizeitbeschäftigungen für Jugendliche (vgl. JIM-Studie 2006). Musikhören ist Hauptaktivität, begleitet oft andere Tätigkeiten im Hintergrund oder ist gleichberechtigte Aktivität neben anderen. Die Rezeption schließt die Mediennutzung und den Umgang mit technischen Geräten ein. Neben der Nutzung von Tonträgern, Musikfernsehen, dem Lesen von Musikzeitschriften - welche die Beschäftigung mit Musik raum-zeitlich entkoppeln - gibt es natürlich nichtmediale Musikaktivitäten wie Disco oder Partys, Konzerte, Festivals, Spielen von Musikinstrumenten, die nur in Echtzeit möglich sind ( $\mathrm{vgl}$. Witte; Möller; Sander 2004, S. 179). Musik spielt also im Alltag eine wichtige Rolle. Besonders der aktive Umgang mit dem Medium dürfte sich stark auf die Identitätsbildung auswirken. Für die meisten Menschen hat Musik zudem das ganze Leben prägenden Charakter.

Grundlegend ist Musik natürlich schlicht Kunst, also Wahrnehmung von Ästhetik, die Unterhaltung bietet. Darüber hinaus kann Musikkonsum und -produktion aber viele Funktionen haben, die je nach Situation in den Vordergrund treten. Zum einen dient der eigene Musikgeschmack der Abgrenzung. Jugendliche positionieren sich zu bestimmten Präferenzen, die sie mit anderen teilen. Andere Musikstile werden - im Jugendalter oft radikal - abgewertet, was der Erhöhung des Selbstwerts dienlich ist. Distinktion ist Ausgang aller identitätssuchenden Unternehmungen Jugendlicher (vgl. Witte; Möller; Sander 2004, S. 186). In diesem Sinne hat der Musikgeschmack Symbolfunktion. Er drückt ein Lebensgefühl, ein eigenes kulturelles Interesse und einen Lebensstil aus und unterstützt damit die Identitätsfindung. Musik ist Selbstausdruck und dient der Selbsterkenntnis. Eine weitere wesentliche Funktion ist die Emotionsregulation. Sie kann Stimmungen verstärken oder kompensieren, beides wird oft bewusst vom Jugendlichen gewählt. Musik tröstet, heitert auf, macht Mut oder hilft Aggressionen abzubauen. So kann sie auch ein Heilmittel sein und wie ein guter Freund - Gefühle von Einsamkeit, Minderwertigkeit und emotionaler Verwirrung kompensieren. In der Pubertät verändert sich der Körper und damit auch die Beziehung zu ihm. Musik ist eng mit der Körperwahrnehmung verknüpft. Sie kann bei entsprechender Intensität in jeder Faser des eigenen Leibes wahrgenom- 
men werden. Tanzen ist Selbstausdruck, bei dem der Körper bewusst gespürt und genutzt wird. Tanz kann Emotionen verstärken und kanalisieren. Musik hat auf diese Art befreiende Wirkung, denn auf Lautstärke wird mit eigener Lautstärke, Schreien oder Mitsingen, geantwortet, auf Rhythmus mit Tanz, auf Emotionen mit eigenen (vgl. Vatterodt 2000, S. 59). Viele Jugendliche setzen sich auch mit den Liedtexten auseinander, finden eigene Themen und bekommen Unterstützung für den Umgang mit Emotionen und Erlebnissen. Sie basteln an ihrer Weltsicht und finden dafür Anregung und Richtschnur.

Musikgeschmack fungiert demnach als Distinktionsmittel, dient symbolischem Selbstausdruck, kann Emotionen regulieren helfen und mit ihren sprachlichen Inhalten auch identitätsstiftend wirken. Die Vielseitigkeit des Mediums entspricht dabei den pluralen Formen heutiger Lebensstile.

Da der spezielle Musikgeschmack grundlegendes Element von Jugendkulturen ist, ist es sinnvoll für die Erforschung jugendlicher Fans, die sich einer Szene zugehörig fühlen, ihre Beziehung zu ihren Musikstars näher zu betrachten. Denn für die jeweiligen Jugendlichen, hier der Gothics, ist ihre Musik und das was sie transportiert tragender Bestandteil des Alltags, ihres Fühlens und ihrer Weltsicht.

\subsection{Schwarze Szene}

Um freie Interviews mit jugendlichen Gothics interpretieren zu können, ist es notwendig sich mit dieser Jugendkultur, ihren Denkund Verhaltensweisen, Normen und Wertvorstellungen auseinander zu setzen.

Die Gothic-Kultur ist in den 80er Jahren aus der Punkbewegung heraus gewachsen. ,Gothic' wird von ,gothic-novel' (Schauergeschichte) abgeleitet und bezeichnet im engeren Sinne Anhänger gitarrenlastiger Gothic-Rock und Gothic-Punkmusik, hat sich aber auch als Sammelbegriff für alle Stile dieser extrem vielfältigen Jugendkultur eingebürgert (vgl. El-Nawab 2007, S. 135). Die Bezeichnung ,Grufti' ist ebenso gängig, allerdings bezeichnen sich die Anhänger der Szene selbst eher als ,schwarz'. Der treffendste Oberbegriff für alle Stilrichtungen ist daher auch ,schwarze Szene'. 
Zur besseren Lesbarkeit, werde ich im Folgenden alle drei Begriffe, ,Gothic', ,Grufti' und ,Schwarze' parallel verwenden.

Wie für alle Jugendkulturen ist ihre Musik für die Gothics zentral. Einer der Urgesteine und Wegbereiter war Robert Smith, Sänger der New Wave Band, The Cure'. Die Atmosphäre der frühen Songs der Band, sein schwarz-morbide-punkiges Aussehen und ausgedrückter Weltschmerz Smiths symbolisieren bis heute den idealtypischen ,Gruftie' (vgl. Behr 2007, S. 72). Weitere musikalische Urgesteine der schwarzen Szene, die den Grundstein dieser Subkultur bildeten, waren vor allem die Bands, Siouxie \& the Banshees', ,Christian Death', ,Alien Sex Fiend', ,Depeche Mode', 'Bauhaus', ,Joy Division' und ,Sisters of Mercy', "[...] die die Ideen des Punk mit düsteren, melancholischen Klängen, z.T. anspruchsvollen, nihilistischen Texten und einem gruseligen bzw. düstermystischen Outfit vermischten" (El-Nawab 2007, S. 136, Auslassung: S.L.). Bis heute haben sich zahlreiche musikalische Stilrichtungen ausgeprägt. Die Palette reicht von sanften, romantischen Klängen, über poppig-melodisch, düster melancholisch bis zu harten, brachialen Sounds. Neben Gothic-Punk und Gothic-Rock kamen Metall-Einflüsse hinzu, woraus Gothic-Metall entstand, ebenso findet sich Black-, Dark- und Death Metall. Weitere Untersparten sind z.B. Electric-Body-Musik, Industrial, Neofolk und Dark Folk, New Wave, Dark Wave, Batcave, ebenso wie mittelalterliche Musik, Electro und Synthiepop. Zudem sind Dudelsäcke sowie Elemente gregorianischer Chöre und klassischer Musik vorzufinden. Die schwarze Szene setzt sich also aus einer Vielzahl an Musikvorlieben und damit den unterschiedlichsten Gruppierungen zusammen, die sich auch im äußerlichen Erscheinungsbild differenzieren. Die Grenzen zwischen den Stilen verschwimmen, was eine genaue Klassifizierung oft nicht möglich macht. Allerdings scheint diese auch nicht notwendig zu sein. Jeder sieht sich als individuell bezüglich Einstellung und Lebensstil an, und das wird in der Szene auch erwartet. Zudem wird als wesentlich erachtet, sich mit den Hintergründen der Kultur auseinanderzusetzen, reine ,Mode-Schwarze' werden nicht akzeptiert.

In den Texten der Bands geht es meist um Gefühle wie Traurigkeit und Einsamkeit, sowie allgemein um emotionale Höhen und Tiefen, mit denen sich die Jugendlichen identifizieren können. Die 
Songtexte haben aber viele Facetten, so werden auch politische oder religiöse Themen verarbeitet (vgl. Wallraff 2001, S. 45).

Das Klischee in der Öffentlichkeit, ,Gruftis' würden auf Friedhöfen rumhängen, Gebeine ausgraben, schwarze Messen abhalten, in Särgen schlafen und Satan anbeten, wird dadurch genährt, dass es Einzelfälle gibt, die auch immer wieder in den Medien , aufgebauscht' werden. Zudem trägt das Auftreten der Gothics sein Übriges bei, denn sie ziehen sich gern zurück und sind in der Öffentlichkeit eher wenig präsent. Auch weil sie eher belächelt werden oder gar auf Ablehnung treffen, bleiben sie lieber unter Ihresgleichen. Ihr Auftritt beschränkt sich auf das Nachtleben: Szeneaktivitäten, Konzerte, Partys und Festivals.

Obwohl es sich insgesamt um eine reichhaltige und differenzierte Szene handelt - teilen alle eine Gemeinsamkeit: sie haben einen Faible für Schwarz, dunkle Farben, düstere Musik, Traurigkeit, Auseinandersetzung mit dem Tod und einen Hang zum Morbiden und (Selbst-)Destruktiven (vgl. El-Nawab 2007, S. 140). Der Grund für einen Jugendlichen sich der schwarzen Szene anzuschließen, ist wie bei anderen Jugendkulturen oft ganz banal der Einfluss der erreichbaren Umwelt. Auch andere mögliche Gründe für die Szenezugehörigkeit sind dieselben wie in anderen Szenen: der Jugendliche will seinen Horizont erweitern, sich von der Familie ablösen, sich vom Normalen absetzen, seinen eigenen Weg gehen - man sucht und braucht Differenz (vgl. Schröder; Leonhardt 1998, S. 184). Dennoch entsprechen die Musik und die Ausstrahlung einer Subkultur immer einem ganz speziellen Lebensgefühl. Wenn man das nicht empfindet, würde man keine Affinität zu diesem Lebensstil, der Musik, der Subkultur entwickeln. Schwarze lieben die Melancholie, die Romantik und beschäftigen sich gern mit Mystik und Okkultem. Sie haben keine Angst vor dunklen Themen und davor, die Abgründe der Seele zu erkunden. Deshalb ist das Thema Tod auch kein Tabu. Dies hat nichts mit Todessehnsucht zu tun, sondern der Tod wird als natürlicher Teil des Lebens angesehen. "Sie lieben düstere Texte und Lieder. Sie haben ganz offensichtlich ein Faible für pessimistische Inhalte. Sie selbst sind aber meist weniger pessimistisch als die Texte, die sie lesen, und die Lieder, die sie hören. Das Leiden, die Melancholie, die bittersüßen Gefühle, mit denen sie ihr Innerstes nach außen kehren, ist 
bei innen zum Teil Inszenierung. Sie machen auf ,hypersensibel', das gehört zur Show" (Großegger 2002, S. 152).

Die Jugendphase als Zeit der Sinnsuche, die früher wie heute oft krisenhaft von starken Stimmungsschwankungen und von Gefühlen der Traurigkeit und Sinn-Zerrissenheit begleitet ist, bietet viele Anknüpfungspunkte um Gothic zu werden - und damit aber einen Weg zu finden, diese Gefühle zu bewältigen und Identität zu formen und zu festigen. Wenn auch überdurchschnittlich viele ,Schwarze' sich mit Leben und Tod auseinandersetzen, depressiv oder melancholisch sind, Suizidgedanken und oft einen schwierigen familiären Hintergrund haben (vgl. El-Nawab 2007, S. 340), finden nicht ausschließlich Jugendliche, deren Leben von Einsamkeit und Traurigkeit geprägt ist, in die Schwarze Szene. Auch wenn sie andere Themen und Ausdrucksformen zeigen als Mitglieder anderer Jugendkulturen, ist der Zusammenhalt unter Gleichgesinnten, Spaß und Aufgehoben-sein wichtig (vgl. Schröder; Leonhardt 1998, S. 176).

Die Szene gilt als eine der friedlichsten, denn Aggressionen richten sich in der Regel nicht auf andere, sondern eher nach innen. Sensibilität ist erwünscht und wird verstanden. So scheint die Szene gerade für Männer, die gerne über ihre Gefühle sprechen und sie zeigen, ein Anziehungspunkt zu sein (vgl. El-Nawab 2007, S. 231).

Speziell an der Gothic-Szene ist außerdem, dass sie viele Menschen über die Adoleszenz hinaus beherbergt. Viele bleiben ihrer Musikkultur auch bis ins höhere Erwachsenenalter treu, legen dann ihren Lebensstil nie wirklich ab, auch wenn sie allgemein weniger aktiv in der Szene sind und durch Familie und Beruf einige Kompromisse machen. Dann ist diese Rebellion gegen den Mainstream, gegen Anpassung und Gleichmachung nicht mehr als pubertäres Gehabe abzutun, sondern als dauerhaft entdeckte Identität und Lebensanschauung zu betrachten. Nach der Anziehung von dieser Jugendkultur durch äußere Kriterien, Mode und Musik, folgt also die Identifikation mit einem Lebensgefühl und einer Weltanschauung. Nachdem in der Jugendphase performativ nach außen Abgrenzung demonstriert wird, bleibt am Ende vielleicht eine eher innen getragene Verbundenheit zur Szene. 
Antrieb, sich in dieser Untersuchung ausgerechnet mit Jugendlichen einer spezifischen, hier der schwarzen, Szene zu beschäftigen, war die Ansicht, dass weniger der Zufall, sondern vielmehr der eigene spezifische Lebensweg und biografische Erfahrungen zu dem Gefühl der Zugehörigkeit zu einer solchen Subkultur führen und sich dadurch auch Beziehungen zu entsprechenden Idolen besonders gestalten. Dabei sind die Gründe und Lebensgeschichten nicht unbedingt gleich, sondern individuell verschieden, wie jeder einzelne Mensch. Trotzdem waren eine spezielle Färbung und Extreme zu erwarten, die interessante Einsichten in die Mechanismen einer solchen Medienbeziehung erwarten ließen.

\section{Studie}

Für die Untersuchung zum Thema Musik-Idole Jugendlicher der Dresdner Gothic-Szene wurden eine schriftliche und eine mündliche Befragung kombiniert. Für Erstere habe ich einen Fragebogen entworfen und in dem Dresdner Gothic-Shop ,Abaddon' ausgelegt. 21 (Post-)Adoleszente zwischen 16 und 29 Jahren nahmen an der Befragung teil und gaben ihre Emailadressen und Telefonnummern an, wenn sie bereit waren, ein persönliches Interview zum Thema zu geben. Zusätzlich setzte ich einen Thread in das Dresdner Internet-Forum ,Gothic-City'3, informierte über die Untersuchung und bat Jugendliche mit einem Musikidol, sich zu melden, wenn Bereitschaft für ein ausführliches Interview bestünde. Auf diese Anfrage reagierte nur der 16-jährige Chris, dessen Fall ich letztlich auch auswählte, um inn ausführlich darzulegen und zu interpretieren. Ursprünglich war das Anliegen, mehrere der geführten qualitativen Interviews auszuwerten und einem Vergleich zu unterziehen. Dadurch wären Gemeinsamkeiten oder Gegensätze, typische Aneignungsmuster oder auch diesbezügliche Vielfalt sichtbar geworden. Das Interview mit Chris offenbarte jedoch eine solche Masse an Informationen, allein an ihm konnten alle Aneignungsmodi aufgezeigt und viele wichtige Funktionen, die ein Idol erfüllen kann, herausgestellt werden, so dass ich mich entschied,

${ }^{3}$ vgl. http://www.gothic-city.de/ Zugriff am 10.4.2009. 
lediglich diesen einen speziellen und prägnanten Einzelfall zu analysieren.

Das Ziel der Arbeit war demnach nicht in erster Linie, möglichst viele Verallgemeinerungen über die Beziehung Jugendlicher zu ihren Stars zu treffen oder Charakteristiken von Anhängern der Gothicszene aufzudecken, sondern durch die intensive Beschäftigung mit Chris ' Geschichte, Gedanken, Einstellungen und Verhaltensweisen, möglichst viele tiefergehende qualitative Erkenntnisse zu gewinnen.

Im Folgenden werden nach Erläuterung der theoretischen Ausgangslage der Untersuchung zunächst die Ergebnisse der schriftlichen Befragung vorgestellt. Anschließend folgt nach Beschreibung der methodischen Vorgehensweise die Darlegung und Interpretation der Inhalte des qualitativen Interviews mit Chris. Die Arbeit schließt mit einer Zusammenfassung und einem Fazit zu den gewonnenen Erkenntnissen sowie dem Ausblick für die weitere wissenschaftliche Forschung.

\subsection{Ausgangslage}

Grundannahme dieser Arbeit ist, dass allgemein Vorbilder, Stars oder Idole im Jugendalter und - wenn auch abgeschwächt - noch im späteren Leben eine wesentliche Rolle spielen. Da für Jugendkulturen wie die Gothics der spezifische Musikstil ein tragendes und definitorisches Moment darstellt, sollten für die Zugehörigen gerade ihre Musikidole wesentliche Bedeutung für das Selbstbild der Gruppe, des Einzelnen sowie für die Ausbildung ihrer individuellen Identität haben. Die Beschränkung auf Musiker in der Untersuchung gewährleistet zudem die Vergleichbarkeit der betrachteten Fälle.

Wegener hatte in ihrer Studie die eher individuellen Werte, die mit der ichbezogenen Ausgestaltung der eigenen Persönlichkeit zu tun haben, wie Aussehen, Kleidung und Verhalten, als die bedeutendsten herausstellen können, welche die Jugendlichen an ihren Stars der Populärkultur schätzen (vgl. Wegener 2008, S. 103). Da die hier durchgeführte Erhebung auf Gothics beschränkt wurde und sich eine solche Subkultur auch über eine von der Allgemeinheit 
abweichende Weltsicht mit entsprechender Kritik an konventionellen Normen definiert, ist anzunehmen, dass es übergeordnete gesellschaftliche Werte gibt, die von den Jugendlichen zumindest gehäuft vertreten werden und die sie daher auch an ihren Idolen schätzen. So könnten über die individuellen Eigenschaften hinaus zum Beispiel ,gegen den Strom schwimmen', ,soziales Engagement zeigen' oder, einen abweichenden Lebensstil pflegen' von den Schwarzen höher bewertet werden.

Da es sich um eine Jugendkultur handelt, die Individualität für den Einzelnen großschreibt, kreative Menschen anzieht, die eigene Lebenswege suchen sowie Angepasstheit und Leistungsstreben geringer bewerten als sich selbst verwirklichen zu können, dürfte sich dies auch in den Bewertungen der Jugendlichen spiegeln. Anderenfalls würde dies den Rückschluss zulassen, dass die Zugehörigkeit zu einer Subkultur nur anders sein (wollen) in Äußerlichkeiten, auffallen und abgrenzen bedeutet, aber wenig mit tatsächlich anderen Denk- und Verhaltensweisen zu tun hat.

Individuelle Einstellungen und Wertmaßstäbe sollten aber auch je nach Persönlichkeit und biografischen Erfahrungen variieren. Sie sind m.E. auch die Grundlage, welche die Auswahl des Idols beeinflusst, da persönliche Anknüpfungspunkte an die Themen des Musikers gegeben sein müssen, um eine Bindung an das Bild von diesem Menschen möglich zu machen.

Gerade dass Idole Jugendlicher, die sich einer Subkultur anschlieBen, häufig von der Norm abweichende Werte und Lebensstile repräsentieren, stimmt viele Erwachsene bedenklich. Da die Wahl eines Vorbilds jedoch nicht passiv aufgedrängt werden kann, sondern immer mit der eigenen Person und eigenen Lebenshintergründen zu tun hat, ist es wichtig, sich mit den Idolen Jugendlicher auseinanderzusetzen, um ihre Faszination zu verstehen und das was Jugendliche bewegt und was sie für ihr Leben wollen und brauchen. Wesentlich ist, dass ,Schwarze' mit der Verehrung ihres Musikers grundlegend dieselben Funktionen, wie ,normale' Jugendliche mit Stars der Populärkultur, erfüllen, da sie letztlich alle denselben Problematiken und Entwicklungsthemen des Jugendalters ausgesetzt sind. 
Dass sich jemand einer Jugendkultur anschließt, ist oft schlicht durch die Erreichbarkeit im näheren Umfeld begründet, durch Freunde erhalten Jugendliche Zugang zu bestimmten Kreisen und der Reiz am Besonderen nährt das motivierende Interesse. Allerdings gibt es zumindest für ein länger andauerndes Zugehörigkeitsgefühl und die tiefer gehende Identifikation mit einer solchen Gruppe auch Lebenslauf-, Persönlichkeits- und einstellungsbedingte Gründe. Gothics haben oft einen schwierigen biografischen Hintergrund. Sie betrachten ihre Jugendkultur häufig selbst als "ein Sammelbecken von verkorksten Seelen" (El-Nawab 2007, S. 339).

Wenn man ,anders' ist, stehen weniger potentielle Identifikationsfiguren im allgemeinen Umfeld zur Verfügung. Findet ein Jugendlicher eine Person, die Extreme bezüglich Erfahrungen, Einstellungen, Persönlichkeit und Verhalten lebt und in sich vereint - die oft jenseits der Norm der Gesellschaft liegen - aber seinem eigenen Lebensgefühl entsprechen, dann wird die Beziehung zu einem solchen Idol vielleicht eine noch bedeutendere Rolle in seinem Leben einnehmen. Die Medienperson wird zu einem Verbündeten, der Einsamkeit nimmt, Bestätigung gibt, sowie Rückhalt und Orientierung für die Bewältigung des Alltags und die Bearbeitung wesentlicher Identitätsthemen bietet.

Es war zu erhoffen, besondere Fälle zu finden, bei denen sich gegenüber behütet aufgewachsenen, ,durchschnittlichen' Jugendlichen - die Bewältigung der typischen Aufgaben im Jugendalter durch problematische Lebensumstände und -themen noch schwieriger gestaltet. Wenn typische Sozialisationsinstanzen wegbrechen oder dem Jugendlichen als Orientierung ungeeignet erscheinen, könnte ein Idol diese teilweise ersetzen. Durch die speziellen Problematiken, die das Leben dieser Jugendlichen prägen, ist interessant, wie besonders sich die Medienbeziehung gestaltet. So sollten die Funktionen und die Rolle im Alltag, die Bedeutung für die Lebensbewältigung und Identitätsbildung auch entsprechend deutlicher sein und sichtbar werden.

Bei den Aneignungsmodi sind individuelle Muster zu erwarten. Diese haben weniger mit dem Star und der jugendkulturellen Zugehörigkeit zu tun, sondern eher mit der eigenen Persönlichkeit und aktuellen Lebens- und Identitätsthemen. Die von Wegener 
beschriebenen Aneignungsmodi ,Identifikation und Projektion', ,parasoziale Interaktion' und ,diskursive Konstruktion und soziale Unterstützung' sollten sich auch bei den ,schwarzen' Jugendlichen finden lassen. Wesentlich bezüglich der Aneignung von Idolen ist, dass Stars nicht einfach kopiert werden. Das heißt einseitige Imitation, also reine Ursache-Wirkungszusammenhänge, sind nicht zu erwarten. Die Beziehung eines Fans zu seinem Idol ist immer ein Wechselspiel von Wahrnehmung und Zuschreibung (vgl. Wegener 2008, S. 70). Die individuelle Deutung der Person findet interpretativ, in Abhängigkeit von der eigenen Lebenslage, statt. Am Anfang stehen Identitätsthemen des Jugendlichen, die er zu seiner Bezugsperson in Beziehung setzt, auf sie projiziert oder tatsächlich in ihr findet. Diese Rückmeldung, die der Fan bekommt, wirkt bestätigend, fördert damit ein höheres Selbstwertgefühl und unterstützt Bewältigungsstrategien, gibt Struktur und Orientierung für den Alltag. Letztlich hilft ein Idol dem Jugendlichen bei der Bildung einer eigenen, gefestigten Identität.

\subsection{Schriftliche Befragung}

\subsubsection{Konzeption und Inhalt des Fragebogens}

Der Einführungstext des Fragebogens informierte grob über das Thema meiner Studie. Es wurden direkt Jugendliche der ,Schwarzen Szene' Dresdens angesprochen, die einen Musiker als Kultfigur oder gar als Idol bezeichnen würden. Die konkrete Frage war dann, von welchem Musiker bzw. welcher Musikerin der Jugendliche besonders begeistert ist. Es sollte vermieden werden, direkt nach einem Vorbild oder Idol zu fragen, um Jugendliche nicht von der Teilnahme abzuschrecken, die diese Begriffe beziehungsweise ihre Bedeutungen negativ assoziieren.

Der Fragebogen bestand insgesamt aus 18 Fragen 4 . Zur Beantwortung musste zum Teil, bei Möglichkeit von Mehrfachnennungen, aus einer Palette an Antwortvorgaben ausgewählt werden.

4 Der Fragebogen orientierte sich inhaltlich an Wegeners Online-Fragebogen (Wegener 2008) und dem Onlinefragebogen des Fan-Forschungsprojekts einer Forschergruppe der Freien Universität Berlin (vgl. http://www.fanforschung.de/ - letzter Zugriff am 1.12.2009.). 
Andere Fragen erforderten eigene Angaben oder verlangten die Wahl des Grades der Zustimmung zu einem Item anhand einer Skala. Am Schluss konnten die Jugendlichen ihre Telefonnummer oder Emailadresse angeben, wenn sie bereit für ein persönliches Interview zum Thema waren.

Inhaltlich ging es zum einen um die Erhebung soziodemografischer Faktoren, wie Alter, Geschlecht und Sozialstatus, um einen ersten Überblick über die diesbezügliche Zusammensetzung und Unterscheidung der Jugendlichen zu erhalten. Es wurden darüber hinaus allgemeine Freizeitaktivitäten erfragt, wodurch ermittelt werden kann, ob Besonderheiten in Interessen und Lebensgestaltung bestehen und ob im Querschnitt bestimmte Häufigkeiten auftreten oder eher breite Streuungen der Interessen zu finden sind. Zudem konnten weitere Personen oder Dinge angegeben werden, von denen der Jugendliche sich ebenso als Fan bezeichnen würde. Daran wird sichtbar, wie ausschließlich sich das Interesse auf diesen einen Star konzentriert, wobei schlussfolgernd anzunehmen ist, je mehr sich das Interesse des Jugendlichen auf ein Idol fokussiert, desto ganzheitlicher und intensiver lebt er diese Beziehung.

Im Zusammenhang mit dem Idol bezog sich eine Frage auf Mediennutzungsgewohnheiten, um eventuelle typische Quellen der Beschäftigung mit dem Musiker aufdecken zu können. Desweiteren zielte der Fragebogen auf die soziale Einbindung des Interesses an dem Star und fragte zum Beispiel nach der Zugehörigkeit zu einer Szene, Fanclubmitgliedschaften und Kontakten zu anderen Fans. Die Frage nach Gruppen oder Personen, die man, weil man Fan dieses Musikers ist, nicht mag, gibt Auskunft über die Stärke der Distinktionsfunktion durch die Zugehörigkeit zu einer Fangemeinschaft.

Ein wesentlicher Punkt war die persönliche Beurteilung des Stellenwerts bestimmter Werte und Eigenschaften, wie Freundschaften, soziales Engagement und Individualität, sowie derer, die der Fan an seinem Idol schätzt. An diesen Aspekten lässt sich die besondere Faszination an dieser Medienperson erahnen und verweist auch auf die Persönlichkeitsstruktur des Fans. Diesbezüglich ist anzunehmen, dass Werte die jemand für sein eigenes Leben erstrebt und an einem Idol schätzt, ähnlich gelagert sind, wobei zwei 
Richtungen der Bildung dieser Prinzipien möglich sind, die sich wechselseitig ergänzen. Zum einen werden eigene Einstellungen an Idolen wiedergefunden, zum anderen auch die Bildung und Präzisierung derer durch das Idol angeregt. Um diesen Aspekt noch deutlicher herausstellen zu können, sollten die Jugendlichen drei Eigenschaften angeben, die sie glauben, mit ihrem Idol zu teilen.

Wesentlich war auch die Frage, die auf die Aneignung und Bedeutung der Idole abzielte. Die Angaben der Fans geben Aufschluss darüber, welcher Qualität die Beziehung zum Star ist und welche Funktionen sie möglicherweise erfüllt. So sein zu wollen wie sein Idol, verweist auf Prozesse der Identifikation, die sich auch in dem Wunsch manifestiert, einen ähnlichen Beruf ergreifen zu wollen. Das Bedürfnis nach Freundschaft mit der Person verweist auf den Modus parasozialer Beziehung. Und die Angabe häufiger Treffen und Gespräche mit anderen Fans spricht für die Aneignung durch diskursive Konstruktion und soziale Unterstützung, wobei die Medienperson als Anlass dient, sich mit anderen Jugendlichen zu vergemeinschaften. In solchen interkommunikativen Prozessen wird auch stellvertretend und unterstützend durch das Idol Macht ausgehandelt, indem Jugendliche mit ihren Eltern zum Beispiel über Art und Lautstärke der Musik diskutieren. Solche Erfahrungen geben die Möglichkeit Autonomiebedürfnisse auszuleben und sich von Erwartungen und Vorlieben Erwachsener abzugrenzen.

Jugendliche tragen ihr Zugehörigkeitsgefühl zu einer Gruppe, einem Musiker auch performativ nach außen. Sie gestalten ihr Zimmer entsprechend ihrem Geschmack, besitzen Platten, CDs und MP3s, die sie laut in der Öffentlichkeit hören und gern anderen zeigen und sie tragen Kleidung, die ihre musikalischen Präferenzen für andere erkenntlich macht. Sich öffentlich zu einem Star zu bekennen und ihn zu verteidigen, wie das Item, ,ich erzähle anderen begeistert von der Musik', ausdrückt, zeigt zunächst die starke Verbundenheit zu seinem Idol, dient auch der Abgrenzung, der Demonstration von Zugehörigkeit und wirkt auf die Selbstdefinition stabilisierend zurück. 
Die Fragebögen ${ }^{5}$ wurden über einen Zeitraum von drei Monaten, von April bis Ende Juni 2009, im Gothic-Shop ,Abaddon' in Dresden ausgelegt. Dort können unter anderem szenetypische Kleidung und Accessoires erworben werden. Dieser Laden ist der größte der wenigen seiner Art in Dresden und erschien mir eine geeignete Anlaufstelle zu sein, da die spezielle Mode der Schwarzen ein wichtiges Kennzeichen und Ausdrucksmittel dieser Jugendkultur ist und für die meisten einen hohen, wenn auch nicht übergeordneten, Stellenwert besitzt. Deshalb war zu erwarten, dass die meisten Dresdner ,Gruftis' diese Shops zumindest gelegentlich aufsuchen. Natürlich kann nicht davon ausgegangen werden, alle potentiellen Interviewpartner auf diesem Weg zu erreichen, zumal die szenetypische Marken-Kleidung besonders für jüngere Jugendliche kaum erschwinglich sein dürfte. Da die Untersuchung sich jedoch auf Dresdner Jugendliche beschränkte, erschien diese Vorgehensweise bezüglich der Selektion effektiver, da Gäste auf schwarzen Partys oder Festivals auch häufiger von außerhalb kommen. Zusätzlich wurde die Suche nach geeigneten Interviewpartnern um einen Aufruf im Dresdner Internet-Forum ,Gothic-City' ergänzt. Erstaunlicherweise hat sich auf diese Anfrage nur eine einzige Person gemeldet.

Ein Vorteil der Pen-\&-Paper-Fragebögen ist, dass auch Nicht-Online-Nutzer erreicht werden. Zudem sind beim handschriftlichen Ausfüllen gegenüber den Online-Fragebögen Anmerkungen zu subjektiv nicht eindeutigen, missverständlichen, unpräzisen oder fehlenden Items möglich, was auch in Anspruch genommen wurde und dann dem Verständnis der Angaben der Jugendlichen zuträglich war. Manche versuchten für sie wesentlichste Aussagen durch entsprechende Markierungen und Unterstreichungen besonderen Ausdruck zu verleihen.

Der Rücklauf war nicht sehr hoch. 20 vollständig ausgefüllte Fragebögen konnten letztlich ausgewertet werden. Dabei entpuppte sich jedoch eine erstaunliche Vielfalt, bezüglich des Alters der Probanden und der verschiedenen genannten Idole. Überraschend

${ }^{5}$ Der vollständige Fragebogen befindet sich im Anhang dieser Arbeit, welcher angefordert werden kann. 
waren sehr viele, genau die Hälfte, der Teilnehmer zu einem ausführlichen Interview bereit.

Durch die geringe Fallzahl ist natürlich kein Anspruch auf Repräsentativität und Generalisierung der Ergebnisse zu erheben. Dies war jedoch auch nicht das Anliegen. Die Auswertung der Fragebögen sollte lediglich der Feststellung einer Tendenz dienen. Hauptsächlich ging es darum, geeignete Interviewpartner zu finden und anhand der vorliegenden ersten Aussagen zu selektieren. Die bedeutendsten Erkenntnisse waren dann durch die qualitativen Interviews und die Analyse der Einzelfälle zu erhoffen.

\subsubsection{Auswertung der Fragebogendaten}

Die inhaltsanalytische Auswertung der Fragebögen hatte lediglich zum Ziel, das Phänomen überblicksartig zu beschreiben. Durch Ermittlung von Häufigkeiten der Angaben und spezifischen Nennungen sollte ein grobes Profil der Fans sichtbar werden, Regelmäßigkeiten und Besonderheiten der Angaben aufgedeckt, ein erster Überblick bezüglich der Unterscheidung oder Ähnlichkeit der Jugendlichen in demografischen Merkmalen, Wahrnehmung des Idols, Wertmaßstäben und Aneignungsmodi gegeben werden.

Das Alter der Probanden reichte von 16 bis 29 Jahren. Der überwiegende Teil der Befragten war jedoch älter als 20 Jahre, so dass der Altersdurchschnitt bei 22 Jahren lag. Dies könnte darin begründet sein, dass die Gothic-Szene generell viele Postadoleszente, Menschen im dritten Lebensjahrzehnt und auch noch darüber hinaus, beherbergt.

Dies bestätigt die These, dass die Verehrung von Vorbildern, Stars und Idolen nicht auf die mittlere Jugend beschränkt ist, sondern die Orientierung an Leitbildern und die Arbeit am Selbstbild noch weit bis in die Postadoleszenz hineinreicht und vermutlich auch später noch nicht abgeschlossen ist.

Dem Altersdurchschnitt entsprechend gehen die meisten Jugendlichen bereits einer Arbeit nach oder befinden sich in Berufsausbildung oder Studium. Der Schulabschluss variierte, zumeist wurde ein Mittelschul-, Realschul- oder Hauptschulabschluss angegeben. Die Nationalität der Jugendlichen war durchweg 
deutsch, nur ein männlicher Proband gab polnische Abstammung an. Dies war angesichts der verhältnismäßig geringen multikulturellen Durchmischung der Stadt Dresden auch zu erwarten. Die Jugendlichen wohnen in den unterschiedlichsten Gebieten der Stadt, womit kein räumlicher Szenemittelpunkt auszumachen ist. Die Dauer des Fan-Seins wurde im Durchschnitt mit bereits fünf Jahren angegeben, was sich auch in dem verhältnismäßig hohen Alter der Befragten begründet.

Die Jugendlichen rechnen sich selbst zumeist der Gothic-Szene zu, einige lehnten es jedoch ab, sich einer speziellen Gruppierung zuzuordnen. Dies wurde in den Kommentaren meist mit der Ablehnung von Schubladendenken und der Betonung ihrer Individualität begründet und spiegelte sich auch in den sich Selbst und dem Idol zugeschriebenen Eigenschaften. Nur einer der Teilnehmenden gab an, Mitglied in einem Fanklub seines Stars zu sein.

Bei den Freizeitbeschäftigungen unterscheiden sich Gothics nicht von anderen Jugendlichen. Musik hören gehört zu den häufigsten Betätigungen, gefolgt von arbeiten oder spielen am Computer sowie surfen im Internet. Ebenso häufig finden Treffen mit Freunden beziehungsweise mit dem Partner statt. Fernsehen ist weniger bedeutend, ähnlich oft betätigen sie sich beim Basteln, schreiben oder zeichnen. Sport treiben und allgemeine Vereinsaktivitäten ebenso wie das Engagement für andere Fans spielen eine eher untergeordnete Rolle.

Die Jugendlichen konnten Dinge oder Personen angeben, von denen sie außer ihrem Musiker ebenso Fan sind. In fast allen Fällen wurden hier Angaben gemacht. Es gab 40 verschiedene Nennungen. Die Palette reichte dabei von anderen im weitesten Sinne Gothic-Bands und Musikern, mehrfach genannt wurden die Gruppen 'ASP' und ,Schandmaul', über Filme, die einen gewissen Kultstatus in der Szene haben, hin zu Schriftstellern wie Hermann Hesse. Auch allgemein ,Tanz' und ,Kunst' sowie ,Mystisches' und ,Mittelalter' wurden genannt. Dinge die man als Fan nicht mag, wurden selten angegeben. Die Jugendlichen scheinen wenig Wert auf diese Distinktionsfunktion zu legen. Genannt wurden politische Haltungen, andere Musikgenre oder persönliche Einstellungen. Die 
häufigsten Quellen für die Beschäftigung mit der Musik waren neben der eigenen Musiksammlung, die alle Fans nutzen, auch die Homepage des Musikers und das Gespräch mit Freunden.

Besonders auffällig war, dass von 20 Jugendlichen, 18 unterschiedliche Idole genannt wurden. Diese Daten bestätigen Erkenntnisse anderer Studien, die innerhalb der Populärkultur keine die Massen verbindende Leitfigur ausmachen konnten und dies mit der Pluralisierung von Lebenslagen sowie gesteigerten Individualisierung der Gesellschaft in Verbindung brachten (z.B. Wegener 2008; Treumann et al. 2007). Dass dieses Ergebnis selbst innerhalb einer spezifischen Szene, wenn auch - oder gerade - bei sehr geringer Fallzahl zu finden ist, unterstreicht noch einmal den Individualisierungsdruck und -wille der heutigen Jugendlichen. Zu den genannten Idolen, die aus den verschiedensten musikalischen Sparten innerhalb der Szene kommen, zählten unter anderem Marylin Manson, Martin L. Gore (Depeche Mode), Johnny Cash, David Bowie, Rudy Ratzinger (Wumpscut), Tilo Wolff (Lacrimosa), Der Graf (Unheilig) und Nick Cave. Dabei ist bemerkenswert, dass kein einziges weibliches Idol angegeben wurde, obwohl über die Hälfte der Fragebögen von weiblichen Personen beantwortet wurden und diese Szene durchaus auch weibliche Stars beherbergt, wie z.B. Siouxsie Sioux, von ,Siouxsie \& the Banshees', oder Tarja Turunen, Ex-Sängerin von ,Nightwish'. Die Wahl eines gegengeschlechtlichen Idols verweist meist auf den Aneignungsmodus parasozialer Interaktion und dort speziell das imaginäre Ausleben sexueller oder partnerschaftlicher Beziehungen. Fast alle Frauen gaben den Wunsch nach Freundschaft und, beziehungsweise oder, Partnerschaft mit ihrem Idol an. Letzteres können sich sieben der zwölf teilgenommenen Frauen vorstellen. Nur zwei lehnten sowohl Partnerschaft als auch Freundschaft ab. Die Zustimmung bewegte sich in diesen Fällen in den Bereichen, andere Fans kennen' und ,etwas mit ihnen unternehmen', was auf Aneignung zum Zwecke sozialer Vergemeinschaftung hinweist. Insgesamt ist anzunehmen, dass gegengeschlechtliche Medienpersonen potentiell nicht nur für parasoziale Beziehungen genutzt werden, sondern auch zur Identifikation und Projektion subjektiv geeignet erscheinen können. 
Den Wunsch nach Freundschaft mit ihrem Musiker hegen 15 Personen. Dieses Ergebnis spricht für den Haupt-Aneignungsmodus der parasozialen Interaktion. Allerdings wären immer vertiefende Interviews nötig, um die Angaben der Jugendlichen als tatsächliche Aneignungsmodi zu deuten. So ist es auch schwierig aus den Antworten auf die Items auf Aneignung durch Identifikation und Projektion zu schließen. Die Frage, ob sie gern selbst mit Musik ihr Geld verdienen würden, bejahten zwölf der 20 Jugendlichen. Die Rolle des Stars für die berufliche Orientierung ist demnach recht groß. Zumindest, eher' genau so sein wie ihr Idol wollen nur sechs der 20 Befragten, fünf sprachen sich eindeutig dagegen aus. Optisch ihrem Idol gleichen wollen nur zwei der Befragten. Diese Items lassen eher Prozesse der Imitation anstatt Identifikation vermuten. Da die Jugendlichen auf ihre Individualität bestehen und Nachahmen von Aussehen, Verhaltensweisen und Einstellungen zum Großteil ablehnen - wie sich in den Randbemerkungen auf dem Fragebogen und in den nachfolgenden Interviews zeigte - stößt diese Art der Frageformulierung vielleicht auf Widerstand.

Auffallend war zudem, dass nur neun Befragte ihren Musiker als ihr Idol bezeichnen, was wohl mit ihrer subjektiven Interpretation des Begriffs zusammenhängt und dem Widerstreben, besonders von Jugendlichen einer Subkultur, die Individualität als zentralen Wert ansieht, sich einem Idol zu verschreiben, dem sie im Sinne eines Vorbilds nacheifern wollen. Dies wurde auch in den Randbemerkungen der Jugendlichen auf dem Fragebogen deutlich und kristallisierte sich besonders in den Interviews heraus, in denen die Jugendlichen betonten, dass sie großen Wert darauf legen, eine ganz eigene Persönlichkeit zu haben und ihren eigenen Weg zu gehen, wobei sie den Musiker und seinen Lebensweg zwar sehr bewundern, jedoch nicht kopieren wollen. Dies heißt aber nicht, dass sie sich bezüglich Verhalten, Aussehen und Lebensweise nicht doch an ihrem Idol orientieren, dies kann trotz bewusster Ablehnung auch unbewusst geschehen. Diesbezüglich ist anzunehmen, dass Jugendliche mit zunehmendem Alter weniger versuchen, Personen nur zu imitieren, sondern sie werden reflektierter und gefestigter in ihrer Identität, so dass sie ein größeres Selbstbewusstsein ausbilden und Eigenschaften anderer lediglich als Anregung nutzen, um eigene Wertvorstellungen zu präzisieren oder zu erweitern. 
Die Frage nach den Dingen, die sie am meisten an ihrem Star bewundern, verweist am ehesten auf Prozesse der Identifikation und Projektion, denn darin spiegeln sich eigene Präferenzen und Einstellungen und solche, die erstrebt werden. Niemand möchte seinen Star exakt kopieren, aber er erkennt vielleicht bereits bestehende Parallelen im Gegenüber, findet viele Anregungen, die in sein Selbstbild passen oder möchte vielleicht in den Punkten, die er bewundert, gern ähnlich sein. Nicht verwunderlich ist, dass fast einstimmig die musikalische Leistung $(20)^{6}$ und das Erlebnis beim Zuschauen und Zuhören (17) im Vordergrund stehen. Als nächstes folgen Sprüche/Ausdrucksweisen/Verhalten (12) und Aussehen/Kleidung (11), sowie Erfolg (10) und dass er gegen den Strom schwimmt (9) sowie die Werte, für die der Musiker steht (8). Diese Eigenschaften besitzen demnach also hohes Identifikationspotential. Kaum eine Rolle spielen der soziale/gesellschaftliche Einsatz (1), Beliebtheit (1) und das Bild in der Öffentlichkeit (4).

Da es sich um Musiker jenseits des Mainstreams handelt, die gerade für abweichende Normen und Verhalten stehen, ist ein Aspekt, den diese Jugendlichen schätzen, dass diese Bands und Musiker polarisieren. Beliebtheit ist daher weniger ein Kriterium als Einzigartigkeit. Das entspricht zum Teil den Ergebnissen von Wegeners Jugendlichen, allerdings spielt, gegen den Strom schwimmen' und die ,Werte für die der Musiker steht' für viele der befragten Gothics eine bedeutendere Rolle. Das bestätigt die Eingangsthese, dass übergeordnete Werte für Subkultur-Zugehörige wichtiger sind, als für Fans von Mainstream-Musikern. Dass diese Eigenschaften teilweise einen sehr hohen Stellenwert bekamen, könnte auch mit dem Alter zusammenhängen. Jedoch wurden diese Werte auch von den jüngeren Gothics genannt. Beispielsweise ist ,Marylin Manson' ein Künstler, der mit Provokationen spielt, in vielen Teilen der Gesellschaft aneckt und genau damit seine Fans anspricht, die wiederum einer spezifischen Subkultur zugehörig sind, die diese Werte vertritt. Somit hat die Bewunderung solcher Eigenschaften, die das Gros der Gesellschaft nicht teilt, letztlich mit den Einstellungen des Fans zu tun. Allerdings

\footnotetext{
${ }^{6}$ Es folgt jeweils in Klammern die Zahl derer (von insgesamt 20 Fans), die dem entsprechenden Item im Fragebogen zustimmten.
} 
kann dies mit den geringen Fallzahlen natürlich nicht belegt, sondern nur vermutet werden.

Die Angabe dreier Merkmale, die der Jugendliche sich selbst und gleichermaßen seinem Idol zuschreibt weist noch einmal verstärkt auf Identifikations- und Projektionsprozesse hin. Es können seitens des Fans nur Mutmaßungen über den tatsächlichen Charakter eines Stars angestellt werden, die aus der ganz persönlichen Wahrnehmung und Interpretation - der persönlichen Lesart - entstehen, als Projektionsfläche dienen und in Bezug zur eigenen Person gesetzt werden. Die Nennungen gingen von optischen Merkmalen , wie ,Größe', ,Haarfarbe', ,schwarz', über persönliche Präferenzen, wie ,derselbe Biergeschmack', ,Vorliebe für Horror', ,Musikgeschmack', ,Liebe zur Szene', ,Ausdrucksweise', ,Lifestyle', hin zu zugeschriebenen Persönlichkeitseigenschaften, wie ,provokant', , sensibel', ,humorvoll', ,kreativ', ,schüchtern', ,tiefgründig', ,ehrgeizig', ,rebellisch', ,durchgeknallt'. Daran wird deutlich, dass es keine bedenklichen, sondern durchaus auch erstrebenswerte Eigenschaften sind, die die Jugendlichen an sich selbst und ihrem Idol schätzen. Von einer Gefährdung durch die Verehrung dieser Musiker kann also nicht die Rede sein.

Die Identifikation ist ein Mechanismus, der überwiegend intrakommunikativ abläuft. Diese Haltung kann bei entsprechender Intensität aber auch nach außen sichtbar werden, so besitzen fast alle Befragten Tonträger ihres Musikers, was zunächst lediglich Voraussetzung für die Beschäftigung mit ihrem Idol ist. Jeweils mehr als die Hälfte sind in Besitz von Kleidung und Gegenständen, die mit dem Star zu tun haben. Somit wird das Zugehörigkeitsgefühl zu ihrem Idol auch performativ für andere erkennbar gemacht. Damit wird das zunächst noch unsichere Selbstbild stabilisiert. Nur fünf der 20 Jugendlichen gestalten ihr Zimmer mit Postern oder Bildern ihres Stars. Eventuell wird diese Form der Wohnungsgestaltung eher in jüngeren Jahren gewählt. Es ist zudem anzunehmen, dass die äußeren Erkennungsmerkmale mit zunehmendem Alter für die meisten Menschen nicht mehr so wichtig sind, weil sie zunehmend stabiler in ihrer Identität werden und ihr Lebensgefühl stärker nur im Herzen tragen oder es sich hauptsächlich in Einstellungen und Handlungsweisen manifestiert. Auch Lebensstil 
und Habitus sind als performatives Darbieten der Bewunderung für einen Menschen zu deuten.

Sieben Fans gaben an, sehr viele Leute zu kennen, die ihren Star auch gut finden. Darin drückt sich Aneignung zum Zwecke der sozialen Vergemeinschaftung aus. Der jeweilige Musiker ist offenbar allgemein Anlass für Kommunikation unter Gleichgesinnten, zumal auch viele das Gespräch mit Freunden (14) und anderen Fans (9) als eine Quelle der Beschäftigung mit ihrem Idol angaben.

Die Werte, die dem Jugendlichen selbst wichtig sind, wurden ebenso im Fragebogen behandelt. Freundschaften bedeuten allen Jugendlichen sehr viel, gefolgt von ihrer Familie. ,Spaß haben' hat ebenfalls für alle einen hohen Stellenwert. Gothics sind ähnlich hedonistisch orientiert, wie die Mehrheit dieser jungen Generation, obwohl innen ein düsteres, melancholisches und sogar depressives Image anhaftet. Das zeigt deutlich, dass es sich um letztlich doch ganz normale lebenshungrige und lebensbejahende Jugendliche handelt und keine sozial zurückgezogenen eigenbrötlerischen Außenseiter. Ebenso wichtig wie Spaß zu haben ist innen auch, individuell zu sein. Wie bereits erläutert, ist dies ein heutiger gesellschaftlich bedingter und geforderter Wert, den aber Anhänger der Gothic-Szene, die sich Individualität auf die Fahnen schreibt, noch stärker anstreben dürften. Ebenso sehr bedeutend ist für die befragten Jugendlichen sich selbst zu verwirklichen. Weniger wichtig sind dagegen hohes Einkommen, soziales Engagement, Leistung bringen und vor allem Politik. Hier zeigt sich eine Kontrahaltung gegenüber bestimmten gesellschaftlich geforderten Werten. Sie möchten nicht in einer Welt leben, in der der Wert eines Menschen an seinen Besitztümern und seiner Leistung gemessen wird. Daher unterscheiden sich die befragten Jugendlichen in diesem Punkt auch von Wegeners Jugendlichen. Es gibt einige, die sich mit Politik beschäftigen oder es zumindest wichtig finden, es fällt innen aber schwer, sich tatsächlich dafür zu interessieren. Da die Gothic-Szene generell als unpolitisch gilt und dies weitgehend auch sein will, entspricht dieses Ergebnis der Erwartung, zumal generell der Großteil der heutigen Jugendlichen eher durch Politikverdrossenheit gekennzeichnet ist.

Zusammenfassend kann festgehalten werden, dass sich die Werte der befragten jungen Menschen hauptsächlich auf soziale Aspekte 
- Familie und Freundschaft - konzentrieren, aber auch solche die mit Selbstverwirklichung und Individualität zu tun haben. Der Erfolgs- und Leistungsdruck der heutigen Gesellschaft, so könnte man die Angaben interpretieren, wird eher abgelehnt.

\subsection{Das Interview}

\subsubsection{Leitfadenkonzeption und Methode}

Zehn Jugendliche waren bereit für ein persönliches Interview und hatten dafür auf dem Fragebogen ihre Emailadresse oder Telefonnummer hinterlassen. Es wurden drei offene leitfadengestützte Einzelinterviews mit Fans verschiedener Musiker, von jeweils etwa anderthalb Stunden Länge geführt und innerhalb weniger Tage nach dem Interview vollständig transkribiert. Das ursprüngliche Vorhaben war, noch weitere durchzuführen und mehrere Geeignete für Analyse und Vergleich auszuwählen. Jedoch fiel letztendlich die Entscheidung darauf, nur einen Einzelfall ausführlich zu beschreiben, inhaltsanalytisch auszuwerten und zu interpretieren - aufgrund des begrenzten Umfangs der Arbeit und durch den hohen Erkenntnisgewinn, der bereits durch diesen einen, wenn auch sehr speziellen Fall, den 16-jährigen Chris, möglich erschien.

"Je weniger Versuchspersonen analysiert werden, desto eher kann man auf die Besonderheiten des Falles eingehen, desto genauer kann die Analyse sein. Tiefer gehende Einsichten sind in so manchen sozialwissenschaftlichen Gegenstandsbereichen nur über Fallanalysen, nur auf dem Hintergrund des ganzen Lebenszusammenhanges einzelner Subjekte möglich" (Mayring 2001, S. 42). Selbstverständlich können die Ergebnisse eines Einzelfalles keine Repräsentativität beanspruchen, jedoch besteht die Chance, durch die Tiefe der Beschäftigung mit dem Thema weitere, bisher unbeachtete, Aspekte aufzudecken und auch wertvolle Anregungen für die weitere Forschung zu bekommen.

"Die Komplexität des ganzen Falles, die Zusammenhänge der Funktions- und Lebensbereiche in der Ganzheit der Person und der historische, lebensgeschichtliche Hintergrund sollen hier besonders betont werden. Fallanalysen stellen eine entscheidende Hilfe dar bei der Suche nach relevanten Einflussfaktoren und bei der 
Interpretation von Zusammenhängen" (ebd.). Das Interview hatte zum Ziel, die spezielle Lebenssituation und den biografischen Hintergrund sowie die persönlichen Werte und Ziele des Jugendlichen zu ergründen und mit der persönlichen Beziehung zwischen Fan und Idol in Verbindung zu setzen. Daraus können individuelle Funktionen dieser Fanbeziehung für die persönliche Entwicklung, Identitätsbildung und Bewältigung des Alltags im Jugendalter erschlossen werden.

Es handelte sich um ein halbstrukturiertes Interview mit offenem Leitfaden7. Das Gespräch wurde mit Tonband aufgenommen. Der Leitfaden enthielt grob formulierte Fragen sortiert nach verschiedenen Themenblöcken. Dabei wurde auch auf aktuelle Informationen eingegangen, die in den Medien über das spezifische Idol verbreitet werden. Der Verlauf des Interviews folgte dann dem natürlichen Erzählfluss des Befragten, so dass die Anordnung der Fragen im Gespräch variiert wurde. Bestimmte Aspekte, auf die der Interviewte detaillierter einging, bekamen dadurch stärkeres Gewicht als andere. Teilweise konnten dabei irrelevante Fragen weggelassen werden oder sich neu ergebende hinzukommen.

Die Themen, die das Interview beinhaltete, behandelten zum einen die persönliche Lebenssituation, betreffend Familie, Freunde, Freizeitverhalten und Wohnsituation sowie biografische Erfahrungen. Weiterhin ging es um die Beziehung zur Musik und speziell zum Idol, wobei auf die Fan-Biografie und den Zusammenhang zwischen der Begeisterung für den Musiker und der eigenen Person eingegangen wurde. Zudem zielten die Fragen auf mögliche Aneignungsmodi, Deutung des Idols, die Einbindung in soziale Beziehungen und den Alltag, performative Darstellung, und auch auf Erkenntnisse über das Informationsverhalten und die Mediennutzung im Zusammenhang mit dem Idol. Nicht zuletzt wurden persönliche Werte des Jugendlichen erfragt, sowie eigene Pläne und Wünsche für die Zukunft.

Der Befragte wurde bei der Interviewterminvereinbarung darum gebeten, ein Bild oder Foto seines Idols zum Gespräch mitzubrin-

\footnotetext{
7 Der Leitfaden orientierte sich - auch zum Zwecke der Vergleichbarkeit - thematisch an dem aus Wegeners (2008) Interviews.
} 
gen, das ihm besonders gefällt. Seine Beschreibung der besonderen Anziehungskraft, die dieses Bild auf ihn ausübt, erleichtert bestenfalls das Nachvollziehen der besonderen Faszination des Musikers für den Jugendlichen und lässt damit weitergehend auch Rückschlüsse über aktuelle Identitätsthemen und Aneignungsweisen zu.

„Für die Fallstrukturierung wird versucht, das Material zu gliedern, in Abhängigkeit von Fragestellung und Theorie das Fallmaterial in einzelne Kategorien zu ordnen" (Mayring 2001, S. 43), auf deren Basis die Interpretation erfolgen kann. Schließlich folgt der Vergleich mit anderen Fällen, wofür hier teilweise auf die von Wegener untersuchten Jugendlichen Bezug genommen wird. Die Inhalte des Interviews wurden in diesem Sinne thematisch sortiert und schließlich inhaltsanalytisch ausgewertet und interpretiert.

Für die Analyse wurden folgende Kategorien gebildet:

1. Interviewsituation und persönlicher Lebenshintergrund

2. Soziale Kontakte und Freizeitbeschäftigungen

3. Fangeschichte

4. Faszination und Funktion der Musik

5. Persönliche Deutung und Bedeutung des Idols und Aneignungsmodi

6. Persönliche Werte und Zukunftspläne

Innerhalb dieser Kategorien wurde den Aspekten sozialer Kontext, Aneignung, Bedeutungszuweisung sowie Identitätsthemen und -projekten besondere Beachtung geschenkt.

\subsubsection{Portrait des Idols}

Der Leitfaden enthielt auch Fragen zu Themen um den Musiker, wie sie in den Medien dargestellt werden, um persönliche Deutungen des Jugendlichen zu konkreten Verhaltensweisen und Einstellungen nachzuvollziehen und mit der (Selbst-)Darstellung seines Idols vergleichen zu können. Um die nötigen Informationen dafür zu beschaffen und die Vorzugslesart herauszustellen, bot sich das 
Internet als Recherchequelle an. Leider werden auch dort insgesamt wenige Informationen bereitgestellt, da Musiker eines musikalischen Genres jenseits des Mainstreams meist Wert darauf legen, dass lediglich ihre Musik im Vordergrund steht und weniger die privaten Details. Auch die Fans bemängeln oft die mangelnden Möglichkeiten Neuigkeiten über musikalische Neuveröffentlichungen des Stars hinaus zu bekommen. Dadurch wird zwar einerseits die Identifikation mit ihrem Star erschwert, aber durch die Erschaffung eines Mysteriums andererseits ein besonderer Reiz aufrecht erhalten.

Die Homepage gaben 13 der 20 Jugendlichen, die den Fragebogen ausgefüllt hatten, als eine Quelle zur Beschäftigung mit dem Musiker an. Die gängigen Musikzeitschriften der schwarzen Szene nutzen dagegen nur sieben der 19 Befragten. Da auch die Jugendlichen, die für ein Interview ausgewählt wurden, angaben, die Homepage als Informationsquelle zu nutzen, erschien es sinnvoll, sich den dortigen Inhalten zu widmen. Ergänzt um Inhalte aus Diskussionsforen schien es im Groben den Basisinformationen der Fans über ihr Idol zu entsprechen, wie sich in den Interviews auch bestätigte. Zusammengestellt aus den wenigen Inhalten, die die Homepage $^{8}$ von Chris' Idol Tilo Wolff, dem Sänger von Lacrimosa, sowie angelagerte Foren und Interviewveröffentlichungen bieten, folgt ein knappes Profil des Musikers, welches als Vorzugslesart betrachtet werden kann.

\section{Kurzportrait von Tilo Wolff}

Über die Person des Sängers und Songschreibers der Band Lacrimosa sind so gut wie keine privaten Details bekannt. Die Homepage enthält lediglich eine Biografie der Band. In folgender Kurzcharakterisierung sind auch Inhalte des auf der Homepage veröffentlichten Interviews sowie Inhalte des dortigen Forums eingegangen.

Die Musikkarriere des 37-jährigen Tilo Wolff begann 1990 mit der Gründung von ,Lacrimosa', zunächst als Solo-Projekt. Er gründete

${ }^{8}$ Vgl. http://www.lacrimosa.ch - letzter Zugriff am 05.10.2009. 
ein eigenes Label namens Hall of Sermon, um sich alle musikalischen Freiheiten zu gewähren und auch anderen schwarzen Bands eine Plattform bieten zu können. 1994 schloss sich die finnische Sängerin Anne Nurmi, Lacrimosa' an. Beide leben heute in der Schweiz. Stilistisch bewegt sich die Musik im Darkwave und Gothic-Rock/Metal-Bereich. Es handelt sich um eine Mischung aus gefühlvollen und harten wuchtigen Klängen, enthält aber auch klassische Elemente. Längst hat die Band treue Anhänger auf der ganzen Welt gewonnen und geht regelmäßig auf Europa- und Welttournee. Seit 2004 betreibt Tilo Wolff auch ein Industrial-Nebenprojekt namens ,Snakeskin'.

Tilo Wolff wird als intelligenter, sensibler, poetischer und zurückhaltender Künstler beschrieben, der sich auf der Bühne eher schwermütig gibt, sich außerhalb jedoch auch lebhaft und aufgeschlossen zeigt. Der Sänger ist gebürtiger Deutscher, lebt aber in der Schweiz. Es ist bekannt, dass er früher Punk gewesen ist. Ihm wird daher politisch auch eher eine linksgerichtete Haltung zugeschrieben, obwohl seine Texte kaum politische Themen behandeln. Es geht vorwiegend um Gefühle, Träume, Liebe, Leid und Schmerz. Wolff gilt als bekennender Christ. Nach eigenen Angaben ist er dem Glauben sehr zugetan, lehnt jedoch die Kirche als Institution $a b$.

Aus der Szene wird dem Musiker teilweise vorgeworfen, sich in den letzten Jahren zunehmend dem Kommerz zuzuwenden. Wolff tritt dieser Kritik mit dem Argument entgegen, dass alles, was nicht kostenlos ist, Kommerz ist.

\subsubsection{Inhaltsanalyse des Interviews mit Chris (16 Jahre, Idol: Tilo Wolff)}

Transkriptionsregeln ${ }^{9}$

9 Die Transkriptionsregeln wurden zusammengestellt nach:

- Altrichter; Posch 1990, S. 121.

- Koring, B.: 1989, S. 787.

- Mayring 1996, S. 70-73. 
C.: = Äußerungen des Interviewten

I. : = Äußerungen der interviewenden Person

(unverständlich) $=$ unverständliche Äußerungen

(Also morgen will ich?) = nicht genau verständlicher, aber vermuteter Wortlaut

$[\ldots]=$ Auslassung durch die transkribierende Person

wahnsinnig = auffällige Betonung (unterstrichen)

wahnsinnig $=$ größere Lautstärke $(\mathrm{fett})$

jaaa = Dehnung (Je mehr Vokale aneinandergereiht sind, desto länger die Dehnung.)

(Lachen) bzw. (lacht), (Unruhe), (geht raus) $=$ Charakterisierung nichtsprachlicher Vorgänge

Ich habe @immer so ein komisches@ Gefühl dabei. = Lachend gesprochene Worte werden zwischen zwei "@-Zeichen" gesetzt.

(kurze Pause), (lange Pause), (3 Sek. Pause) = Absetzen einer sprachlichen Äußerung, evtl. in Sekundenangabe

\subsubsection{Interviewsituation und persönlicher Lebenshinter- grund}

Chris ist zum Zeitpunkt des Interviews 16 Jahre alt und lebt mit anderen Jugendlichen in einer an ein Kinderheim angelagerten Einrichtung für Betreutes Wohnen, die zweimal die Woche betreut wird. Er war der Einzige, der sich auf meine in dem Dresdner Internetforum "gothic-city.de" gesetzte Anzeige gemeldet hatte, in der ich über meine Studie informierte und Jugendliche suchte, die sich mit mir über ihr Idol unterhalten möchten.

Chris lebt zum Zeitpunkt des Interviews, im Juni 2009, erst seit einem Jahr in Dresden - geboren und aufgewachsen ist er in einer Kleinstadt in Thüringen. Nachdem seiner Mutter, die an Schizophrenie leidet, das Sorgerecht entzogen wurde, musste er zunächst ins Heim ziehen und dann zu seinem - bis dahin für inn unbekannten - Vater nach Dresden. Nachdem er dort einige Zeit 
gelebt hatte, es jedoch Probleme gab, zog er schließlich ins Betreute Wohnen, wo er voraussichtlich bis zu seinem 18. Geburtstag leben wird. Chris hat einen Realschulabschluss gemacht und beginnt im September 2009 ein freiwilliges soziales Jahr in einem Kindergarten. Zum Zeitpunkt des Interviews absolvierte er ein Praktikum im angelagerten Kinderheim, half dort bei der Wirtschaft und Hausaufgabenbetreuung.

Per Email bekam Chris vorab den Fragebogen zugesandt. Diesen sendete er vor dem verabredeten Interviewtermin vollständig ausgefüllt zurück, so dass auf diese Angaben im Gespräch vertiefend eingegangen werden konnte und sie in die Auswertung der gesamten Fragebögen einfließen konnten.

Das Treffen fand in Chris ' derzeitiger Unterkunft im Betreuten Wohnen statt. Es begegnete mir ein schmächtiger Junge mit etwas längeren schwarz gefärbten Haaren mit hellblonden Strähnen. Er trug schwarze Jeans, T-Shirt und Lederjacke, er machte zunächst einen etwas schüchternen, jedoch sehr freundlichen und offenen Eindruck. Chris zeigte mir zuerst die Gemeinschaftsräume der Einrichtung. Danach gingen wir für das Interview in sein Zimmer, das hell und freundlich gestrichen und sehr ordentlich war. An den Wänden und über dem Bett befanden sich Poster und zumeist kleinere Bilder, aus Zeitungen ausgeschnitten, vorwiegend von seinen Lieblingsbands ,Lacrimosa' und ,L'amme immortel'. Die Möblierung war eher spartanisch. Es gab einen Schreibtisch, ein flaches Sideboard, Schrank und Bett. Aus dem Fenster schaute man auf einen grünen Innenhof.

Als Chris seine Jacke auszog, kamen an den Armen vernarbte Schnittwunden zum Vorschein, auf die er mich sogleich hinwies, um mich nicht zu erschrecken, wie er sagte. Er erzählte, dass er Borderline habe und deswegen auch bis vor kurzem stationär in Behandlung gewesen sei. Auf dem Sideboard lag auch ein Buch über Borderline und Verbandszeug sowie eine Rasierklinge, die er nachdem ich sie gesehen hatte, wegräumte und sich entschuldigte. Insgesamt schien er bewusst auf seine Krankheit hinweisen zu wollen, er ging sehr plakativ damit um, fast als würde er sich damit profilieren wollen. 
Im Interview begann er zunächst recht leise, langsam und etwas unsicher zu sprechen. Die Atmosphäre lockerte sich aber zunehmend und war letztlich sehr entspannt - wir lachten sehr viel im Gespräch. Zu Beginn ging es um seine derzeitige Lebenssituation und familiäre Hintergründe, die dazu geführt haben. Er sprach auch über seine Krankheit, weshalb die Stimmung eher drückend war. Als wir jedoch auf die Musik und sein Idol Tilo Wolff zu sprechen kamen, blühte Chris merklich auf, wurde heiterer und aufgeschlossener, redete selbstbewusster mit kräftiger, melodischer Stimme. Ich war erstaunt, wie reif und reflektiert dieser 16-jährige Junge mit mir sprach. Er war ein sehr intelligenter Gesprächspartner, der sich für sein Alter sehr gut artikulieren konnte. Das Interview dauerte ca. anderthalb Stunden.

Die Tatsache, dass es sich bei Chris nicht um einen typischen Jugendlichen handelt, sondern dass er aus schwierigen Verhältnissen stammt und an Borderline erkrankt ist, macht diesen Fall zu etwas Besonderem. Hier sind noch weniger als bei Einzelfällen ohnehin schon Verallgemeinerungen auf andere Jugendliche und auch andere Jugendliche der Gothic-Szene legitim.

\section{Exkurs Borderline}

Borderline ist die Bezeichnung für eine Persönlichkeitsstörung. Betroffene zeigen Instabilität in zwischenmenschlichen Beziehungen, Affekten und Selbstbild sowie starke Impulsivität.

Nach DSM IV gibt es neun Kriterien für eine Borderline-Diagnose, von denen mindestens fünf erfüllt sein müssen. Es zeigt sich ein instabiles, aber intensives Muster in zwischenmenschlichen Beziehungen, das zwischen den Extremen von Idealisierung und Entwertung einer Person schwankt. Zudem kommt es zu impulsivem Verhalten, das sich in mindestens zwei potentiell selbstschädigenden Bereichen äußert, zum Beispiel Sexualität, Substanzmissbrauch, gestörtem Essverhalten oder Geldausgaben. Ein weiteres Kriterium ist ausgeprägte Reaktivität der Stimmungen, die affektive Instabilität bedingt und sich in episodischer Depression, Reizbarkeit oder Angst zeigt. Häufig treten heftige und unangemessene Wutausbrüche auf oder Probleme diese Gefühle zu kontrollieren. Zudem kommt es oft zu selbstverletzendem Verhalten, wie 
schneiden, verbrennen, schürfen oder beißen, oder auch suizidalem Verhalten. Charakteristisch ist auch das Auftreten von Identitätsstörungen, die sich in ausgeprägter und andauernder Instabilität des Selbstbildes oder der Selbstwahrnehmung, auch des Körperbildes, äußern kann, jedoch nichts mit den typischen adoleszenten ,Identitätsverwirrungen' zu tun haben. Zudem treten häufig Gefühle von Leere auf. Typisch für Borderline-Patienten ist darüber hinaus auch die chronische Angst vor dem Verlassen werden und das verzweifelte Bemühen vermutetes oder tatsächliches Verlassen werden zu vermeiden. Ein letztes mögliches Symptom sind Störungen des Realitätsempfindens, ausgedrückt in Depersonalisation, Derealisation und halluzinogenen Erscheinungen.

Als Kern dieser Störung wird die mangelnde Affektregulation gesehen, die im Zusammenhang mit allen anderen diagnostischen Kriterien steht. Die Emotionen sind leicht auslösbar, werden sehr extrem erlebt und kommen nur langsam wieder auf das Ausgangsniveau zurück (vgl. Bohus 2002, S. 6).

Die Tendenz zu schwarz-weiß-Denken, die sich darin zeigt, dass Personen entweder über-idealisiert oder entwertet werden, könnte sich auch verstärkend auf die Beziehung zu einem selbstgewähltem Idol auswirken, wenn die Person nahezu verherrlicht und wenig kritisch-differenziert wahrgenommen wird. Zudem neigen Borderliner zur projektiven Identifikation, was ebenfalls in der Aneignung von Idolen deutlich werden könnte. Eigene Werte, Gedanken, Gefühle und Eigenschaften werden als der anderen Person zugehörig wahrgenommen. Da Borderline-Patienten aber oft das Gefühl verspüren, anders als andere zu sein und damit einsam und allein auf der Welt (vgl. ebd., S. 7), könnten sie durch die Bewunderung ihres Idols und das projektive Erkennen von eigenen Eigenschaften in der anderen Person, das Gefühl bekommen, einen Verbündeten zu haben, dem es ähnlich ergeht wie innen selbst und dadurch rückwirkend ein Gefühl der Selbstbestätigung, dass der Stabilität des Selbstbildes und dem Selbstbewusstsein zuträglich ist.

Wesentlich für die Thematik der identitätsbildenden Funktion von Idolen ist auch das Kriterium der Identitätsstörung bei BorderlinePatienten. Sie haben häufig das Gefühl, nicht zu wissen, wer sie 
wirklich sind (vgl. ebd.). Da dieses Empfinden auch pubertierenden Jugendlichen nicht fremd ist, könnte ein Idol hier ähnlich stabilisierend wirken wie bei ,normalen' Jugendlichen, Leitlinien für Verhalten und Persönlichkeit vorgeben und sich damit positiv auf den Krankheitsverlauf auswirken.

Wesentlich ist aber und auch für die Brauchbarkeit des Interviews mit Chris, dass Borderliner nach derzeitigem Forschungsstand nicht generell kognitiv eingeschränkt sind, also in der Lage sind, ganz normal wie jeder andere Mensch zu denken (vgl. ebd., S. 9).

Ich habe Chris nicht als einen Menschen mit einer Persönlichkeitsstörung betrachtet, sondern in erster Linie als pubertierenden Jugendlichen, mit Sorgen und Befürchtungen, Hoffnungen und Träumen, der im Begriff ist, seine Identität auszubilden und dabei spezifische Themen in dieser Lebensphase bearbeiten muss. Sicher sind seine Probleme sehr ausgeprägt und teilweise anders gelagert als bei Jugendlichen, die in einem behütenden Elternhaus aufwachsen, seine Krankheit kommt beeinträchtigend und verstärkend hinzu. Jedoch ist gerade diese Prägnanz eine Möglichkeit, Prozesse bei der Aneignung von Idolen, die spezifischen Funktionen einer Medienbeziehung in einem Leben deutlicher aufzuzeigen und herauszustellen. Weil Chris in besonderen Umständen lebt, nutzt er deshalb keine anderen Aneignungsweisen. Es fanden sich allerdings sogar alle Aneignungsmodi, die sonst in dieser Ausprägung bei keiner der interviewten Personen zu finden waren. Von daher kann der Fall Chris das Thema exemplarisch wunderbar aufzeigen. Seine Reflexionsfähigkeit, Intelligenz und Bereitschaft über seine Bedürfnisse und Gedanken zu sprechen, waren sehr hilfreich für die Rekonstruktion der Qualität und Bedeutung seiner Beziehung zu seinem Idol Tilo Wolff. Sicherlich ist Chris' große Fähigkeit zur Selbstreflexion und das verhältnismäßig reife Auftreten auch Folge seiner erzwungenen frühen Selbstständigkeit, angesichts dessen, dass seine Mutter aufgrund ihrer Krankheit nicht in der Lage war, seine Halbschwester und inn ausreichend zu versorgen. Seine Schwester habe er schließlich wie ein eigenes Kind umsorgt, "[...] weil meine Mutter is seehr depressiv und auch schizophren. (kurze Pause) Die hat sich da nie drum @kümmern könn@" (S. 115, Z. 22 f., Auslassung: S.L.). Auch die Tatsache, dass sich Chris schon länger in Psychotherapie befindet und dadurch zur 
Auseinandersetzung mit sich gezwungen ist, wird zu seiner Selbstkenntnis beigetragen haben.

Stärker als in anderen Fällen, kommt bei dem Jungen im positiven Sinne zum Ausdruck, wie wesentlich Musik und die Identifikation sowie parasoziale Beziehung zu einem Idol in einem Leben sein kann und dass sie sogar eine Art lebensrettende Funktion übernehmen kann, wenn andere Sicherungspunkte im Leben wegbrechen, gerade in einer ohnehin schon verunsichernden Lebensphase wie der Jugendzeit.

\subsubsection{Soziale Kontakte und Freizeitbeschäftigungen}

Chris lebt derzeit ziemlich isoliert von Freunden, Familie und engeren Bezugspersonen. In dieser schweren Phase seines Lebens kommen bei ihm zu typischen Problemen Jugendlicher, die mit Identitätssuche, Entwicklung von Freundschafts- und Liebesbeziehungen und allgemeinen Zukunftsprojekten zusammenhängen, noch seine Erkrankung, die Trennung von seiner Mutter, seinen Freunden und die distanzierte Beziehung zu seinem Vater hinzu. Er hat in Thüringen einen - wie er sagt - großen Freundes- und Bekanntenkreis, auf den er jetzt verzichten muss: "Ich habe eigentlich alles zurück gelassen" (S. 115, Z. 8). In Dresden hat er noch Probleme neue Kontakte aufzubauen. Zudem verbietet ihm sein Vater, seine Heimat zu besuchen, was ihm als Sorgeberechtigtem auch gestattet ist. Der Junge vertröstet sich selbst auf seinen 18. Geburtstag, wenn er rechtlich als Erwachsener gilt, selbstverantwortlich handeln muss und damit die Möglichkeit hat, selbst zu entscheiden, wo er leben möchte.

Chris kreuzte im Fragebogen an, dass er sich nie mit anderen Fans träfe, was in seiner Situation begründet ist, neu in Dresden zu sein. Er erzählte mir auch, dass er trotz vieler Bemühungen, auch über Internetforen, Probleme hätte neue Leute kennen zu lernen, was seiner Meinung nach an der Verschlossenheit der Gothics in Sachsen läge. "[...] [D]a gibs zum Beispiel son großes Forum für Dresden, Gothic City uund viel versucht kennen zu lernen, keiner sich gemeldet zurück oder so. [...] [D]ie stelln das rein und es antwortet keiner drauf. Wenn man die Leute dann anschreibt, die auch was reingestellt haben, dann antworten die aber nich zurück" (S. 133, Z. 11-17, Auslassung und Anpassung: S.L.). 
Mit seinen Mitbewohnern im betreuten Wohnen kommt er gut klar, wenn sich daraus auch keine Freundschaften entwickeln. „[...] [S]o im Groben is des Verständnis schon da, alsoo man kann sich Hallo und Tschüss sagen, also zwischen dem einen und dem andern mehr und zwischen dem und dem wieder weniger [...]. Aber des is meistens so, wenn viele Menschen aufm Haufen leben. Jaa. Und dann sind wir ja auch alle, sag ich mal Jugendliche mit ner Geschichte. Mit ner Vorgeschichte. Wo des auch nich so einfach war bei allen und da kann man nich erwarten, dass jeder da so hundert Prozent soziaal auch is zu den andern. Kommen schon verschiedenste Dinge vor" (S. 114, Z. 26-33, Auslassung und Anpassung: S.L.). Es gibt jedoch ein Mädchen, das gerade in seine Wohngemeinschaft gezogen ist, die er schon als gute Freundin betrachtet und mit der er möglichst viel Zeit verbringt: "[...] wir tun immer viel rausgehn, viel angucken und sowas, wenn sie Zeit hat" (S. 115, Z. 3 f., Auslassung: S.L.).

Mittlerweile hat er auch wieder ein relativ gutes Verhältnis zu seinem Vater, den er manchmal besucht. Sonst ist Chris sehr aktiv, er arbeitet freiwillig im Kinderheim, acht Stunden täglich, und ist viel unterwegs, geht regelmäßig in die Stadt, leiht sich Zeitschriften, Bücher und CDs in der Stadtbibliothek aus oder sieht sich die Natur und Sehenswürdigkeiten an. Er hat auch noch viel mit Behördengängen zu tun.

Die Bibliothek ist ein großer Schatz für ihn, da er mit sehr wenig Geld im Monat auskommen muss und so eine Möglichkeit hat, fast kostenfrei seiner Musikleidenschaft nachzugehen. „Ich tu mir das dann auch auf MP 3 noch mit machen und so uund sammle das. Wie verrückt (lacht)" (S. 118, Z. 1 f.). Chris leiht sich dort auch Gothic-Zeitschriften aus: „Uund, da findet man denn ooch manchmal was raus und so über neue Bands, in den Zeitschriften, wenn da mal wer aufm Cover is, dann frag ich mich, wer is das, dann hör ich den Namen und dann guck ich, ob die die CD da haben. Und wenn dann pack ich se ein und. Also Informationen such ich mir viel beim Orkus, beim Zillo und Legacy und auch beim Gothic" (S. 141, Z. 18-22).

In seiner Freizeit hilft Chris bei der Hausarbeit, denn die Jugendlichen in der Wohngemeinschaft müssen sich selbst versorgen und Ordnung halten. Er telefoniert häufig, manchmal liest er Bücher 
und Zeitschriften und surft im Internet. Er hört und macht auch selbst Musik. Früher in Thüringen war er der Sänger in einer Gothic-Band, dieser Leidenschaft würde er gern wieder nachgehen. Er hat früher auch Gedichte geschrieben, um einen Kanal für seine Emotionen und Gedanken zu finden, denn es fällt ihm oft schwer sie auszudrücken oder seine Wünsche anderen, besonders seiner Familie gegenüber, zu vermitteln: „Ja. So meine Ausdrucksform. Also ich kann mich, soo kann ich mich verbal sehr gut ausdrücken, ich hab auch nen relativ großen Wortschatz, aba es hapert dann am Selbstbewusstsein irgendwo gegenüber der Familie und am Durchsetzungsvermögen" (S. 118, Z. 12 ff.).

Als Chris von seiner Selbstverletzung spricht, klingt an, dass er sich oft sehr einsam und ungeliebt fühlt. „[...] [D]adurch dass ich jetzt niemandem so sehr am Herzen liege oder so, is mir die Selbstverletzung in dem Sinne eigentlich egal. Sie hat nichts Schlechtes für mich" (vgl. S. 118, Z. 23 ff., Auslassung und Anpassung: S.L.) - nur Erleichterung in diesem Augenblick.

\subsubsection{Fangeschichte}

Als sein Idol hat Chris Tilo Wolff - den Sänger und Songschreiber der Gothic-Band Lacrimosa - angegeben, von dem er seit rund zwei Jahren Fan ist. Seit einem halben Jahr ist er auch Mitglied in dem Internet-Fanclub, Lichtgestalten'. Für die Beschäftigung mit der Musik nutzt er seine Musiksammlung, Gothic-Zeitschriften, Homepage und Fansite der Band sowie Internetforen.

Die Leidenschaft für Musik hat sich schon früh im Leben von Chris ausgeprägt. Auf die Frage, wann er denn angefangen hat, GothicMusik zu hören, gab der 16-jährige Junge an, dass das acht bis neun Jahre her sei. In der ersten Klasse habe er jemanden kennengelernt, dessen Eltern Rammstein gehört haben. Vorher habe er "[...] totaal auf Pop-Musik gestanden [...]" (S. 119, Z. 9, Auslassung: S.L.). Seine Mutter habe häufig wechselnde Partner gehabt, darunter waren auch welche die Gothic, Mittelaltermusik und Klassik gehört haben. „[...] [Meine Mutter] hatte sozusagen jeden Tag $\mathrm{n}$ andren Mann und so und die ham alle natürlich ihre Musik mitgebracht dazu. Also zu ihrm Wesen auch die Musik und so. Und da hab ich da so immer $\mathrm{n}$ bisschen zu den verschiedenen Mu- 
sikrichtungen gefunden." (S. 119, Z. 12 ff., Auslassung und Einfügung: S.L.) Von Rammstein ausgehend weitete sich sein Musikgeschmack über verschiedenste Gothicbands aus, von zunächst englischsprachigen Gruppen wie ,Nightwish' und ,L'amme immortel', hin zu deutsch-singenden Bands wie ,In Extremo', ,Subway to Sally' und ,Schandmaul'. Auf ,Lacrimosa' und damit Tilo Wolff ist er dann mit 13 Jahren gestoßen, „[...] weeeil da gabs mal n großen Fernsehbericht über den, Tilo Wolff, dass der halt ne CD veröffentlicht. [...] Der Morgen danach oder so war das Lied was ich zuerst gehört hab. [...] Und so bin ich dann weiter da drauf, hab ich gedacht, das muss ich jetzt alles hörn. Weil wenn ich eine Band höre, muss ich alle Alben von denen hörn. Weil, ich muss das komplett hörn, was die fabriziert haben und so. Ich mag des nich, ein Album hab ich und des andre hör ich nie, also muss ich schon alles irgendwann mal gehört haben" (S. 120, Z. 31-39, Auslassung: S.L.). Mit seiner damaligen Band, die er gemeinsam mit Mitschülern gründete, spielte er vorwiegend Cover-Lieder, aber sie hatten damit auch im Umkreis Auftritte, also "[...] wir warn schon $\mathrm{n}$ bissel bekannt bei uns" (S. 119, Z. 37, Auslassung: S.L.) betont Chris, wodurch er wiederum viele Bands und ihre Musik kennenlernte. Die haben ihn "[...] dann auch mit so durch die Gothicschiene geführt [...]" (S. 120, Z. 13, Auslassung: S.L.). Er kannte auch „[...] ganz ganz viele Menschen [...], die da drauf total gestanden haben (S. 119, Z. 37 f., Auslassung: S.L.).

Chris sagt von sich, dass er relativ offen ist, was die verschiedenen Sparten der schwarzen Musik betrifft. „Ich hör alles, Wave, GothMetal, Goth-Rock, EBM, (Medi-Eval?) viel, ja Goth-Pop hör ich sogar ab und zu, hier (zeigt auf eine CD auf dem Tisch) Within Temptation. Zählt ja teils unter Goth-Pop. Also so hör ich eigentlich schonn jegliche Richtung. " (S. 138, Z. 24-27). Er beschreibt auch, was ihm an der Gothik-Mode gefällt: „Unauffällig (kurze Pause) als Mann, schönen schwarzen Mantel, nich auffallen. Und die Frau muss natürlich prachtvoll, in prachtvollen Kleidern, da steh ich total drauf. Ich liebe diese Kleider. Also ich bin auch sehr weiblich irgendwo" (S. 138, Z. 33-36). Hierfür hat er auch eine Begründung: "Ich bin fast, fast nur unter Frauen aufgewachsen. Also, meine Mutter hatte zwar jeden Tag nen andern, aber so als ständiger Begleiter waren nur Frauen, deswegen bin ich sehr feminin, in gewissen Punkten" (S. 138, Z. 36 ff.). Chris erwähnte auch, 
dass er mit Männern schlecht umgehen kann und auch fast nur weibliche Freunde hat. Es gäbe einen bestimmten Typ Mann, vor dem er panische Angst habe. Viele schlechte Erfahrungen werden zu diesem Umstand beigetragen haben. Es fehlte ihm auch eine stabile und positive Vaterfigur in seiner Kindheit. Tilo Wolff könnte selbst in diesem Sinne als Leitbild fungieren, indem er für Chris eine positive Art von Männlichkeit repräsentiert, mit der er sich identifizieren kann.

Chris war noch nie auf einem Konzert von Lacrimosa, sondern bisher war er dort nur ,Zaungast'. Als Grund gibt er an, dass sie "[...] fast (50?) Euro fürs Konzert haben [wollen]" (S. 141, Z. 28 f., Einfügung und Umstellung: S.L.). Zudem findet er, dass sie nicht viel für den Preis bieten: "[...] die ham ne tolle Lichtshow, aber keine Pyroeffekte, [...] keine Story die erzählt wird, geh ich zum Beispiel bei L'amme immortel auf Konzert, dann hat man so ne Art Geschichte die erzählt wird. Von Anfang an bis Ende, son wien Roman wird da erzählt. Nur aus den Liedern, hat eigentlich total Unsinn wenn man die Lieder so hinternander weg hört, aber die bringen des halt zu ner Geschichte zusammen, das bei Lacrimosa halt selten. Is ja bei den verschiedenen Themen glaub ich auch garnich möglich, wenn die Lieder dann auch zehn Minuten gehen" (S. 141, Z. 29-36, Auslassung: S.L.). Trotz der Kritik ist seine Begeisterung für die Band ungebrochen: „Ich würd es mir trotz allem nochmal anschaun. [...] [D]ie sind gut Partymacher, also die machen super Stimmung auf den Konzerten, des is echt geil" (S. 142, Z. 2 ff., Auslassung und Anpassung: S.L.).

\subsubsection{Faszination und Funktion der Musik}

Chris entgegnete mir auf die Frage, ob er das denn beschreiben könne, was ihn an der Gothic-Musik so fasziniert habe, "[...] sie wirkt so kunstvoll so, künstlerisch, sehr" (S. 120, Z. 18, Auslassung: S.L.). Im Gegensatz zur Popmusik ist Gothic-Musik für ihn sehr viel abwechslungsreicher und tiefgehender. "Bei Popmusik wiederholt sich des, man hat den ständig wiederkehrenden Chorus und alles so ähnlich aufgebaut. Und wenn man genau hinhört, alle fünf Monate kommt $\mathrm{n}$ Lied was sich genauso anhört wie des davor. Und die Bands ham dann immer nachgelassen und so und des hat mich dann nich fasziniert und bei der Gothic-Musik is es so (kurze 
Pause), es immer imma individuell und selbst die Texte sagen sehr viel aus, auch wenn die Lieder manchmal gleich klingen" (S. 120, Z. 19-25).

In Bezug auf Lacrimosa sagt er "[...] okay die ersten Alben hörn sich ein wenig an wie die letzten. Aber [..] bei Liedern von ner viertel Stunde Länge kann man glaub ich über zehn Jahre nich immer wieder was Neues machen und grade die Texte ham mich auch fasziniert mit (kurze Pause) und natürlich viele klassische Elemente, so wie n (unverständlich) Orchesta und sowas" (S. 120, Z. 25-29, Auslassung: S.L.). Chris scheint angezogen von der Tiefe und Vielseitigkeit dieser Musikrichtung. Er hört Musik nicht oberflächlich, sondern intensiv, achtet auf Details und setzt sich auch stark mit den Texten einer Band auseinander, wenn er erst einmal auf sie aufmerksam geworden ist.

Die Musik begleitet Chris durch seinen Alltag und übernimmt dabei auch strukturierende Funktion. „Ich kann ohne Musik, kann ich überhaupt nicht leben, von vierundzwanzig Stunden hör ich bestimmt zehn Stunden Musik. Von früh bis Abend, des läuft immer. [...] [I]ch habs auch im Hintergrund, weil intensiv tu ich wirklich abends mal hörn oder wenn ich, wie heute, unterwegs bin und ich sitz in der Bahn und muss wirklich lange Zeit warten, dann hab ich die Musik laufen und hör natürlich auch aufn Text. Wenn ich mir ne CD neu besorge, dann hör ich auch erst mal auf die Lieder, auf die Texte. Und wenn ich das dann einmal gehört hab und sozusagen mitgekriegt hab worums geht, dann hör ich die auch mal nebenbei. Lass ich die einfach auch mal laufen, das is auch Okay. (kurze Pause) Aber so bin ich sehr Musik-verliebt (lacht)" (S. 130, Z. 1-12, Auslassung und Anpassung: S.L.).

Musik hat für Chris auch stimmungsregulierende Funktion. Er wählt sie sowohl stimmungskongruent als auch stimmungskompensierend aus. "Also wenn ich sag Okay, ich hab gute Laune, dann brauch ich mein Beat, mein Bass, EBM oder was schnelles von Lacrimosa. [...] So Emo-like (lacht). [...] Ich kleide mich nich nach Stimmung, ich höre nach Stimmung. [...] Ich krieg grade von Deprimusik, von Lacrimosa-Liedern, krieg ich total gute Laune. Da dreh ich total frei. Aber ich hör das auch mal wenn ich Depri drauf bin, also ein Lied kann so viele Wirkung auf mich haben, mal tuts mich total runterziehn und mal tuts mir gute Laune machen. [...] 
naja, isn bisschen krank" (S. 129, Z. 16-31, Auslassung: S.L.). Er ist sich nicht ganz sicher, wie und warum ihm Musik in bestimmten Momenten gefällt und wie sie wann wirkt, da es sich vermutlich auch um ein Mittel handelt, dass er nur teilweise bewusst einsetzt. Mit den Liedern von Lacrimosa verhält es sich ähnlich. „[...] [I]s n ganz anderes Feeling wenn man das Studioalbum hört, als wenn man das Life-Album hört. Beim Life-Album is alles so fröhlich so, richtig als wenn man auf ner Disco is oder was. Und bei dem Studioalbum handelts sich wirklich um intensive Gefühle, die da auf einen einströmen, die da ausgehen von. [...] [I]ch find beides gut, des stimmungsabhängig. [...] [A]lso da gibs die Momente, wo ich gute Laune hab, da muss ich wirklich Life hörn. Geh ich da ab und so (lacht). Uund ja manchmal hab ich auch auf die Deprilieder Lust" (S. 142, Z. 4-14, Auslassung und Anpassung: S.L.).

Chris erwähnte, dass viele Leute diese Musik hören, wenn sie sich selbst verletzen. Es sei eine Art Ritual. Auf die Frage, ob das auch bei ihm so wäre, gibt er zu: „Ja (leise). Es dauert schon mal gerne drei Stunden" (S. 129, Z. 3). Er hört dann „@Viel Lacrimosa@, L'amme Immortel vielleicht und jaa, eigentlich mehr L'amme Immortel grade. So, da gibt's son ganz bestimmtes Lied, das heißt Blutrot, da geht's grade um Selbstverletzung und sowas ja. Das fand ich sehr toll, dass die das gemacht haben, da war ich sehr beeindruckt, dass die son Lied geschrieben haben. (3 Sekunden Pause) Naja und sone Depri-Musik (lacht) hör ich dann gerne" (S. 129, Z. 5-9). Dabei ist wichtig, dass m.E. nicht die Musik es ist, die inn zur Selbstverletzung treibt, sondern er wählt die Musik passend zu der Gefühlslage, in der er sich dann befindet. Er ist beeindruckt, dass eine seiner Lieblingsbands ein Lied über die Selbstverletzung geschrieben hat, wobei zu befürchten wäre, dass solche Texte bestätigend und verstärkend auf sein diesbezügliches Denken und Verhalten zurückwirken, da sie ihm dadurch das Gefühl geben, aufgrund des Ritzens im positiven Sinne jemand besonderes zu sein. Die Betrachtung der Darstellung des Themas im Liedtext wäre notwendig, um mögliche diesbezügliche Einflüsse nachzuvollziehen. Wahrscheinlich ist jedoch, dass die Auseinandersetzung einer seiner Lieblingsbands mit diesem Thema Chris schlicht das Gefühl gibt, verstanden zu werden und nicht allein mit seinem Problem zu sein. 
In Auseinandersetzung mit seinen Mitbewohnern in der Wohngemeinschaft zeigt sich auch die Abgrenzungsfunktion durch den Musikstil. Während die anderen Jugendlichen Schranzmusik und Hiphop hören, womit Chris überhaupt nichts anfangen kann, ist er der einzige, der Gothic-Musik hört, die wiederum die anderen als untragbar empfinden. Somit kämpft er allein gegen den Rest, was ihn aber nicht zu stören scheint. Im Gegenteil, es gibt inm den Status, besonders und individuell zu sein. "Die Gothic-Richtung kann kaum jemand nachvollziehn, der kein Gothic is. Die finden das alle einfach nur @abartig@, solche Musiik. [...] [Ich höre] vor allem auch liebend gern laut. [...] [A]b und zu [gibt's dann auch Streit], aber das macht nichts, die hörn so Schranzmusik. So ähnlich wie Einstürzende Neubauten, so totaal so technomäßig mit so ums ums ums, als wenns total kaputt is so, Kratz-Geräusche und so Piepen, so piiiep, (ich lache) wie von der Autoalarmanlage. Totaler Rotz. [...] das passiert auch, dass die da drüben zum Beispiel auch mal HipHop hörn, da krieg ich ja Pusteln, ich hasse diese Musik total. Ich sage zwar denn erstmal nischt, aber ich reg mich da innerlich total off. Und denn mach ich meine Musik an und denn schaukelt sich das immer höher und immer höher [...]" (S. 140, Z. 25 bis S. 141, Z. 9, Auslassung, Einfügung und Anpassung: S.L.). Auch wenn also gegenseitig mittels der Musik und der Lautstärke provoziert wird, so gibt es deswegen aber keinen Anlass zu echtem Streit. Es gibt nur Spannungen, die nicht unangenehm empfunden werden sondern der Selbstdefinition und Abgrenzung dienen. Während andere Jugendliche, die im Elternhaus wohnen, die Musik nutzen, um ihre Grenzen bei den Eltern auszutesten, sich abzugrenzen, zu provozieren, sind es hier die gleichaltrigen Mitbewohner, die dieses Gegenüber für die Reflexion des Selbst stellen.

\subsubsection{Persönliche Deutung und Bedeutung des Idols und Aneignungsmodi}

Der Aneignungsmodus diskursive Konstruktion und soziale Unterstützung zeigt sich in interkommunikativen Prozessen. Wie bereits beschrieben, gerät Chris häufiger in Diskussionen mit seinen Mitbewohnern über Stil und Lautstärke seiner Musik. Zum einen werden dabei Machtverhältnisse geklärt und Selbstbehauptung geübt. 
Zudem spiegeln die Reaktionen der anderen ihm seine speziellen Vorlieben und wirken damit formend auf sein Selbstbild zurück.

Er trägt seine Zuneigung zur Szene und der Musik performativ nach außen. Er steht zu seinem Stil und es gefällt inm, wenn er bemerkt, dass er spezielle Vorlieben, Einstellungen und eine eigene Lebensweise hat, die ihn von anderen unterscheiden.

Chris gab im Fragebogen an, dass er viele Leute kennt, die Tilo Wolff auch gut finden. Vermutlich bezieht sich das eher auf Menschen an seinem Heimatort und andere Mitglieder in dem Internetfanklub, dem er zugehörig ist. Seine dortige Aktivität im Forum integriert inn in ein soziales Kollektiv, dessen Verbundenheit zunächst in der gemeinsamen Leidenschaft für diese Musik und speziell diesen Musiker begründet ist. Aufbauend auf diese Basis besteht jedoch die Möglichkeit, tiefer gehende Freundschaften zu knüpfen. Durch die Gespräche mit anderen Fans erfährt er zudem viel über die Musik und auch hintergründige Themen.

Chris gab im Fragebogen an, Wolff eher nicht als sein Idol bezeichnen zu wollen. Dies begründete er im Interview mit seinem persönlichen Verständnis von einem Idol, dem man im Sinne eines Vorbilds nachahmen würde, was er aber nicht wolle. Er betonte sein Bedürfnis nach Individualität. Selbst würde er ihn als seinen Star bezeichnen. "Weil n Idol is ja son Vorbild-Funktion. Uund er is ja kein Vorbild, ich will ja nich hundert Prozent so sein wie er, ich will ja ein Individuum bleiben, was ich bin, ich will schon sein, wie ich bin. Ich find seine Musik toll, aber ich will auch niee dieselbe Musik machen wie er. Ich hätte gerne seine Eingebung, die er hat, wenn er die Texte schreibt. Ich würde auch gerne solche Texte schreiben können. Aber so dieselbe Musik würd ich nich machen wollen. Von daher Idol nich. Idol als Vorbild-Sinne jetzt weniger, sondern einfach nur wirklich als Fan. Ich würde inn als meinen Star @bezeichnen@ (setzt Anführungszeichen in die Luft)" (S. 135, Z. 24-31). Hier zeigt sich deutlich, dass die Ablehnung der Bezeichnungen Idol oder Vorbild nicht bedeuten muss, dass eine Person nicht diese Funktion erfüllt, sie spiegelt nur den Wunsch nach Individualität wider und die subjektive Deutung des Begriffes Idol als eine Person, die man gänzlich kopieren will. Im Fragebogen gab Chris an, voll und ganz genauso sein zu wollen wie sein Idol und gern selbst mit Musik sein Geld verdienen zu wollen. Im 
Grunde ist Wolff durchaus Leitbild für ihn, er hätte nichts dagegen so zu sein, weil er die Person bewundert. Seinen musikalischen Weg möchte er auf ähnliche Weise gehen, auch wenn das Ziel letztlich anders aussieht. Chris weigert sich lediglich gegen das Kopieren-wollen einer Person und in diesem Fall seiner Musik. Er würde Wolff am Ehesten noch eine Orientierungsfunktion zugestehen.

Bezüglich der Charaktermerkmale seines Stars räumt Chris dagegen schon eher ein, dass er in vielen Punkten gern so wäre. Hierbei geht es ja auch nicht ums nachahmen, sondern um Eigenschaften, die prinzipiell viele Menschen besitzen können und Werte, die ein Jeder für sich wählen kann. In diesem Sinne ist Tilo Wolff also durchaus Vor- oder Wunschbild für Chris. "[...] [I]ch möchte so sein wie er, im Sinne von den Charaktereigenschaften, nich vom musikalischen her. Vom musikalischen her bezeichne ich inn deswegen auch nich als Idol, weil ich musikalisch nich so sein will wie er, aber als Mensch würde ich schon irgendwie gern sein wie er" (S. 135, Z. 34 bis S. 136, Z. 2, Auslassung und Anpassung: S.L.). Er wehrte sich jedoch weiterhin vehement gegen den Begriff Idol an sich: "[...] [E]igentlich weiß ich ja garnich so viel über ihn als Mensch, aber die Neugierde, wie er sein könnte, lässt mich gerne so werden wie er. Deswegen möchte ich ja so werden wie er, weil man weiß nichts über ihn. Er is so rätselhaft. Uund Idol wärs ja eigentlich nur, wenn ich alles gut finden würde was er tut und das auch so machen will. Das will ich nich. Ich find halt seine Geheimhaltung vom Privatleben so interessant und der gibt eigentlich so viele Gefühle in seinen Liedern Preis, dass man denkt, der erzählt uns so viel von sich, man müsste den eigentlich kennen. Man kennt inn trotzdem nich. Deshalb möchte ich so werden wie er" (S. 136, Z. 4-11, Auslassung und Anpassung: S.L.). Hierin kommt auch die starke Faszination zum Ausdruck, die durch mangelnde Hintergrundinformationen und dadurch kreierte Mystifizierung der Person bewirkt wird.

Die Bewunderung für sein Idol zeigt sich zudem in dem Wunsch, so auszusehen wie Tilo Wolff, wobei deutlich wird, dass Chris letztlich doch auch die typischen Identitätsthemen eines pubertierenden Jugendlichen bearbeitet. „Ich hätte auf jeden Fall seine Frisur sehr gern. Ich liiebe sie. (lacht) [...] [O]hja, der hat so wahnsinnig 
lange Haare. Sozusagen macht der die so hoch (zeigt Geste) und hat dann hier alles voll mit Haaren, wie so ne Kante, wie ausgefüllt, als wenn der son Viereck aufm Kopf hätte. Und das geht dann hier runter, aber immer noch bis zu den Schultern" (S. 130, Z. 1520, Auslassung und Anpassung: S.L.).

Was Chris laut seinen Angaben im Fragebogen besonders an Tilo Wolff schätzt, sind seine Ausdrucksweise und sein Verhalten, seine musikalische Leistung und das Erlebnis beim Zuhören und Zuschauen.

Die drei Eigenschaften die Chris sich und Tilo gleichermaßen zuschreibt, sind Ausdrucksweise, Lifestyle und Sensibilität. In diesen Angaben zeigt sich der Aneignungsmodus der Identifikation und Projektion, der in diesem Fall stark zum Ausdruck kommt. Chris projiziert eigene Charaktereigenschaften auf sein Idol. Ob diese Parallelen tatsächlich bestehen, ist dabei nicht wesentlich, denn wichtig ist nur die Funktion, die diese Übertragung erfüllt. Er findet einen Verbündeten in seinem Lebenskampf, der ähnliche Probleme hat, ähnliche Schwierigkeiten in Auseinandersetzung mit sich selbst und seiner Umwelt. Dabei findet er in seinem Idol eine Identifikationsfigur, die seine eigenen projizierten Eigenschaften vereint und es damit geschafft hat attraktiv und erfolgreich zu sein. Unter anderem schreibt er sich selbst und gleichsam seinem Idol eine hohe Sensibilität zu. „[...] [E]r isn sehr sehr sensibler Mensch. Das merkt man an seinen Texten, dass er ja sehr verletzlich auch ist und er hat ja auch viele Beziehungen hinter sich und nach diesem Beziehungs-Aus, hat er dann halt son Lied geschrieben, in dem er eben auch sagt, dass er verletzt war und dass es schade war, was da geschehen is. Dass er eigentlich garnich damit klar kommt. Also er is wirklich $\mathrm{n}$ Sensibelchen was das angeht, denk ich" (S. 127, Z. 7-12, Auslassung und Anpassung: S.L.). Ähnlich sieht er auch sich selbst: "[...] [I]ch bin $\mathrm{n}$ totaal sensibler Mensch. Ich bin auch totaal am Wasser gebaut. Wenn ich Nur die Liebe Zählt gucke, dann könnt ich ooch weenen. (lacht) Also da bin ich sehr, nee, ich bin sehr sensibel. Und auch sehr emotional veranlagt also. Könnt ich garnich, eiskalt durch die Welt gehn. Jaa (lacht)" (S. 127, Z. 14-17, Auslassung und Anpassung: S.L.). Chris stellt sich selbst als sehr sensiblen Menschen dar, er redete auch sehr gefühlvoll von seinem Idol Tilo Wolff und der Musik an 
sich, bediente sich oft einer sehr verträumten, schwelgenden und fantasievollen Ausdrucksweise. Gerade die vermeintliche Schwäche eines Mannes, sehr sensibel zu sein, lässt Chris einen Menschen bewundern, der scheinbar ähnliche Sensibilität besitzt, die inn aber keineswegs erfolglos oder unattraktiv macht, sondern sich sogar als großes Potential erweist, weil es den Musiker befähigt, gefühlvolle Musik zu komponieren und poetische Texte zu schreiben und damit viele Menschen zu begeistern.

Eine weitere Eigenschaft die er glaubt mit Tilo Wolff zu teilen, ist neben der Ausdrucksweise - auf die weiter unten noch näher eingegangen wird - auch der Lifestyle. Er hat ein differenziertes Bild davon, was es heißt Gothic zu sein. Diese Grundsätze sieht er in Tilo Wolff verkörpert. "[...] [M]an gestaltet sich selbst, man verwirklicht sich in künstlerischer Weise durch Kleidung zum Beispiel, übertriebenes Makeup. Man will auffallen, man weiß aber auch um die Defizite der Menschheit. Man setzt sich auch für gewisse Dinge ein. [...] [B]ei inm geht's noch um die Kunst vom Gothic-Sein, um die künstlerische Verwirklichung des Seelbst, er verwirklicht sich nicht nur in seiner Kleidung, auch in der Lyrik die er schreibt, in seinen Liedern, in seinen Texten, in all dem, was er halt fabriziert. [...] [D]as is sone Eigenschaft, die ich mit inm gleich verbinde. Weeil ich mich halt auch künstlerisch viel verwirkliche und auch die Ansichten habe, des Gothic. Gothic is ja sehr poetisch und viel bezogen auf Goth-Texte und auf Bücher und solche Dinge" (S. 127 , Z. 24-128, Z. 19, Auslassung und Anpassung: S.L.). Gleichzeitig kritisiert er, die Entwicklung innerhalb der Szene: „Heutzutage is der Gothic leider verkommen. Das heißt, die ganze FetischSache, gehört zu Gothic dazu, sag ich nich, aber Fetisch nimmt langsam die Überhand an. Es geht in den meisten Gothicbands nur noch ums Thema Sex und solche Dinge. Die Kleidung wird auch immer knapper uund also es entwickelt sich fast eher zu wirklich soner erotischen Szene. Ich meine dass Gothic erotisch anziehend is, ist klar, durch die ganzen Sachen und so. [...] [U]und es gibt viele, sag ich mal Möchtegern-Gothics heutzutage, die laufen draußen rum und sind schwarz, schwarze Lippen, Patchoulie, weiße Haut uund vielleicht noch die schönsten (Newhawk?)-Boots und Aderlass-Hosen oder so und Mantel und meinen ich bin Gothic. Und ich meine, ich hab nich wirklich viele Gothic-Klamotten und bin trotzdem ein Gothic, ich meine das liegt wie gesagt an der 
Verwirklichung. Und die Jugendlichen, die das halt sagen, ich bin Gothic, die tun nichts dafür, die sagen, ich bins halt, weil ich schwarz rumlauf. (kurze Pause) Nur weil ich n Springerstiefel anziehe, bin ich auch kein Rechter. Also von daher, das find ich momentan schade und deswegen denk ich, is der Lifestyle heutzutage, der Gothic-Lifestyle selten geworden" (S. 127, Z. 26 bis S. 128 , Z. 16, Auslassung und Anpassung: S.L.).

Ich hatte Chris im Vorfeld gebeten, ein Bild von seinem Idol zum Interview mitzubringen, das ihm besonders gefällt. Es war ein sehr eindrucksvolles Bild, ausgeschnitten aus einer Zeitschrift. Es hatte etwas Geheimnisvolles und der Musiker wirkte sehr würdevoll. Er steht auf der Bühne, im Kunstnebel, mit leicht gesenktem Kopf und ausgebreiteten Armen. Chris' Erklärung warum er dieses Bild so besonders findet, verweist auf sein eigenes Wesen, Prozesse der Projektion und Identifikation. „Na, also man muss seine $\mathrm{Ge}$ schichte kennen. (sehr enthusiastisch) Tilo Wolff is ja n sehr kranker Mensch, der is psychisch ja seehr (kurze Pause) wie sagt man, ballaballa, son bissel (lacht). Ähm, der hat, is in den guten Fankreisen eigentlich bekannt, hat acht Jahre lang in seinem Keller gelebt. Und nicht ans Tageslicht gegangen und nichts und hat sich nur Pizza kommen lassen. Und von da aus hat er sein Plattenlabel gegründet, Hell, Hell of Sermon oder so. Uuund, ich muss mal (nimmt sich einen Keks) und er hat dann, eines Tages halt, seine CDs veröffentlicht, so zweiundneunzich kam glaube die erste und hat nie Konzerte gegeben, des hat der einfach nich gemacht, weil er nie ausm Keller kam. (lacht) [...] Und auf diesem Foto sieht man ihn soo verwandelt, wenn man bedenkt, dass dieser Mensch wirklich in Abstinenz der Welt gelebt hat. Er war ja nie präsent, sozusagen, niemand hat inn je gesehn oder so. Und jetzt zeigt er sich vor tausenden Leuten, in ner so offenen Geste, dass so ein Mensch aus ihm geworden is, das find ich einfach bewundernswert in diesem Moment. (kurze Pause) Ja" (S. 121, Z. 24 bis S. 122, Z. 3, Auslassung: S.L.). Es ist zu erkennen, dass sich Chris ausführlich mit der Persönlichkeit seines Idols auseinandergesetzt hat. Die Informationen aus Wolffs Privatleben, die natürlich nicht nachprüfbar sind, bekam er von anderen Foren-Mitgliedern. Er bezeichnet den Musiker als kranken Menschen, er sieht darin eine Gemeinsamkeit zu sich selbst, schreibt inm eine ähnlich labile Psyche zu. 
Diese Diagnose stellt er aufgrund weniger unsicherer Informationen. Er projiziert eigene Befindlichkeiten auf seinen Star und erzeugt damit das Gefühl von Zugehörigkeit. Chris bewundert, dass Wolff seine Schüchternheit überwunden hat, so dass es inm jetzt möglich ist, sich offen vor vielen Menschen zu zeigen. Es spricht eine Sehnsucht aus Chris' Worten, nämlich selbst einmal so stark zu sein, seine eigene Krankheit zu überwinden und ein solches Selbstbewusstsein zu entwickeln, um sich im Leben zu behaupten. In diesem Sinne hat der Musiker Vorbildfunktion, denn dass dem Sänger diese Entwicklung möglich war, zeigt Chris Wege auf, gibt ihm Hoffnung, Kraft und den Glauben daran, dass solche Schwierigkeiten überwindbar sind.

Eine daran anknüpfende Frage an den Interviewten war, ob er glaubt, dass der Sänger sich auf der Bühne verwandelt, also eine andere Person darstellt, als er in Wirklichkeit ist. Die Antwort des Jungen offenbart, dass er sich sehr intensiv mit dieser Person auseinandergesetzt hat, trotz der wenigen erhältlichen Hintergrundinformationen. Dabei ist er aber in der Lage zu reflektieren, dass er nur Vermutungen anstellen kann. „Also ich kenn ihn, so privat kenn ich ihn ja nich, aber ich hab inn schon, bei vielen FanclubTreffen bin ich ihm begegnet, so aus der Ferne, aber da sind so viele hundert Leute, dass man des gornich sieht. Oder sehn schon, aber man hat nich die Möglichkeit, selbst mit ihm zu reden. Ääh, wenn er vor den Leuten steht und etwas sagt oder so, dann is er sehr (2 Sekunden Pause) naja introvertiert, sehr in sich gekehrt auch, so, schon eher dieser, man merkt schon, dass er sehr zurückhaltend ist und ähm schüchtern auch teilweise. Uund auf der Bühne is er ja son bisschen, ich weiß nich wie mans beschreiben soll, man merkt den Unterschied zu ner Band, die wirklich ne Sängerin hat, die jetzt soo offiziell so gut steht und so. Zum Beispiel bei Nightwish, die hatten ja dann Tarja Turunen und die war soo öffentlich präsent, die hat sich da wohlgefühlt, die hat gelebt auf der Bühne, für die war die Bühne alles. Und bei ihm merkt man, er is so bissel fremd am Platz da. Also er macht sein Ding, er hat seine Choreografie aber er will sehr schnell wieder runter, man merkt das auch" (S. 122, Z. 5-18). Die extrovertierte Art des Musikers auf der Bühne sieht Chris nur als Fassade. Die eigentliche Person - Tilo Wolff - betrachtet er als eher schüchtern und introvertiert, die sich im Rampenlicht nicht besonders wohl fühlt. Dabei 
projiziert er eigene Empfindungen, die Vorstellung wie er selbst sich in dieser Situation fühlen würde, auf sein Idol, was sein Gefühl der Verbundenheit und Nähe zu diesem Menschen verstärkt. Dass er sich intensiv Gedanken um die Motive seines Idols macht, verweist zudem auf den Modus der parasozialen Interaktion. Sein Star ist ein guter Freund, mit dem er viel gemeinsam hat, den er versteht, weil er ihn zu kennen glaubt.

Chris' Vorstellung von Tilo Wolffs Persönlichkeit ist noch tiefgehender. "Er leidet sehr stark an Depressionen und so und viele viele Psychologen haben auch in den Medien über ihn gesprochen, als das damals war mit seinen Alben, als er so richtig publik wurde und Touren gegeben hat [...]. Es kam auch teilweise schon in verschiedenen Reportagen mal was über ihn oder so. Da ham viele Psychologen auch gesagt, dass er nen Hang zur Schizophrenie hat, weil er angeblich unter Verfolgungswahn leidet. Also, dass er psychisch depressiv is, is glaub ich keine Frage, das merkt man an allem, was er macht und so. (kurze Pause) Man findet zwar diesen Funken der Leidenschaft, aber man empfindet keine Freude irgendwie bei inm, er freut sich da nich so wirklich. Da gibs zum Beispiel son ganz bestimmtes Liied von Lacrimosa, das heißt Liebesspiel. Da beschreibt er halt den Akt der Liebe und mit so einer Gleichgültigkeit in der Stimme, das ist Wahnsinn. (kurze Pause) Als wenns ihm egal wär. [...] [E]r is so, ja, so, weiß ich nich, so so total abgehoben so irgendwie mit seinen Gedanken. Ich sag mal die Lieder sind schon teilweise krass was er schreibt, also von den Texten her. Entweder er is wirklich $n$ Genie oder er is meiner Meinung nach @durchgeknallt@" (S. 123, Z. 24 bis S. 124, Z. 4, Auslassung und Anpassung: S.L.). Es ist interessant, wie weitgehend sich Chris Gedanken über das Seelenleben seines Idols macht und wie ausgefeilt seine Vorstellung von ihm schon ist. Auch hier zeigt sich wieder die Projektion eigener Problemlagen und zudem die starke Ausprägung einer parasozialen Beziehung.

Chris erzählte, er habe auf der Homepage der Band, in einem Thread des Forums, schon einmal eine Frage an Tilo Wolff gestellt, die auch beantwortet wurde. Stolz erzählt er: "Und wenn man Glück hat, schreibt er ne Antwort. Aber nich zu jeder Frage" (S. 123, Z. 2 f.). Aber zu seiner. Die lautete "[...] ob er freiwillig in die Schweiz gezogen is, oder ob des eher so der Zwang von Anne 
Nurmi war" (S. 123, Z. 5 f., Auslassung: S.L.). Sie ist zweites Mitglied von Lacrimosa, erst später zu der Band hinzugekommen und übernimmt jetzt den weiblichen Gesangspart neben Tilo Wolff. Die Antwort, die er von Wolff bekam, war, dass er es freiwillig getan habe, weil er der Überzeugung war und er ein gutes Gefühl dabei hatte. Ob tatsächlich der Musiker selbst diese Fragen beantwortet, ist unklar, aber Chris geht davon aus. Er empfand die Antwort als Privileg, im Gegensatz zu vielen anderen, denen auf eine offenbar weniger gute Frage, nicht geantwortet wurde. Durch diese Kommunikationsmöglichkeit wird die imaginäre Beziehung zu dem Musiker ansatzweise in eine reale transformiert. Chris fühlt sich dadurch geehrt, dass er eine Antwort erhielt. Die Annahme, dass seine Frage beantwortet wurde, bestätigt ihm zudem, dass er seinen Star, seinen Freund, gut genug kennt, um die richtigen Fragen zu stellen.

Desweiteren wurde im Interview versucht, das Verhältnis des Befragten zu der Sängerin Anne Nurmi zu ergründen. Er sprach in einem relativ abwertenden Ton über sie, machte auch deutlich, dass er ihre Rolle eigentlich als überflüssig ansah. Teilweise wirkte es, als wäre er eifersüchtig auf sie. Er spielte ihr Können herunter, letztlich tat er aber, als wäre es ihm egal und es wäre okay, dass sie in der Band ist. Chris erzählte, dass man sehr wenig über Lacrimosas Privatleben erfährt. Fast mystisch anmutend betont er: "Das Privatleben von Lacrimosa is eigentlich soo sehr geschützt, wie bei selten nem Künstler" (S. 123, Z. 15 f.). Auch ist unklar, ob Tilo Wolff und Anne Nurmi ein Liebespaar sind. "Das mit dem Keller is das Einzige dass man aus dem Privatleben weiß und dass er in die Schweiz zog. Man weiß nich wirklich wo er in der Schweiz lebt (3 Sekunden Pause) und man weiß auch nich ob die $\mathrm{n}$ Paar sind. Man weiß es nich. Man [...] muutmaaßt es, ich denks auch, aber (kurze Pause) naja" (S. 123, Z. 16-20, Auslassung: S.L.).

Wie sich auf Nachfragen herausstellte, ist Chris tatsächlich eifersüchtig, weniger auf den Platz Anne Nurmis, den sie im Privatleben seines Idols einnehmen könnte, als vielmehr die Position als musikalischer Partner. Auf die Frage welche Rolle Anne Nurmi für inn in der Band spiele, antwortete Chris: "Momentan so, Mittel zum Zweck geworden bei Lacrimosa. Die macht nichts selbst, die singt einfach nur (leicht abwertend in Gesichtsausdruck und Stimme). 
Und spielt ab und zu mal n Instrument" (S. 139, Z. 19 ff.). "[...] [V]orher war er alleine, da hat er das alles durch Synthesizer gemacht und solche Dinge uund jetzt hat er halt die Frau dazu (abwertende Stimme). Aba, die bringt sich überhaupt nich in die kreativen Phasen ein, also vom Texte schreiben her, also eigentlich sind alle geschrieben vom Tilo ganz allein. Uund sie is eigentlich nur $n$ Zusatz. Ich finds cool, dass sie da is, ich find die auch schön die Stimme die se hat, passt auch gut rein, aba ich glaube überlebenswichtig is sie nich für Lacrimosa. Weil er hat ja auch jahrelang ohne sie bestanden. Von daher übernimmt sie eher diese Schattenrolle" (S. 139, Z. 23-30, Auslassung und Anpassung: S.L.).

Es zeigt sich, wie sehr er sein Idol hochhebt, da er ihn als Ausnahmekünstler sieht, der keine Bandmitglieder braucht, um seine Arbeit zu verbessern. Er ist der Überzeugung, dass die Leistung und Genialität der Musik Lacrimosas allein der Verdienst des Sängers ist. Dieser Aspekt verweist auch auf Aneignung durch parasoziale Interaktion, denn er verteidigt seinen Freund und seine Leistung. Auf meine anschließend direkte Frage, ob er eifersüchtig sei, gab er schließlich zögernd zu, dass zumindest etwas Neid dabei sei. "(Lacht) Najaaa, nee jaa. Früher hat ich viel so Neid auf diese Band. Ich hab gedacht, daa musst du reein. Irgendwann willst du in dieser Band spielen" (S. 139, Z. 32 f.). Er erwähnt, dass er sich früher auch gewünscht hat, in der Band ,Nightwish' mitzuspielen, als diese eine neue Sängerin suchte. "Und da hab ich mich so verflucht, dass ich nicht weiblich bin. (lacht) Aaah, da wollt ich unbedingt in diese Band. Mit vierzehn. Oh Gott, nee des war schon" (S. 140, Z. 3 ff.).

Chris bewundert auch Tilos Erfolg als Musiker. "Nich so, nich dass ich seinen Erfolg beneide, so garnich, aber ich möchte auch gern mal irgendwann ähnlich erfolgreich werden" (S. 131, Z. 25 f.). Im Fragebogen hatte Chris angegeben, sich einen Partner wie sein Idol zu wünschen. Auf Nachfrage stellte sich jedoch heraus, dass er einen musikalischen Partner meinte. „Also mit Partner meinte ich so musikalisch, könnt ich mir total gut vorstellen so jemanden im Team zu haben. Der dann seine Ideen reinbringt und wirklich mal total Spinnereien reinbringt. Zum Beispiel hat er hier in som 
Lied, da tutn Baby Hallo und Gagga rufen. Am Anfang in Erinnerung is das. Es klingt gut, es klingt gut. Man glaubt es nicht" (S. 136 , Z. 34 bis S. 137 , Z. 4).

Der Traum von einer eigenen Musikkarriere scheint sich in einer parasozialen Beziehung auszudrücken und manifestiert sich in Neid und Eifersucht gegenüber Wolffs Gesangspartnerin Anne Nurmi. Der offensichtliche Neid auf den Platz der Sängerin an der Seite seines Idols, zeigt deutlich, dass Chris eine Rolle als musikalischer Partner neben Tilo Wolff imaginiert. Die parasoziale Beziehung lebt er so stark aus, dass er reale Eifersucht empfindet.

Er wies darauf hin, dass er durchaus auf Frauen stünde, seine Traumfrau könne jedoch so etwas wie die weibliche Version von Tilo Wolff sein. „Also ich würde des total genial finden, wenn meine Freundin auch total von Gothic überzeugt wäre. Von der Lebenseinstellung, vom Text schreiben, so musikalisch engagiert is. Das würd ich total toll finden" (S. 136, Z. 32 ff.). Demnach dient sein Star sogar der Ausformulierung partnerschaftlicher Wunschvorstellungen.

Chris setzt sich intensiv mit den Liedtexten der Band auseinander. Er und die anderen Fans in den Foren spekulieren regelmäßig über die Intention des Musikers. Wolff beantwortet auch kaum Fragen zu Textinterpretationen, auch dazu hat Chris eine Theorie: „[...] [A] lso bei solchen Fragen is er sehr eitel. Zwei Mal hat er da geantwortet, aber so nie bezieht er Stellung zu seinen Liedern, also. [...] [N]aja er is so denk ich der Typ der, der den Leuten das Denken überlässt. Der macht die Lieder und denkt sich vielleicht, die Leute solln interpretiern oder so. Kann ich mir vorstellen, ich weiß es nich" (S. 124, Z. 34 bis S. 125, Z. 4, Auslassung und Anpassung: S.L.).

Als das Bewundernswerteste an Tilo Wolff bezeichnet Chris dessen Mut, Kritik an der Gesellschaft und den Menschen im Allgemeinen zu üben und wie er diese Einstellung künstlerisch subtil zum Ausdruck bringt. "Ich liebe seine Ausdrucksart, also seine Form, wie er das schreibt. Des is so total (kurze Pause) Wahnsinn, da gibs zum Beispiel $n$ Lied, des heißt Fassade erster Satz, da schreibt er über den Egoismus der Welt und dass die Menschen einfach nur noch abartig sind, dass alles nur noch nach nem System geht, was 
Leistungszwang heißt. Und dass der Mensch total vergessen wird und dass eigentlich Kinder $\mathrm{n}$ Fremdwort für die Menschen sind, weil die des gornich mehr kennen. Die kennen zwar Kinder, aber wie man sich drum kümmert, wissen die nich mehr. Hauptsache Leistung. Und das drückt er soo aus, dass man das eigentlich nur zwischen den Zeilen son bissel lesen kann" (S. 125, Z. 6-14). "[...] Es is schonn mutig von ihm, finde ich. Weil er kritisiert ja nich nur die Politik, er kritisiert ja den Menschen im Allgemeinen. Die ganze Menschheit, obs nun hier is oder in Japan. Er meint alle Menschen. Und das finde ich so Wahnsinn, dass er eigentlich der ganzen Welt mit seinen Liedern Vorwürfe macht. Oder auch irgendwelche Anschuldigungen den Menschen gegenüber bringt, die meiner Meinung gerechtfertigt sind. Aba des is halt nich überall wirklich angesehn und ich wüsste nich, ob ichs mich getraut hätte. An seiner Stelle solche Dinge zu veröffentlichen" (S. 125, Z. 20-26). Hier zeigt sich Chris' Bewunderung für den Mut des Musikers. Er sieht sich selbst nicht so mutig und würde gern auch so offen Anschuldigungen gegenüber anderen ausdrücken können. Er hätte angesichts seiner Vergangenheit auch allen Grund Erwachsenen Vorwürfe zu machen. In diesem Sinne hat Tilo Wolff Vorbildfunktion für den Jungen. Er ist dabei eigene Stärke zu entwickeln, ein solches Selbstbewusstsein, um seine Meinung offen sagen und sich gegen Missstände in seinem Leben zur Wehr setzen zu können.

Auch diese Ansichten, die Chris aus den Liedtexten herausliest, kann er, bedingt durch schmerzhafte Erfahrungen in seinem Leben, teilen und sie bieten inm daher ebenfalls Identifikationsmöglichkeiten. „Also ich hab des am eigenem Leib erfahrn. Menschen sind wirklich, für mich, Wesen [...] die einfach meinen Respekt nich mehr verdient haben. Weil es gibt niemanden, der sich aus Leidenschaft gerne so selbst zerstört wie der Mensch, die ganzen Kriege die geführt werden. Das findet man bei keinen andern Lebewesen. Die töten zwar auch andre Lebewesen, aber nich ihres gleichen oder selten. Jedenfalls nich in so krassen Kriegen, wie wir das tun. Wir müssen ja gleich die ganze Welt mitnehmen, es reicht ja nicht, dass wir uns töten. Jaa, also von daher, die Antipathie gegen den Menschen empfind ich ihm schon nach. Ja" (S. 125, Z. 29-36, Auslassung: S.L.). An diesen Aussagen wird außerdem deutlich, dass der 16-jährige Junge tiefergehend über die Welt und ihre Zusammenhänge nachdenkt. 
Es gibt noch einen weiteren Aspekt, in dem sein Idol für Chris wichtige Funktion erfüllt. Er interpretiert dessen Textinhalte in einer Weise, die inm Anknüpfungspunkte für sein Leben gibt. "Äh, bei ihm is es so, er schreibt viel über seine Erinnerungen auch und damit will er denk ich auch sagen, dass man die Erinnerung zulassen muss, auf ne gewisse Art und Weise. Dass man nur glücklich werden kann, wenn man mit seiner Vergangenheit im Einklang lebt. Und die Einstellung trag ich auch (kurze Pause) momentan. [...] [A]ber ich bin halt noch nich im Einklang mit der Vergangenheit, aber ich denke, wenn ichs wäre, würd es mir wesentlich besser gehen" (S. 126, Z. 3-9, Auslassung und Anpassung: S.L.). In gewisser Weise liest er Weisheiten heraus, Einstellungen, die ihm helfen können, mit seinem Leben klar zu kommen und Lösungswege zu finden, seine eigene Krankheit zu überwinden.

Chris sieht sein Idol nicht restlos positiv, auf Nachfrage ist er durchaus in der Lage Kritik an der Entwicklung des Musikers zu üben. Zum einen betrifft sie das neue Album von Lacrimosa. Chris bemängelt, dass es schneller geworden ist, aber vor allem legt er viel Wert darauf, dass Wolff deutlich singt, er würde nur noch brüllen. Da sich Chris stark mit den Texten auseinandersetzt, legt er auch viel Wert darauf, dass sie verständlich sind. „[...] [W]enn er deutlich singt, kommt das besser zur Geltung, was er damit ausdrücken möchte" (S. 126, Z. 24 f., Auslassung und Anpassung: S.L.).

Weiterhin bemängelt er, dass die Band wenig Auftritte in Deutschland gibt. "[...] [I]ch find es im Moment halt schade, dass sie sich wenig auf Festivals treffen lassen können oder sowas. [...] [V]on daher denk ich, diese Präsenz sollte vielleicht für die Fans grade aus Deutschland, der is einfach Deutscher, er kommt hier her, er kommt aus Europa, er sollte sich hier wirklich mehr beschäftigen" (S. 133, Z. 27-34, Auslassung und Anpassung: S.L.). Als Grund für die wenigen Deutschland-Konzerte vermutet Chris, dass es der Band immer mehr ums Geld verdienen geht. „Er is wirklich momentan. Keine Ahnung. Ich bin so mehr fuck the commerz-Ding und er scheint mir grad eher fürn Kommerz viel zu machen. Deswegen die ganzen Welttouren, er hat ja auch seine zwei-JahresWelttour gemacht. Wo ich sage krass, 2 Jahre am Stück, alsoo 
dickes Ding. Aber da denk ich halt, könnt er viel mehr in Deutschland machen" (S. 133, Z. 34 bis S. 134, Z. 3).

Chris sieht seinen Star also nicht gänzlich unfehlbar, sondern ist trotz seiner Bewunderung zu kritischer Reflexion fähig. Seine Kritik deckt sich dabei mit der allgemeinen Kritik der Fans, die in den Forenbeiträgen auf der Homepage herauszulesen waren.

Chris gibt an, dass er sich von dem Musiker distanzieren würde, wenn er zum Beispiel rechtsradikales Gedankengut oder Kinderschändung verherrlichen würde. Dabei betont er aber, dass es ihm nicht darauf ankommt welcher Gesinnung Tilo Wolff ist, sondern lediglich, ob es sich in seinen Texten niederschlägt. „[...] [W]enn er sagt er ist rechts, is das schön für ihn, solang es auf die Musik sich nicht auswirkt" (S. 134, Z. 16 f., Auslassung und Anpassung: S.L.). Dabei kommt wiederum eine gewisse, gewollte, Distanz zum Ausdruck, indem er lediglich die Musik und nicht den Künstler in den Mittelpunkt stellt.

Peinlich wäre ihm nichts was sein Idol tut, solange dieser auch dahinter steht, "[...] aber wenn er dann nich dazu steht und versucht des alles zu vertuschen oder des anders aussehen zu lassen (kurze Pause), dann würde ichs peinlich finden. Da würde ich sagen okay, da distanzier ich mich jetzt, wenns nich ehrlich is. Nich aufrichtig" (S. 135, Z. 13 ff., Auslassung: S.L.). Hier stellt Chris doch wieder Erwartungen an sein gegenüber, ähnlich einer Freundschaft, in der man enttäuscht wäre von bestimmten Handlungen seines Gegenübers. Diese Denkweise verweist auf den Aneignungsmodus parasozialer Interaktion.

Chris kann sich nur bedingt eine echte Freundschaft mit seinem Idol vorstellen. Er geht sehr realistisch an das Thema heran: "[...] [I]ch denke mal, wir würden uns glaube gar nichts zu sagen haben oder so. Ich wüsst garnich worüber ich mit ihm sprechen sollte, er is einfach mal jemand der (3 Sekunden Pause) in ner Band spielt, für inn is des was ganz normales, für mich is das auch was normales, in ner Band zu sein. Und er is für mich eigentlich genauso $\mathrm{n}$ Mensch wie jeder andere auch. Und nur weil er berühmt is, möchte ich nich mit inm befreundet sein" (S. 136, Z. 13-18, Auslassung und Anpassung: S.L.). Diese Antwort zeigt eine reife und realitätsnahe Einschätzung der Angelegenheit, Tilo Wolff ist ein 
Mensch, den er im Grunde nicht kennt und deshalb wäre eine Freundschaft unwahrscheinlich, so wie mit jedem Fremden auch. Ich fragte jedoch indirekter nach, ob er sich vorstellen könnte, dass sie sich gut verstehen würden, weil er ja auch glaubt, viele Gemeinsamkeiten mit seinem Idol zu haben. "Ich weiß es nicht, weil ich ihn eben nicht kenne, es kann natürlich sein. [...] [A] Iso treffen so [würde ich inn gerne] ja, aber Freundschaft kann ich eben noch nich sagen. Wenn ich merk okay, es würde passen, die Stimmung, dann ja, ansonsten äh nee" (S. 136, Z. 20-24, Einfügung, Auslassung und Anpassung: S.L.). Gemeinsamkeiten sieht er schon, aber "Naja man sagt ja immer, das Gleiche stößt sich ab. Ich weiß es nich. (lacht)" (S.1 36, Z. 27).

Die parasoziale Beziehung zu seinem Idol betrifft demnach weniger eine freundschaftliche Beziehung, sonst würde diese Vorstellung hier deutlicher zum Ausdruck kommen. Es ist aber auch nachvollziehbar, dass Chris eine Freundschaft für eher unwahrscheinlich hält, gerade weil der Künstler für ihn den Status eines unnahbaren und übergroßen Idols hat. Wäre eine Freundschaft ohne weiteres denkbar, ginge die Faszination, das Mysterium um diese Person verloren. Darin könnte der fühlbare Widerwillen, sich eine gleichberechtigte Freundschaft mit dem Musiker vorzustellen, begründet sein.

\subsubsection{Persönliche Werte und Zukunftspläne}

Interessant war Chris' Angabe im Fragebogen, dass inm seine Freunde nicht wichtiger sind als die Musik, was nicht damit zusammenhängt, dass er keine Freunde habe oder Freunde inm nicht so wichtig wären. Er erzählte mir, dass er in seiner Heimat einen groBen Freundeskreis habe und gab zu der Frage nach den persönlichen Werten im Fragebogen an, dass ihm Freunde sehr wichtig wären. Sondern tatsächlich scheint die Musik für ihn den höheren Stellenwert zu besitzen. Sie ist auch das einzige beständige und zuverlässige Element in seinem Leben.

Zu den Werten die ihm außerdem noch sehr wichtig sind, zählen neben Individualität, soziales Engagement und Leistung zu bringen. Wichtig sind auch Familie, Spaß haben und Selbstverwirklichung. Wenig wichtig ist ihm ein hohes Einkommen und Interesse für Politik. 
Tilo Wolff sagt von sich selbst, er sei ein gläubiger Christ. Deshalb hat mich Chris' Einstellung zum Thema interessiert. „Naja also ich persönlich bin nicht direkt gläubig, ich bin jetzt aber auch kein Atheist. Also gläubig schonn, ich gehör nur keiner Konfession an. Ich glaube schon an das Götterbild vom Christentum, aber ich kann mich jetzt mit keiner Institution äh anfreunden, weder mit der katholischen Kirche, die ja total aus Diktatur lebt meiner Meinung nach. Und der evangelische Glaube hat für mich kein Hand und $F u ß$ irgendwo. Ich kann mich garnich damit identifizieren, ich fühl mich da irgendwie total fremd. Und so glaub ich an meinen Gott und gut und ich glaube auch an Engel, auch an Teufel und Lucifer glaub ich auch und ja. Also ich finds gutt wenn er gläubig is" (S. 137, Z. 11-18). In seinen Aussagen spiegelt sich, ob bewusst oder unbewusst die Einstellung des Sängers zum Thema, die jener auch in Interviews kundgetan hat. Chris selbst ist atheistisch aufgewachsen. Aber er hat kein Problem damit, wenn Gothic-Bands sich zum christlichen Glauben bekennen (vgl. S. 137, Z. 25 f.).

Chris träumt davon, eine eigene Band zu haben, mit der er sich langsam den Erfolg erarbeitet. In seinen Tagträumen stellt er sich konkret vor, welche Musik er machen wird "So Industrial-mäßig oder Tanzmusik, oder sowas wie Unheilig gefällt mir zum Beipiel. ,Hört mein Wort' Zum Beispiel des is ja so, hach, so toll einfach [...]" (S. 140, Z. 12 ff., Auslassung: S.L.).

Chris hat allgemein sehr bodenständige Vorstellungen von seinem Leben in fünf oder zehn Jahren. „Ja in fünf Jahren hoff ich doch, dass ich dann meine Erzieherausbildung fertig hab, vielleicht jemanden kennen gelernt hab. Hoffentlich nich so @viele zwischendurch, sondern nur eine Person@, die dann auch treu is und dass ich dann vielleicht auch glücklich so in Ruhe lebe oder so, kein Stress" (S. 142, Z. 19-22).

Chris kann sich auch vorstellen in Dresden zu bleiben: "[...] [W]enns mich hier hält ja. Wenn ich hier jemanden kennen lerne, ansonsten geh ich nächstes Jahr zurück. Ich hab mir sone Frist gesetzt, ich bleib dieses Jahr noch hier, bis nächstes Jahr und wenn ich bis dahin nichts gefunden hab, geh ich wieder. Also was soll ich denn hier bleiben, bis jetzt kenn ich hier keene Sau und nüscht. Jaa und von daher, mal schaun, wo ich dann lebe, kann 
ich so genau noch nich sagen. Hoffentlich wie gesagt, die Erzieherausbildung fertig, jemand kennen gelernt, vielleicht musikalisch was im Gange. Und dann mal schauen. Führerschein. Und vielleicht eines Tages mal studiern oder so. Ich weiß zwar noch nicht was, aber findet sich schon was" (S. 142, Z. 24-32, Auslassung und Anpassung: S.L.).

Trotz all seiner Probleme wirkt Chris sehr optimistisch und zielstrebig. Er hat sehr solide und auch realistische Vorstellungen und Träume von der Zukunft. Seine Aussagen zeigen, dass er im Grunde sehr konservative Werte vertritt. In diese Richtung gingen auch die Aussagen der anderen Jugendlichen Gothics, die ich interviewt hatte. Chris sehnt sich im Grunde nur nach einer festen, treuen Partnerin, einem sicheren Zuhause und einer soliden Ausbildung. Darüber hinaus würde er sich musikalisch Erfolg wünschen und vielleicht auch später noch studieren.

\section{Zusammenfassung und Fazit}

Die vorliegende Arbeit beschäftigte sich mit der Einbindung von Musik-Idolen in die Lebenswelt Jugendlicher - hier insbesondere solcher, die der Subkultur der Gothics angehören. Insbesondere ging es um die Motivation eine solche Medienbeziehung einzugehen, die Funktionen, die sie besonders hinsichtlich der Identitätsbildung erfüllt und psychologischen Mechanismen, die mit der Verehrung einer Person verbunden sind.

Generell zielt die Beschäftigung mit Medienangeboten zunächst natürlich auf Unterhaltung und Spaß. Wesentliche Funktion der Bewunderung eines selbstgewählten Idols ist schlicht die Möglichkeit gedanklich aus dem Alltag auszubrechen, zu träumen und Phantasien auszuleben. Darüber hinaus aber ist ein wesentlicher unbewusster Antrieb für die Identifikation mit einem Vorbild, Star oder Idol der Versuch der Bildung einer eigenen stabilen Identität, die als wesentliche Entwicklungsaufgabe im Jugendalter betrachtet werden kann. Identifikation und Formen parasozialer Interaktion dienen dem Ausprobieren gewünschter, aber (noch) nicht gelebter sozialer Beziehungen. Welchen Stellenwert eine Medienperson bekommt, welche inneren Themen, Problemlagen und Werte sie anspricht, auf welche Weise sie sich der junge Mensch aneignet 
und wie er seine Themen bearbeitet und das Idol zur Orientierung nutzt, ist jeweils ein individueller Vorgang, da diese Prozesse mit der persönlichen Lebensgeschichte, der sozialen Situation, aktuellen Entwicklungsthemen und der eigenen Persönlichkeitsstruktur zusammenhängen. Ein medialer Text, die Darstellung eines Musikers in den Medien, wird auf dieser Grundlage immer subjektiv gelesen und interpretiert, deshalb können dieselben Personen von unterschiedlichen Fans ganz verschieden wahrgenommen werden.

Das Hauptaugenmerk dieser Untersuchung lag auf der Medienbeziehung des 16-jährigen Chris zu seinem Idol Tilo Wolff - Sänger der Gothic-Rock-Band ,Lacrimosa'. Der dem qualitativen Interview vorgeschaltete Fragebogen bot jedoch einen ersten Einblick in die Thematik, wobei die Befragung insgesamt nur wenige Jugendliche und Postadoleszente der schwarzen Szene Dresdens einschloss. Die zwanzig auswertbaren Fragebögen erlauben keinerlei generalisierende Rückschlüsse über Jugendliche allgemein und auch nicht solche, die dieser Subkultur angehören. Dennoch sollen im Folgenden noch einmal die wesentlichen Ergebnisse zusammengefasst werden.

Das Alter der Probanden erstreckte sich von 16 bis 29 Jahren. Sogar die Mehrheit derer, die den Fragebogen ausfüllten, war über 20 Jahre alt. Dies bestätigt, dass Fan-sein sowie Subkulturzugehörigkeit nicht als ,Spinnerei' Pubertierender abzutun ist und zudem die Postadoleszenz als Verlängerung der Jugendzeit an Bedeutung gewinnt.

Weiterhin auffällig war, dass bereits bei so geringer Fallzahl, fast jeder ein anderes Idol angab - 20 Jugendliche benannten 18 verschiedene Musiker. Darin wird zum einen deutlich welch breites Angebot an potentiellen Identifikationsfiguren in den Medien und selbst innerhalb der Musikszene und hier allein der Gothic-Kultur geboten ist. Zum anderen unterstreicht es den Individualisierungswillen der jungen Generation. Es ist nicht wichtig, dass möglichst viele Fans im nahen Umfeld die Leidenschaft für einen Lieblingsmusiker teilen, eher noch, so könnte man annehmen, unterstreicht der ,ganz eigene' Star die persönliche Einzigartigkeit. In diesem Sinne lässt sich auch der Unwillen einiger Befragter interpretieren, sich selbst einer spezifischen Szene zuzurechnen. Die 
Ablehnung von Schubladendenken kam in den Kommentaren dazu deutlich zum Ausdruck.

Die Hoffnung, es würden sich Jugendliche finden, die Musiker bewundern, die im Sinne der eingangs erwähnten Definition für sie als Idole fungieren, Kultfiguren die mystifiziert und übermäßig verehrt werden, hat sich nicht erfüllt. Die hier genannten Personen haben für ihre Fans eher den Status eines Stars denn eines Idols. Dies schmälerte jedoch nicht den Erkenntnisgewinn durch die Befragung.

Fast alle benannten auch andere Personen und Dinge, von denen sie ebenso Fan sind. Es kann angenommen werden, je weniger sich ihre Aufmerksamkeit fokussiert, desto weniger ganzheitlich und intensiv leben sie die Medienbeziehung zu einem Star.

Informationen über ihren Musiker erhalten die meisten über die Fan- und Homepages sowie Internetforen. Auch wenn Fanklubmitgliedschaften eher eine untergeordnete Rolle spielen, scheinen die Kontakte zu anderen Fans sehr wichtig zu sein, da der Musiker oft Anlass für Gespräche mit Freunden und anderen Fans ist und sich viele in Internetforen aktiv beteiligen. Darin zeigt sich die Aneignung zum Zweck der Vergemeinschaftung mit anderen.

Interessant war, dass keine der Frauen, die den Fragebogen ausfüllten, eine weibliche Bezugsperson angab. Dies ist erstaunlich, da es keinen Mangel an Musikerinnen in der Szene gibt und nur die Minderheit der Befragten Frauen sich eine Partnerschaft mit ihrem Idol wünscht, also die Medienbeziehung zum imaginären Ausleben und Erproben von Liebesbeziehungen nutzt. Frauen kann demnach auch eine männliche Person als Identifikationsfigur für Eigenschaften, Einstellungen, Verhalten und berufliche Ziele dienen.

Die wichtigsten Werte für die befragten Jugendlichen sind Familie und Freunde, gefolgt von Spaß haben, individuell sein und sich selbst verwirklichen. Wenig Bedeutung bekommen Leistungsstreben, hohes Einkommen, soziales Engagement und Politik. Dass ein hohes Einkommen und Leistung zu bringen verhältnismäßig wenig Gewicht bekommt, widerspricht den Angaben der von Wegener befragten Jugendlichen sowie dem allgemeinen Bestreben der 
meisten Mitglieder unserer Gesellschaft. Darin äußert sich die Abwehrhaltung gegenüber bestimmten gesellschaftlichen Erfordernissen in der heutigen Zeit, die auch schon in der Zugehörigkeit zu einer Subkultur und der Abwendung vom Mainstream deutlich wird.

Die Nennung dreier Eigenschaften, die ein Fan glaubt mit seinem Idol zu teilen, lässt am ehesten Schlüsse über die persönliche Faszination an dem Musiker erkennen und verweist besonders auf Identifikations- und Projektionsprozesse als Aneignungsmodus. Diese Eigenschaften und Werte werden weder schlicht übernommen, noch einseitig auf den Star projiziert, sondern sie bilden sich wechselseitig. Zum einen werden eigene Einstellungen an dem Musiker wiederentdeckt und zum anderen auch durch diesen vertieft und gefestigt oder die Einstellung des Stars regt zum Einnehmen eines Standpunktes zu einem Thema an, zu dem bisher keine klare Position eingenommen wurde. Auch hier wird nicht kritiklos übernommen, sondern in eigene Sichtweisen integriert. Genannte Eigenschaften bewegten sich im Wesentlichen in den Bereichen, die Individualität betonen, wie provokant zu sein, rebellisch oder direkt und eine spezielle Lebenseinstellung zu besitzen. Auch Ehrlichkeit, in dem man zu seiner Einstellung steht, oder auch Menschlichkeit wurde betont, wobei letzteres mehrfach im genannten Merkmal ,Sensibilität' zum Ausdruck kam.

Die offensichtlich intensive Auseinandersetzung mit Eigenschaften des Musikers lässt nur vermuten, dass es sich um Aneignung durch parasoziale Interaktion handelt. Viele gaben jedoch auch an, sich eine Freundschaft oder sogar Partnerschaft mit ihrem Idol zu wünschen, was ebenfalls auf diesen Aneignungsmodus hinweist.

Der Fokus der Studie lag in der Auswertung und Interpretation des qualitativen Leitfadeninterviews mit Chris. Es konnten reichhaltige Informationen über dessen Vergangenheit, derzeitige Lebenssituation und seine speziellen Einstellungen, Hintergründe und Problemlagen gewonnen werden, sowie über die damit im Zusammenhang stehende Beziehung zu seinem Idol Tilo Wolff. Seine Situation stellt sich sehr untypisch für einen Jungen seines Alters dar, weshalb es sich um einen Sonderfall handelt, der aber gerade deshalb interessante Einsichten in die Thematik erbrachte. Dass er 
aus schwierigen Verhältnissen stammt, im Betreuten Wohnen, getrennt von Heimat, Familie und allem inm bisher Vertrauten leben und zudem gegen eine psychische Krankheit, eine Borderline-Persönlichkeitsstörung, kämpfen muss, erfordert viel Kraft von diesem jungen Menschen, der aufgrund seiner Vergangenheit, die ihn zu Selbstständigkeit zwang und vermutlich mit Hilfe seiner offensichtlich ausgeprägten Intelligenz eine ungewöhnliche Reife entwickelt hat und Überlebensstrategien, die ihm helfen seine Situation zu akzeptieren, nebenbei die typischen Entwicklungsproblematiken der Adoleszenz zu bewältigen und dabei mutig nach vorne $z u$ sehen und sehr realistische sowie optimistische Vorstellungen von seiner Zukunft zu entwickeln.

Chris teilt mit seinem Idol die musikalischen Vorlieben und das Zugehörigkeitsgefühl zur Subkultur der Gothics - einer Gruppe von Menschen, die Melancholie, Einsamkeit und Trauer ebenso integriert und symbolisiert wie Lebensfreude, Optimismus und den Wunsch nach Spaß und Individualität - das aus einem speziellen Lebensgefühl und teils problematischen Erfahrungen heraus gewachsen ist.

Die Qualität der Medienbeziehung hat nichts mit der Zugehörigkeit zu einer Szene zu tun, denn die Themen, die jugendliche Gothics bearbeiten sind dieselben wie die anderer Jugendlicher. Dies zeigten die hier aus Komplexitätsgründen nicht veröffentlichten Interviews. Da gibt es das 20-jährige Mädchen, die in ihren Star verliebt ist, damit probeweise imaginär eine Liebesbeziehung auslebt, oder den 23-jährigen Nick, der sich für Rudy Ratzinger (Wumpscut) - einen zynischen Eigenbrötler - begeistert, der zwar nicht von jedem geliebt wird, aber dennoch ein Meister auf seinem Gebiet ist und treue Anhänger findet. Damit verarbeitet der Junge auch eigene Unzulänglichkeitsgefühle, die er in der Schulzeit entwickelte, als er als Außenseiter gehandelt wurde. Sein Idol gibt inm Selbstvertrauen und Mut, sich den anderen zu stellen und persönliche Stärke und Durchsetzungsfähigkeit zu entwickeln. Wie hier bereits deutlich wird, steht die Wahl eines Idols mit den eigenen Lebenserfahrungen in Verbindung, wodurch schon eher eventuelle qualitative Unterschiede der Medienbeziehung verschiedener Fans begründet sind, als durch die bloße Zugehörigkeit zu einer Szene. Quantitativ gibt es keine Unterschiede, zum Beispiel 
kann ein Fan von Robbie Williams, der vielleicht im Gegensatz zu Chris eher behütet aufgewachsen und bezüglich Normen und Einstellungen angepasster ist, seinen Star ähnlich intensiv bewundern, verschieden sind nur die Schwerpunkte, die bei der Aneignung gesetzt werden. Die Themen, die sein Idol anspricht und die er mit dessen Hilfe bearbeitet, könnten mehr jugendtypisch und weniger existentiell und tiefgründig sein wie bei Chris. Die Funktionen sind ähnlich, die Formen der Aneignung sind gleich, nur die Farbe, der Inhalt, sind vielleicht anders.

Die Musik an sich hat für Chris einen existentiellen Stellenwert, gerade weil ihm sein Umfeld, seine Familie und Kontakte, nicht diesen Halt und die Geborgenheit geben können, wie ein pubertierender junger Mensch sie eigentlich nötig hätte, um sich gesund zu entwickeln. Bereits mit sieben Jahren begann sich Chris mit Musik zu beschäftigen, wendete sich auch relativ schnell der Gothicszene und -musik zu, die inn fasziniert, da sie inm sehr vielfältig und tiefgründig erscheint. Er setzt sich auch stark mit den Texten der Bands auseinander und kann sich mit innen identifizieren. Der Junge gab im Fragebogen an, Musik sei ihm wichtiger als seine Freunde. Vermutlich war sie ihm während seiner schwierigen Kindheit bereits Freund und ständiger Begleiter. Heute hat sie daneben vor allem tagesstrukturierende Funktion und unterstützt inn bei der Regulation seiner intensiven Emotionen.

Chris kann sich neben Tilo Wolff auch für andere Musiker begeistern, eine besondere Rolle scheint der Sänger der Band ,L'amme immortel' zu spielen. Er beschränkt sich also demnach nicht auf dieses eine Idol, was gut zu Vermutungen und Ergebnissen anderer Studien passt, die begründet in der Pluralisierung der Gesellschaft und dem vermeintlichen Erfordernis Patchworkidentitäten zu entwickeln, immer mehrere Stars als leitend ansehen, von denen ein Mensch sich dann je unterschiedliche Aspekte auswählt, um sie für sich zu bearbeiten und zu nutzen. Chris verwendet sein Idol jedoch trotzdem erstaunlich ganzheitlich. Sehr viele Aspekte dieses Menschen dienen der Identifikation und Projektion und bieten Orientierung für die Bewältigung des Alltags, aktueller Identitätsthemen und für die Entwicklung von Zukunftsplänen. Das Idol ist nicht zufällig ein solches geworden, sondern nur weil es An- 
knüpfungspunkte bietet, an seine eigene Vergangenheit und soziale Situation, seine Bedürfnisse und Rollenmuster. Seine Borderline-Erkrankung macht ihn geneigt Personen zu überidealisieren, was auch ein Grund für die sehr komplexe Verehrung von Eigenschaften dieses Musikers sein könnte. Doch besteht dadurch hier keine Gefährdung. Denn trotz intensiver Identifikation und relativ ganzheitlicher Verwendung des Idols sieht Chris nicht alles an Wolffs musikalischer Entwicklung, seiner Person und seinem Tun restlos positiv. Er kritisiert die stilistische Entwicklung der Musik, wirft dem Musiker die Zuwendung zum Kommerz und Vernachlässigung seiner Fans in Deutschland vor. Chris übernimmt bei der Deutung seines Idols größtenteils die Vorzugslesart, also wie die Darstellung des Künstlers in den Medien intendiert ist, und knüpft auch mit seiner Kritik an allgemeine Vorwürfe an, die in der Öffentlichkeit und in Fankreisen vorherrschen. Darüber hinaus hat er jedoch ganz eigene, wenn auch nicht oppositionelle, und vor allem tiefgehende Interpretationen über die Person des Sängers und seine Motive, womit es sich zum Teil auch um eine ausgehandelte Lesart handelt. Chris' Kritikfähigkeit zeigt, dass er die Person nicht restlos positiv verklärt und übermäßig verehrt, wie das im Sinne der Idol-Definition geschehen würde. Dabei bestünde auch die Gefahr der Überidentifizierung, dem Verlust der eigenen Identität und Selbstabwertung, da das Idol unerreichbar idealisiert wird. Chris selbst möchte Wolff eher als seinen Star als sein Idol bezeichnen, weil er ihn nicht kopieren möchte. In der Ablehnung dieses Begriffes äußert sich jedoch nur der ausgeprägte Wunsch individuell zu sein.

Die Faszination an diesem Musiker wird stark erzeugt durch die Geheimhaltung seines Privatlebens und generell schwer erhältliche Hintergrundinformationen über die Person, stattdessen werden wage und abstruse Geschichten über dessen Vergangenheit verbreitet, wodurch die Person stark und doch wieder Idol-typisch mystifiziert wird.

Es wird sehr deutlich, dass Tilo Wolff eine wichtige Bezugsperson für diesen Jungen darstellt, gerade weil inm brauchbare Vorbilder in seiner Vergangenheit fehlten und er auch heute weitgehend auf sich allein gestellt ist. Sein Idol hilft ihm, ein gesundes Selbstbild 
und Selbstbewusstsein aufzubauen, da dieser Mensch in seiner Biografie und Persönlichkeit ebenso von der Norm abzuweichen scheint, wie Chris selbst und dabei trotzdem sehr erfolgreich geworden ist. In Wolffs Erfahrungen, Einstellungen und Verhaltensweisen sieht Chris viele Parallelen. Er ist für inn zugleich Projektionsfläche, Spiegelbild und Verbündeter in seinem Lebenskampf.

Chris eignet sich sein Idol stark durch Identifikation und Projektion an. Er identifiziert sich mit dem, was sein Idol darzustellen scheint. Er stellt viele Vermutungen über dessen Persönlichkeit, Motive und Beweggründe an und projiziert viele seiner eigenen Problemlagen und Einstellungen auf diese Person. Auch dieser Aspekt könnte durch seine Borderline-Störung verstärkt sein, hat in diesem Fall m.E. aber keine negativen Konsequenzen. Tilo Wolff wird eine ähnlich schwierige psychologische Problematik zugeschrieben. $\mathrm{Er}$ soll jahrelang isoliert von der Außenwelt in seinem Keller gelebt haben. Dieses Alleinsein kann Chris in seiner derzeitigen Lebenssituation nachempfinden. Besonders charakterlich sieht Chris ebenso viele Parallelen zu sich selbst. So wird der Sänger als schüchtern, depressiv und tiefgründig dargestellt, bei gleichzeitig auch hedonistischen, lebensfrohen Zügen. Diese Eigenschaften überschneiden sich mit der Selbstwahrnehmung des Jungen. Angesichts der starken Ausprägung von Identitätsstörungen bei Borderlinern, über dessen Existenz oder Ausmaß bei Chris aber nur spekuliert werden kann, hat die Funktion seines Idols als Orientierung bei der Findung eines stabilen Selbstbildes noch größere Bedeutung als bei Jugendlichen im Allgemeinen. Wolff ist eine Person, die selbst vermutlich keinen geraden Weg im Leben gegangen ist und trotz psychischer Probleme und Anderssein zu Erfolg und Anerkennung gelangt ist, was dem Jungen Mut und Zuversicht für seine eigene Zukunft gibt.

Wolff entspricht auch optisch den Wunschvorstellungen des Jungen, er möchte sich die Haare wachsen lassen, färbt sie schwarz mit blonden Strähnen - ähnlich wie sein Idol. Darin zeigt sich die Auseinandersetzung mit dem für die Jugendzeit typischen Identitätsthema der Akzeptanz und Gestaltung des eigenen Körpers. Am Wesentlichsten ist jedoch das Gefühl, eine Lebenseinstellung, Lebensstil, Werte und Ansichten mit seinem Idol zu teilen. Zum Bei- 
spiel hat Chris eine differenzierte Einstellung zum Glauben entwickelt, wobei er diese mit Wolff teilt. Die Richtung der Bildung dieser Einstellung ist unklar, vermutlich ist sie auch durch sein Idol inspiriert. Weil sich seine Gedanken und Ansichten, die er, wie er sagt, seinem Idol nachempfindet, teilweise sehr gesellschaftskritisch gestalten und diese sich auch vom Horizont der Masse pubertierender Jugendlicher abheben, weshalb er dort auch kaum Bestätigung und Gleichgesinnte finden kann, ist die Identifikation mit diesem Menschen besonders stark ausgeprägt. Chris bewundert den Mut des Musikers, in seinen Texten seine Meinung offen zu äußern und die ganze Menschheit und ihre Missstände anzuklagen. Gern hätte er selbst diese Stärke, um für seine Meinung und seine Rechte einzustehen. Ihm fehlt es dafür noch an Selbstbewusstsein und Durchsetzungsfähigkeit, selbst seiner Familie gegenüber.

Die Leidenschaft für Musik teilt er mit seinem Idol und sie ist Bewältigungsstrategie, die in schwierigen Situationen Halt gibt, aufmuntert und Einsamkeit vertreibt. Wolff ist auch Vorbild für die berufliche Orientierung, denn Chris möchte selbst gern einmal eine Band gründen, ähnlich erfolgreich werden und mit Musik sein Geld verdienen können. Wolff lebt seinen Traum und zeigt ihm, dass es sich lohnt, daran zu glauben. Zugleich bleibt Chris aber realistisch in seinen beruflichen Plänen, denn er erstrebt zunächst eine solide Ausbildung als Erzieher.

Auch in Chris Zukunftsvorstellungen kam zum Ausdruck, dass es letztlich ganz grundlegende konservative Werte sind, die er anstrebt - eine glückliche Beziehung, ein Haus als Rückzugsort, ein ruhiges Leben, Sicherheit und Geborgenheit und einen Beruf, der ihn erfüllt.

Wolff ist ebenso Leitbild für die Entwicklung seiner Geschlechtsrolle. In Chris' Leben fehlten und fehlen wesentliche Sozialisationsinstanzen, positive, erstrebenswerte erwachsene Vorbilder in der Nahwelt. Insbesondere hatte der Junge Schwierigkeiten geeignete männliche Identifikationsfiguren zu finden. Es gab keine stabile Vaterfigur in seiner Kindheit und das Gefühl Männern gegenüber, die er kennenlernen musste, ist eher angstbesetzt. Dies kann sein Idol kompensieren. Wolff repräsentiert eine sehr androgyne Art von Männlichkeit, die aber mit dem Selbstbild des Jungen 
gut vereinbar ist, denn er erlebt sich selbst als sehr femininen und auch sehr gefühlvollen Menschen.

Darüber hinaus dient Wolff sogar als Orientierung bei der Entwicklung eines Partnerwunschbildes sowie der Imagination einer Partnerschaft mit einer solchen Person. Chris fühlt sich eindeutig zu Frauen hingezogen, wünscht sich als Partnerin aber eine weibliche Version von Tilo Wolff - die ebenso künstlerisch und dem Gothic zugetan ist, wie er.

Der 16-jährige ist fasziniert von der Poesie und Ausdrucksweise des Sängers. Er selbst schreibt Gedichte und Songtexte und versucht sich dabei in ähnlicher Weise auszudrücken. Diese Leidenschaft ist nicht erst angeregt durch den Sänger, von dem er erst seit zwei Jahren Fan ist, sondern nach eigenen Angaben schrieb er auch schon vorher Gedichte und spielte selbst in einer Band.

Chris interpretiert die Inhalte der Songtexte des Musikers auch in einer Weise, dass sie inm Botschaften mitgeben, die er als Lebenshilfe nutzen kann, als Anregungen zu aktiven Bewältigungsstrategien für seine Probleme. So glaubt Chris, dass Wolff deshalb viel über seine Vergangenheit schreibt, weil er sie damit verarbeitet und dass der Sänger damit sagen möchte, dass man nur glücklich werden kann, wenn man mit seiner Vergangenheit im Einklang lebt. Chris teilt diese Überzeugung und erstrebt diesen Weg auch für sich selbst.

Der Aneignungsmodus der parasozialen Interaktion ist ebenso stark in dieser Medienbeziehung ausgeprägt. Tilo Wolff hat für den Jungen den Stellenwert eines guten Freundes, er macht sich Gedanken um dessen Vergangenheit, seine psychische Gesundheit, sein Privatleben, seine Einstellungen, Ängste, Motive und Pläne. Chris versucht die Inspiration des Sängers für seine Texte zu ergründen und stellt konkrete Vermutungen darüber an, warum dieser ungern über der Bedeutung dieser Inhalte spricht. So schreibt er inm die Einstellung zu, dass er den Leuten selbst das Denken überlassen wolle. Die parasoziale Beziehung zu dem Musiker äuBert sich zudem in Neid gegenüber dessen Gesangspartnerin Anne Nurmi. Chris imaginiert eine musikalische Partnerschaft mit seinem Idol, er träumt von der Rolle als Bandmitglied ,Lacrimosas'. Chris stellt auch Erwartungen an Wolff, ähnlich einer echten 
Freundschaft, indem er betont, dass er sich von ihm abwenden würde, wenn dieser nicht ehrlich und aufrichtig zu den Dingen stehen würde, die er tut. Reale Freundschaft will er sich aber nur ungern vorstellen. Zwar glaubt er dem Sänger sehr ähnlich zu sein, weshalb die Möglichkeit bestünde, sich gut zu verstehen, doch wäre eine Freundschaft real möglich, hieße das, dass sich beide auf Augenhöhe begegnen. Dies würde jedoch entmystifizierend wirken und sein einstiges Idol würde damit für Chris die Funktion als Leitbild verlieren.

Diskursive Konstruktion und soziale Unterstützung als Modus der Aneignung spielt ebenso keine unwesentliche Rolle. In Diskussionen mit seinen Mitbewohnern werden Macht- und Autonomieverhältnisse geklärt und erprobt. Er knüpft, vor allem durch die Mitgliedschaft in einem Internet-Fanclub, auch Kontakte zu anderen Fans, versucht zudem über regionale Foren, in Kontakt zu Dresdner Gothics zu treten - worin Aneignung zum Zwecke der Vergemeinschaftung zum Ausdruck kommt. Er kompensiert damit auch fehlende soziale Kontakte.

Chris bearbeitet also mit seiner Bezugsperson mehrere Identitätsund Entwicklungsthemen, die Verarbeitung und Integration seiner Vergangenheit, die Akzeptanz und Überwindung seiner Krankheit, Entwicklung von Problembewältigungsstrategien, die Auseinandersetzung mit der eigenen geschlechtlichen Identität und seinem Aussehen, Erfahrung von Autonomie und Abgrenzung, Entwicklung fester Wertmaßstäbe, sowie Kompensation und Erweiterung sozialer Beziehungen. Zudem ist sein Idol auch Vorlage für Profession und Leistung. Letztendlich bietet es Orientierung für die Entwicklung eines positiven Selbstbildes als Mann, als Künstler und schlicht als Mensch.

Ohne seine Leidenschaft für Musik, die Chris schon sehr früh entwickelt hat und ohne die sehr intensive Beziehung zu seiner medialen Bezugsperson, die ihm Bestätigung für sich selbst gibt sowie ein für inn positives und erstrebenswertes Vor-Bild darstellt für seinen eigenen Lebensweg, seine Art der Welt zu begegnen und seine eigene musikalische Entwicklung - wäre dieser Junge vermutlich weit weniger stabil, als es in diesem Gespräch den Anschein hatte. 
Die Extreme, die Chris' kurzes Leben bereits aufzeigte, spiegeln sich in dem was über sein Idol in Erfahrung zu bringen ist. Durch diese Parallelen sind seine inneren Themen deutlich aufzeigbar. Ob Tilo Wolff tatsächlich all diese Eigenschaften besitzt, die Chris ihm zuschreibt, ist unwesentlich, wenn diese Gewissheit inm dabei hilft ein positives Selbstbild aufzubauen. Die Bestätigung, die der Junge durch diese scheinbaren Gemeinsamkeiten findet, erhöht sein Selbstwertgefühl und der Lebensentwurf, den Wolff ihm aufzeigt, gibt ihm Orientierung angesichts der für einen jeden unsicheren Jugendzeit und der besonderen Haltlosigkeit in Chris' Leben, in dem ihn umgebende erwachsene Bezugspersonen wenig erstrebenswerte Vorbilder sein konnten.

In diesem Sinne zeigt dieser Fall eindrucksvoll, welch lebenswichtige Funktion ein Idol, das im Auge anderer vielleicht mehr als zweifelhaft erscheinen mag, im Leben eines sich entwickelnden und durch schwierige Umstände geplagten jungen Menschen übernehmen kann. Vor diesem Hintergrund erscheint es absurd, das Fan sein, als jugendliche ,Spinnerei' abzutun oder gar Gefahr darin zu wittern, wenn Kinder und Jugendliche sich intensiv mit einer solchen Person auseinandersetzen, gerade weil Lebenseinstellungen und Verhaltensweisen nicht einfach imitiert werden, sondern erst durch eigene Strukturen überhaupt attraktiv werden, da sie wiedergefunden und gespiegelt werden und dadurch Bestätigung geben. Gerade wenn ein junger Mensch bemerkt, dass er anders als andere ist oder es schwerer hat als sie, kann das passende Idol das Gefühl vermitteln, nicht unnormal sondern im positiven Sinne besonders und nicht allein zu sein.

Chris muss all seine vergangenen, teilweise schwierigen Erfahrungen verarbeiten, muss lernen, sie als einen Teil von sich selbst zu erkennen und zu akzeptieren, darf nicht zulassen, dass sich Minderwertigkeitsgefühle in inm manifestieren. Er muss sie integrieren, positive Erfahrungen sammeln, eigene Leistungen vollbringen, um schließlich eine gefestigte Identität zu entwickeln, die er mit seiner Lebenswelt in Einklang bringen kann. Sein Idol allein kann das alles nicht leisten, jedoch ist es ein Wegweiser, der dem Jungen erleichtert, sein Leben, wie abnorm es doch aussehen mag, in für ihn konstruktive Bahnen zu lenken und glücklich zu werden. 
Gefolgert werden kann, dass Vorbilder, Stars und Idole der Kinder nicht nur kritisch ablehnend beäugt werden sollten. Sie dürfen nicht als Personen gesehen werden, die schlechtes Gedankengut in die jungen Menschen einzupflanzen versuchen, sondern als solche, die das Seelenleben der Teenager spiegeln. Die Faszination an einer Medienperson kann verstanden werden als Ausdruck innerer Beweggründe und Bedürfnisse. Die Auseinandersetzung mit ihnen kann helfen, die Sehnsüchte, Ängste und Probleme der Jugendlichen zu erkennen und zu verstehen. Im Gespräch mit dem Fan über seinen Star, dem ehrlichen Interesse an dem wofür es steht, was es tut und subjektiv symbolisiert, können Erwachsene viel über die Themen erfahren, die den Jugendlichen beschäftigen. Dies könnte den oftmals breiten Graben überwinden helfen, zwischen der oft schon festgefahrenen Lebenswelt Erwachsener und den noch in der Entwicklung befindlichen Vorstellungen, die der junge Mensch vom Leben hat. Dabei bedarf es auch Vertrauen, denn die Erwachsenen sollten das Seelenleben des Teenagers nicht restlos entschlüsseln wollen. Jugendliche brauchen ihre Privatsphäre, man muss ihnen die Funktion, die ihr Idol erfüllt, nämlich Entwicklung von Autonomie, zugestehen. Durch echtes Interesse an den medialen Bezugspersonen der Jugendlichen, können Erwachsene sich aber den nötigen Zugang verschaffen, um sie bei der Bewältigung ihrer Probleme zu unterstützen, anstatt ständig Distanz zu schaffen durch grundlegende Ablehnung all dessen, das innen fremd ist und deshalb gefährdend erscheint.

\section{Ausblick}

Angesichts dessen, dass wir uns im Zeitalter pluralisierter Medienwelten befinden, ist anzunehmen, dass Medienpersonen weiterhin zunehmend eine wichtige Rolle im Leben der Kinder und Jugendlichen einnehmen werden. Konkret auf dem Gebiet der subjektorientierten Erforschung persönlicher Beziehungen von Fans zu ihrer medialen Bezugsperson gibt es angesichts einer noch recht übersichtlichen Anzahl an Studien genügend Forschungsbedarf. 
Besonders erscheinen Langzeitstudien sinnvoll, um die tatsächliche Bedeutung von Vorbildern, Stars und Idolen für die Identitätsbildung nachvollziehen zu können. Denn erst in der langfristigen und nachhaltigen Wirkung der Orientierung an Stars auf die Bildung der jungen Persönlichkeit zeigt sich die Relevanz des Themas. So wäre interessant, wie stabil die im Zuge der Medienbeziehung generierten und gefestigten Einstellungen und Werthaltungen sind und ob gewonnene Lösungen für Identitätsthemen dauerhaft umgesetzt werden. Auch ob das Idol Zukunftsprojekte nachhaltig beeinflusst oder sie nur als kurzfristige Träumerei zu betrachten sind, wäre dadurch feststellbar. Zudem würde die retrospektive Betrachtung eines (vielleicht mittlerweile ehemaligen) Fans auf seine Bezugsperson zeigen, wie sie aus späterer Sicht gedeutet wird sowie ob und wie diese von der einstigen Einstellung abweicht. Auch ob und in welcher Frequenz Stars durch andere abgelöst werden, könnte durch Langzeitstudien nachvollzogen werden.

Desweiteren wäre interessant, welche Bedeutung Vorbilder, Stars und Idole für Menschen jenseits der Adoleszenz erhalten, angesichts der Tatsache, dass in einer individualisierten Welt, die stetige Umorientierungen abverlangt, auch immer Orientierungspunkte nötig sind, die nie nur aus sich selbst heraus gefunden werden können, sondern immer an Vorlagen anderer Personen geknüpft sind.

Darüber hinaus wäre zu erforschen, inwieweit bestimmte biografische Erfahrungen im Vergleich zu anderen die Funktionen, den Wirkkreis und die Nachhaltigkeit sowie die Ganzheitlichkeit der individuellen Fan-Idol-Beziehung beeinflussen. Insgesamt fehlen Studien, die sich mit sozial benachteiligten Rezipienten beschäftigen, oder auch mit solchen, die ihr Leben jenseits einer Normalbiografie leben. Da genau diese Jugendlichen am ehesten als gefährdet eingeschätzt werden, könnten entsprechende Ergebnisse diese Befürchtungen überprüfen.

Vorliegende Arbeit beschäftigte sich in diesem Sinne mit der Medienbeziehung eines durch schwierige Lebensumstände gekennzeichneten Fans. Der Fall Chris widerlegt Wegeners These, dass mediale Bezugspersonen heute keine ganzheitliche Verwendung 
mehr finden (vgl. Wegener 2008, S. 380). Durch diesen hier vorgestellten Einzelfall kann nicht entschieden werden, ob dieses Phänomen der sozialen Isolation und der Borderline-Erkrankung des Jungen geschuldet ist oder ob sich dieses Muster auch bei anderen Jugendlichen bestätigen würde. Meine Vermutung ist, dass es viele Jugendliche - jenseits sektenartiger Gruppierungen ( $\mathrm{vgl}$. Wegener 2008, S. 380) - gibt, die eine Medienbeziehung ähnlich intensiv leben. Diese These gilt es in weiteren Studien zu untersuchen. Vorliegende Arbeit bietet auch Anknüpfungspunkte für die weitere Forschung in Bezug auf Kinder und Jugendliche, die unter schwierigen Umständen Leben müssen, wie zum Beispiel Heimkinder und psychisch kranke Menschen. Speziell in Bezug auf die Borderline-Thematik konnte bei Chris eine Verstärkung und Intensivierung der Medienbeziehung sowie eine Unterstützung seiner Genesung mit Hilfe seines Idols vermutet werden. Die Befragung weiterer Fans mit einer Borderline-Persönlichkeitsstörung könnte die Gültigkeit hier gewonnener Thesen überprüfen. 


\section{Literatur}

ABELS, H.: Jugend vor der Moderne. Soziologische und psychologische Theorien des 20. Jahrhunderts. Opladen: Leske und Budrich 1993.

ABEL, J.; MÖLLER, R.; PALENTIEN, C. (HRSG.): Jugend im Fokus empirischer Forschung. Münster: Waxmann Verlag GmbH 2004.

ALTRICHTER, H.; POSCH, P.: Lehrer erforschen ihren Unterricht. Eine Einführung in die Methoden der Aktionsforschung. Bad Heilbrunn: Verlag Julius Klinkhardt 1990, S. 121.

BAACKE, D.: Zum Problem 'Lebensweltverstehen'. Zu Theorie und Praxis qualitativ-narrativer Interviews. Werkstattbericht. (Reihe: Lebensweltanalyse von Fernstudenten). Hagen: 1978.

BAACKE, D.: Jugend und Jugendkulturen. Darstellung und Deutung. 1. Auflage, Weinheim: Juventa-Verlag 1987.

BAACKE, D.: Vom Ende des jugendlichen Helden. Postmoderne Perspektiven auf Jugendalter und Jugendforschung. Vortrag auf dem DGfE-Kongreß 1990 in Bielefeld. MS 1990.

BAACKE, D.: Jugendkulturen und Musik. In: Bruhn, H.; Oerter, R.; Rösing, H. (Hrsg.): Musikpsychologie. Ein Handbuch. Hamburg: rororo 1993, S. 228-237.

BAACKE, D.: Medien-Idole und Videoclips als Zitatmontage. Neue Formen der Wahrnehmung und Welterfassung in den Medien. Bielefeld: MS 1994.

BAACKE, D.; FERCHHOFF, W.: Von den Jugendsubkulturen zu den Jugendkulturen. Der Abschied vom traditionellen Jugendsubkulturkonzept. In: Neue Soziale Bewegungen Jg. 8/1995, Heft 2, S. 33-46.

BAACKE, D.: Jugend und Jugendkulturen. Darstellung und Deutung. 4. Auflage, Weinheim/München: Juventa-Verlag 2004.

BAETHGE, M.; SCHOMBURG, H.; VOSKAMP, U.: Jugend und Krise. Krise aktueller Jugendforschung. Frankfurt/Main-New York: Campus 1983. 
BARTHELMES, J.; SANDER, E.: Medien in Familie und Peergroup. Vom Nutzen der Medien für 13- und 14jährige. Medienerfahrungen von Jugendlichen. Band 1, München: DJI (Deutsches Jugendinstitut) 1997.

BARTHELMES, J.; SANDER, E.: Erst die Freunde, dann die Medien. Medien als Begleiter in Pubertät und Adoleszenz. Medienerfahrungen von Jugendlichen. Band 2, München: DJI 2001.

BAST, W.: James Dean. Idol einer Jugend. München: Paul List Verlag 1957.

BECHDOLF, U.: Puzzling Gender. Re- und De-Konstruktionen von Geschlechterverhältnissen im und beim Musikfernsehen. Weinheim: Deutscher Studienverlag 1999.

BECHDOLF, U.: Nur scharfe Girls und knackige Boys? Traditionelle und innovative Geschlechterbilder in Musikvideos. In: Fromm, M.; Haase, F.; Schlottke, P.F. (Hrsg.): Inszenierte Wirklichkeiten. Lernen und Entwicklung in der Medienwelt. Baden-Baden: Nomos Verlagsgesellschaft 2000, S. 83-102.

BEHNE, K.-E.: Hörertypologien. Zur Psychologie des jugendlichen Musikgeschmacks. Regensburg: Bosse 1986.

BEHR, J.: Identitätssuche in jugendlichen Subkulturen. Skinheads, Punks und Gothiks. Saarbrücken: VDM Verlag Dr. Müller 2007.

BIERMANN, C. [U.A.]: Editorial. In: Friedrich-Jahresheft Schüler '97. Stars, Idole, Vorbilder. Seelze: Friedrich 1997, S.1.

BLOS, P.: Adoleszenz. Stuttgart: Klett-Cotta 1961.

BOHUS, M.: Borderline-Störung. Göttingen [u.a.]: Hogrefe-Verlag 2002.

BOS, W.; TARNAI, C. (HRSG.): Angewandte Inhaltsanalyse in Empirischer Pädagogik und Psychologie. Münster-New York: Waxmann Verlag 1989.

BOSSE, D.; MESSNER, R.: Idole in der Entwicklung von Kindern und Jugendlichen. In: Thema Jugend, Familien und Gesellschaft. Zürich: Verlag Pro Juventute Jg. 83/2002, H. 2, S. 2-4. 
Bosse, D.; Messner, R.: Idole im Leben von Kindern und Jugendlichen. In: Pädagogik, 2003, Heft 4, S. 40-43.

BREUER, A.: Die Begleitung Jugendlicher bei der Bewältigung von Entwicklungsaufgaben durch Rock- und Popmusik. In: Unsere Jugend 1998, Jg. 50 (8)/1998, S. 355-359.

BUBA, H.: Entwicklungsverläufe in der Postadoleszenz und Ablösung vom Elternhaus. In: Silbereisen, R. K.; Vaskovics, L.A.; Zinnecker, J. (Hrsg.): Jungsein in Deutschland. Jugendliche und junge Erwachsene 1991 und 1996. Opladen: Leske und Budrich 1996, S. 349-365.

CAMPBELL, J.: Der Heros in 1000 Gestalten. 4. Auflage (orig. 1949: Hero Man of 1000 Faces), Frankfurt am Main: Insel 1999.

CHARLTON, M.: Fernsehstars als Vorbilder? Warum Fernsehzuschauer nach Vorbildern suchen und warum Fernsehmacher daraus Konsequenzen ziehen sollten. In: Medien praktisch, 1994, Heft 1, S. 29-31.

CLARKE, J. [U.A.]: Jugendkultur als Widerstand, Frankfurt am Main: Syndikat 1979.

CORNELIßEN, W.: Klischee oder Leitbild? Geschlechtsspezifische Rezeption von Frauen- und Männerbildern im Fernsehen. Opladen: Westdeutscher Verlag 1995.

CORNELIßEN, W.: Die Kategorie Geschlecht und ihr Erklärungspotential für die Aneignung von medialen Präsentationen. In: Marci-Boehncke, G.; Werner, P.; Wischermann, U. (Hrsg.): Blickrichtung Frauen. Theorien und Methoden geschlechtsspezifischer Rezeptionsforschung. Weinheim: Deutscher Studienverlag 1996, S. 15-35.

DEUBER-MANKOWSKY, A.: Lara Croft - Modell, Medium, Cyberheldin. Das virtuelle Geschlecht und seine metaphysischen Tücken. Frankfurt am Main: Suhrkamp 2001.

DEWE, B.; FERCHHOFF, W.: Deutungsmuster. In: Kerber, H.; Schmieder, A. (Hrsg.): Handbuch Soziologie. Zur Theorie und Praxis sozialer Beziehungen. Reinbek: Rowohlt 1984, S. 76-81. 
DIEKMANN, A.: Empirische Sozialforschung. Grundlagen Methoden Anwendungen. 18. Auflage, Reinbek: Rowohlt 2007.

DREHER, E.; DREHER, M.: Wahrnehmung und Bewältigung von Entwicklungsaufgaben im Jugendalter: Fragen, Ergebnisse und Hypothesen zum Konzept einer Entwicklungs- und Pädagogischen Psychologie des Jugendalters. In: Oerter, R. (Hrsg.): Lebensbewältigungen im Jugendalter. Weinheim: VCH Verlagsgesellschaft 1985, S. 30-60.

DROSDOWSKI, G.; SCHOLZE-STUBENRECHT, W.; WERMKE, M.: DUDEN Fremdwörterbuch. 6. (erweiterte) Auflage, Mannheim: Brockhaus AG 1997.

EHRENREICH, B.; HESS, E.; JACOBS, G.: Beatlemania: Girls Just Want to Have Fun. In: Lewis, L.A. (ed.): The adoring audience: fan culture and popular media. London/New York: Routledge 1992, S. 84-106.

EL-NAWAB, S.: Skinheads Gothics Rockabillies. Gewalt, Tod \& Rock `n 'Roll. Berlin: Archiv der Jugendkulturen Verlag KG 2007.

ERIKSON, E. H.: Identität und Lebenszyklus. Sonderausgabe. Frankfurt am Main: Suhrkamp 1966.

ERIKSON, E.-H.: Identität und Lebenszyklus. Frankfurt am Main: Suhrkamp 1973.

ERIKSON, E.-H.: Jugend und Krise. Die Psychodynamik im sozialen Wandel. 5.Auflage, Stuttgart: Klett-Cotta 2003.

FAHR, A.; ZUBAYR, C.: Fernsehbeziehungen: Vorbilder oder Trugbilder für Jugendliche? München: Fischer 1999.

FAULSTICH, W.; KORTE, H. (HRSG.): Der Star. Geschichte, Rezeption, Bedeutung. München: Wilhelm Fink 1997.

FERCHHOFF, W.: Jugend und Jugendkulturen im 21. Jahrhundert. Lebensformen und Lebensstile. 1.Auflage, Wiesbaden: VS Verlag für Sozialwissenschaften 2007.

FISKE, J.: Die kulturelle Ökonomie des Fantums. In: SPoKK (Hrsg.): Kursbuch Jugendkultur. Stile, Szenen und Identitäten 
vor der Jahrtausendwende. Mannheim: Bollmann Verlag 1997, S. 54-69.

FRITZSCHE, B.: Pop-Fans. Studie einer Mädchenkultur. Opladen: Leske und Budrich 2003.

FUCHS-HEINRITZ, W. [U.A.] (HRSG.): Lexikon zur Soziologie. 3. Auflage, Opladen: Westdeutscher Verlag 1994.

FUHS, B.: Qualitative Methoden in der Erziehungswissenschaft. Darmstadt: WBG 2007.

GEMBRIS, H.: Situationsbezogene Präferenzen und Wirkungen von Musik. In: Jahrbuch Musikpsychologie. Bd.7, Wilhelmshaven: Noetzel 1990, S. 73-95.

GIOMI, E.: Lara Croft: Ein neues Vorbild für Actionheldinnen und Frauen? In: tv diskurs, 2005, Heft 34, S. 44-49.

GIOMI, E.: Lara Croft: Ein neues Vorbild für Action-Heldinnen und Frauen? In: Mikos, J.; Winter, R.; Hoffmann, D. (Hrsg.): Mediennutzung, Identität und Identifikationen. Die Sozialisationsrelevanz der Medien im Selbstfindungsprozess von Jugendlichen. Weinheim/München: Juventa 2007, S. 67-82.

GRIESE, H.M.: Personale Orientierungen im Jugendalter - Vorbilder und Idole. In: Sander, U.; Vollbrecht, R. (Hrsg.): Jugend im 20. Jahrhundert. Sichtweisen - Orientierungen - Risiken. Neuwied: Luchterhand 2000, S. 211-253.

GRIESE, H. M.; MANSEL, J.: Jugendtheoretische Diskurse. In: Mansel, J.; Griese, H. M.; Scherr, A. (Hrsg.): Theoriedefizite der Jugendforschung. Standortbestimmung und Perspektiven. Weinheim-München: Juventa 2003, S. 11-30.

GÖTTLICH, U.; NIELAND, J.-U.: Kultinszenierungen und Vermarktungsstrategie im Kontext von Endlosserien und Musiksendungen. Grenzen und Perspektiven. In: Willems, H. (Hrsg.): Die Gesellschaft der Werbung. Kontexte und Texte. Produktionen und Rezeptionen. Entwicklungen und Perspektiven. Konstanz: Westdeutscher Verlag 2002, S. 549-564. 
GÖTZ, M.: Wenn Mädchen Fans sind... Facetten der Medienaneignung in der weiblichen Adoleszenz. In: Beinzinger, D. [u.a.] (Hrsg.): Im Wyberspace. Mädchen und Frauen in der Medienlandschaft. Dokumentation, Wissenschaft, Essay, Praxismodelle. GMK-Schriften zur Medienpädagogik 26. Bielefeld: AJZVerlag 1998, S. 111-123.

GROßEGGER, B.: Jugendkultur Guide. 1. Auflage, Wien: öbv-hpt Verlagsgmbh\&Co KG 2002.

GRUNDMANN, M.: Aspekte einer sozialisationstheoretischen Fundierung der Jugendforschung. In: Hoffmann, D.; Merkens, $\mathrm{H}$. (Hrsg.): Jugendsoziologische Sozialisationstheorie. Impulse für die Jugendforschung. Weinheim-München: Juventa 2004; S.1734.

GUNDERSON, J.G.: Borderline. Diagnostik, Therapie, Forschung. Bern [u.a.]: Verlag Hans Huber 2005.

HALL, S.: Encoding/Decoding. In: Hall, S. [u.a.] (Hrsg.): Culture, Media, Language. London: Routledge 1980.

HALL, S.: Kulturelle Identität und Globalisierung. In: Winter, R.; Hörning, K.-H. (Hrsg.): Widerspenstige Kulturen. Cultural Studies als Herausforderung. Frankfurt am Main: Suhrkamp 1999.

HAMMANN, J.: Die Heldenreise im Film. Frankfurt: Zweitausendeins 2006.

HAUTZINGER, M. (HRSG.); DAVISON, G.C.; NEALE, J.M.: Klinische Psychologie. 6. Auflage, Weinheim: Beltz PVU 2002.

HAVIGHURST, R.J.: Developmental Tasks and Education, New York: Mckay 1972.

HÄUSERMANN, J. (HRSG.): Inszeniertes Charisma. Medien und Persönlichkeit. Tübingen: Max Niemeyer Verlag 2001.

HECKMANN, F.: Interpretationsregeln zur Auswertung qualitativer Interviews und sozialwissenschaftlich relevanter Texte. Anwendungen der Hermeneutik für die empirische Sozialforschung. In: Hoffmeyer- Zlotnik, J. (Hrsg.): Analyse verbaler Daten. Opladen: Westdeutscher Verlag 1992, S. 142-167. 
HOFFMANN, D.; MIKOS, L. (HRSG.): Mediensozialisationstheorien. Neue Modelle und Ansätze in der Diskussion. Wiesbaden: Verlag für Sozialwissenschaften 2007.

HORTON, D.; WOHL, R.-R.: Mass Communication and Para-Social Interaction: Observation on Intimacy at a Distance. In: G. Gumpert; R. Cathcart (Hrsg.): Inter Media Interpersonal Communication in a Media World. New York: Oxford University Press 1956.

HROB, G.: BLADE und die Shell-Studie. Warum sich die Teenies für düstere Comic-Helden begeistern. In: tv diskurs, Nr. 23, Januar 2003, S. 62-67.

HURRELMANN, K.: Lebensphase Jugend. Eine Einführung in die sozialwissenschaftliche Jugendforschung. 7. Auflage, Weinheim-München: Juventa 2004.

HURTH, E.: Vorbilder und Stars. Von Mutter Theresa zu Lara Croft. In: medien praktisch, 2001, Heft 1, S. 22-25.

IFEP GMBH: IBM-Jugendstudie `95. Tabellenband. Köln, 1995.

JANKE, K.: Stars, Idole, Vorbilder. In: Friedrich-Jahresheft Schüler '97. Stars, Idole, Vorbilder. Seelze: Friedrich 1997, S. 18-21.

JANKE, K.: Die Welt der Pop-Idole. In: Friedrich-Jahresheft Schüler '97. Stars, Idole, Vorbilder. Seelze: Friedrich 1997, S. 8588.

JUGENDWERK DER DEUTSCHEN SHELL (HRSG.): Jugend '97 [12. Shell Jugendstudie]. Opladen: Leske und Budrich 1997.

JUGENDWERK DER DEUTSCHEN SHELL (HRSG.): Jugend 2000 [13. Shell Jugendstudie]. Opladen: Leske und Budrich 2000.

KEUPP, H.: Auf dem Weg zur Patchwork-Identität? In: Verhaltenstherapie und Psychosoziale Praxis. 1988, Heft 4, S. 425-438.

KEUPP, H.: Die Reflexive Modernisierung von Identitätskontruktionen. Wie heute Identität geschaffen wird. In: Hafeneger, B. (Hrsg.): Subjektdiagnosen. Subjekt, Modernisierung und Bildung. Schwalbach /Ts.: Wochenschau-Verlag 2005, S. 60-91. 
KOEBNER, T. [U.A.]: Superhelden zwischen Comic und Film. Reihe: Film-Konzepte. 6. Auflage, München: Verlag edition text+kritik 2007.

KONRAD, K.: Mündliche und schriftliche Befragung. Landau: Verlag empirische Pädagogik 1999.

KORING, B.: Zur Professionalisierung der Lehrtätigkeit. Eine empirisch-hermeneutische Fallstudie. In: Zeitschrift für Pädagogik, Nr. 6, 1989, S. 787.

KRÜGER, H.; RICHARD. B.: Alte Muster und neue Namen. In: Friedrich-Jahresheft Schüler '97. Stars, Idole, Vorbilder. Seelze: Friedrich 1997, S. 30-33.

KRÜGER, H.-H.: Einführung in Theorien und Methoden der Erziehungswissenschaft. 4. Auflage, Opladen; Farmington Hills: Verlag Barbara Budrich 2006.

LAU, T.: Tank Girl in Taka-Tuka-Land. Über die Mutter und die Großmutter aller Girlies. In: SPoKK (Hrsg.): Kursbuch Jugendkultur. Stile, Szenen und Identitäten vor der Jahrtausendwende. Mannheim: Bollmann Verlag 1997, S. 214-219.

LAU, T.: Idole, Ikonen und andere Menschen. Madonna, Michael Jackson und die Fans. In: Kemper, P.; Langhoff, T.; Sonnenschein, U. (Hrsg.): „Alles so schön bunt hier." Die Geschichte der Popkultur von den Fünfzigern bis heute. Stuttgart: Reclam Philipp Junior 1999, S. 241-253.

LEICHSENRING, F.: Borderline-Stile. Denken, Fühlen, Abwehr und Objektbeziehungen von Borderline-Patienten. Bern [u.a.]: Verlag Hans Huber 1996.

LENZHOFER, K.: Chicks Rule! Die schönen neuen Heldinnen in USamerikanischen Fernsehserien. Bielefeld: transcript-Verlag 2006.

LEWIS, L.A. (ED.): The adoring audience: fan culture and popular media. London; New York: Routledge 1992.

LIEBAU, E.: Sehnsucht nach Sinn. In: Stars - Idole - Vorbilder. Friedrich Jahresheft '97. Seelze: Friedrich 1997, S. 22-25. 
LUCA, R.: "Rambo" und „Barbie". Mediale Gewaltdarstellung und -rezeption ist an die Geschlechtsrolle gebunden. In: Schorb, B.; Stiehler, H.-J. (Hrsg.): Medienlust - Medienlast. Was bringt die Rezipientenforschung den Rezipienten. München: KoPäd Verlag 1996, S. 143-152.

LUCA, R.: Medien und weibliche Identitätsbildung. Körper, Sexualität und Begehren in Selbst- und Fremdbildern junger Frauen. Frankfurt am Main: Campus 1998.

MARCIA, J.-E. [U.A.]: Ego Identity. A Handbook for Psychological Research. New York: Springer 1993.

MAYRING, P.: Einführung in die qualitative Sozialforschung. Eine Anleitung zu qualitativem Denken. München: Psychologie-Verlags Union 1990.

MAYRING, P.: Einführung in die qualitative Sozialforschung. Eine Anleitung zu qualitativem Denken. 3. überarbeitete Auflage, München: Psychologie Verlags Union 1996, S. 70-73.

MAYRING, P.: Einführung in die qualitative Sozialforschung. Eine Anleitung zu qualitativem Denken. 5.Auflage, Weinheim; Basel: Beltz Verlag 2001.

MEDIENPÄDAGOGISCHER FORSCHUNGSVERBUND SÜDWEST (HRSG.): JIM-Studie 2006. Jugend, Information, (Multi-) Media. Basisuntersuchung zum Medienumgang 12- bis 19-Jähriger. Stuttgart: 2006.

MEHLER, F.: Von Albert Schweitzer zu Madonna - braucht die Jugend heute noch Vorbilder? In: Deutsche Jugend, 43. Jg./1995, Heft 10, S. 453-459.

MIKOS, L.: Struktur-funktionale Film- und Fernsehanalyse. Teil 7: Helden, Versager und andere Typen. In: medien praktisch Zeitschrift für Medienpädagogik, 1998, Heft 4, S. 48-54.

MIKOS, L.: Helden zwischen Kampfgetümmel und Selbstzweifel. In: tv diskurs, 2003, Heft 6, S. 28-35.

MIKOS, L.; WEGENER, C. (HRSG.): Qualitative Medienforschung. Ein Handbuch. Konstanz: UVK-Verlag 2005. 
MÜLLER, R.: Soziale Bedingungen der Umgehensweisen Jugendlicher mit Musik. Essen: Die Blaue Eule 1990.

NIEHUES, S.: Wie werden Stars gemacht. Mechanismen der Unterhaltungsindustrie. In: Friedrich-Jahresheft Schüler '97. Stars, Idole, Vorbilder. Seelze: Friedrich 1997, S.70-72.

PAUS-HAASE, I.: Heldenbilder im Fernsehen. Eine Untersuchung zur Symbolik von Serienfavoriten. Opladen: Westdeutscher Verlag 1998.

RETTBERG, L.: Zu schön um wahr zu sein. Die digitale Lara Croft. In: montage a/v, 8. Jg./1999, Heft 2, S. 89-110.

RETTBERG, L.: Lara Croft. Geburt und Leben eines virtuellen Stars. In: tv diskurs, 2001, Heft 16, S. 64-69.

REULECKE, J.: Jugend - Entdeckung oder Erfindung? Zum Jugendbegriff vom Ende des 19. Jahrhunderts bis heute. In: Deutscher Werkbund e.V./Württembergischer Kunstverein (Hrsg.): Schock und Schöpfung. Jugendästhetik im 20. Jahrhundert. Darmstadt; Neuwied: Luchterhand 1986, S. 21-25.

RHEIN, S.: Teenie-Fans: Stiefkinder der Populärmusikforschung. Eine Befragung Jugendlicher am MultiMediaComputer über ihre Nutzung fankultureller Angebote. In: Heinrichs, W.; Klein, A. (Hrsg.): Deutsches Jahrbuch für Kulturmanagement 1999. Band 3. Baden-Baden: Nomos-Verlag 2000, S. 165-194.

RICHARD, B.: Beckham's Style Kicks! Die metrosexuellen Körperbilder der Jungenidole. In: Neumann-Braun, K.; Richard, B. (Hrsg.): Coolhunters - Jugendkulturen zwischen Medien und Markt. Frankfurt: Suhrkamp 2005, S. 244-260.

RINK, D.: Beunruhigende Normalisierung: Zum Wandel von Jugendkulturen in Deutschland. In: Das Parlament. Aus Politik und Zeitgeschichte, Band 5, 2002, S. 3-6.

SANDER, U.; VOLLBRECHT, R.: Zwischen Kindheit und Jugend. Träume, Hoffnungen und Alltag 13- bis 15jähriger. Weinheim; München: Juventa 1985, S. 22-29. 
SAB, H. [U.A.]: Diagnostisches und Statistisches Manual Psychischer Störungen - Textrevision - DSM-IV-TR. Göttingen: Hogrefe 2003.

SCHÄFER, H.: Helden, Verräter, Superstars. Agenten und Spione im Film. In: Stiftung Haus der Geschichte der Bundesrepublik Deutschland/Zeitgeschichtliches Forum Leipzig (Hrsg): Duell im Dunkel. Spionage im geteilten Deutschland. Köln: Böhlau-Verlag 2002, S. 145-151.

SCHÄFER, K.-H.: Homer und Platon als Gründerväter der Medienpädagogik. In: Fischer-Buck, A. [u.a.] (Hrsg.): Werte - pädagogische, biographische, politische Perspektiven. Franz Fischer Jahrbuch 2. Norderstedt: 1997, S. 75-95.

SCHÄFFER, B.: Die Band. Stil und ästhetische Praxis im Jugendalter. Opladen: Leske und Budrich 1996.

SCHLOTTAU, H., WALDMANN, K. (HRSG): Mehr als Karriere und Konsum. Jugendliche auf der Suche nach moralischen Orientierungen. Bad Segeberg: Verlag C.H. Wäser 1995.

SCHRÖDER, A.; LEONHARDT, U.: Jugendkulturen und Adoleszenz. Verstehende Zugänge zu Jugendlichen in ihren Szenen. Neuwied, Kriftel: Luchterhand Verlag GmbH 1998.

SCHWEIGER, W.: Theorien der Mediennutzung. Eine Einführung. Wiesbaden: VS 2007.

SELG, H.: Filmhelden als Gewaltmodell? Was gelernt wird, hängt von der Gesamtaussage ab (Interview). In: tv diskurs, 1998, Heft 6, S. 36-47.

SENNEWALD, N.: Alien Gender. Die Inszenierung von Geschlecht in Science-Fiction-Serien. Bielefeld: Transcript Verlag 2007.

SOMMER, C. M.: Stars als Mittel der Identitätskonstruktion. Überlegungen zum Phänomen des Star-Kults aus sozialpsychologischer Sicht. In: Faulstich, W.; Korte, H. (Hrsg.): Der Star. Geschichte, Rezeption, Bedeutung. München: Wilhelm Fink 1997, S. $114-124$. 
THEUNERT, H.: > > Einsame Wölfe $<<$ und $>$ s schöne Bräute $<<$. Was Mädchen und Jungen in Cartoons finden. München: BLM Schriftenreihe 1993.

TRÄM, A.: Die Bedeutung von Popstars für weibliche Jugendliche, betrachtet am Beispiel der Fans von Boygroups. Erklärungsansätze und medienpädagogische Schlußfolgerungen. Diplomarbeit im Fachbereich Pädagogik an der Universität Bielefeld 2001.

TREUMANN, K.-P. U.A: Medienhandeln Jugendlicher. Mediennutzung und Medienkompetenz. Das Bielefelder Medienkompetenzmodell. Wiesbaden: Verlag für Sozialwissenschaften 2007.

VATTERODT, NIKOLA: Boygroups und ihre Fans. Annäherung an ein Popphänomen der neunziger Jahre. Karben: Coda Musikservice und Verlag 2000.

VOLLBRECHT, R.: Von Subkulturen zu Lebensstilen. Jugendkulturen im Wandel, in: SpoKK (Hrsg.): Kursbuch Jugendkultur. Mannheim: Bollmann-Verlag 1997, S. 22-31.

VOLLBRECHT, R.: Politische Vorbilder von Jugendlichen? Ökorebellen als letzte Helden und das Ende der Vorbilder in der Postmoderne. In: Friedrich-Jahresheft Schüler '97. Stars, Idole, Vorbilder. Seelze: Friedrich 1997, S. 34-37.

VOLLBRECHT, R.: Jugendmedien. Tübingen: Niemeyer 2002.

WALLRAFF, K.: Weiss wie Schnee rot wie Blut und schwarz wie Ebenholz - Die Gothics, 2. Teil. 1. Aufl., Bad Tölz: Tilsner 2001.

WEGENER, C.: Identitätskonstruktion durch Vorbilder. Über Prozesse der Selektion, Aneignung und Interpretation medialer Bezugspersonen. In: medien + erziehung, 2004, Heft 6, S. 20-31.

WEGENER, C.: Medien, Aneignung und Identität. Stars im Alltag jugendlicher Fans. Wiesbaden: Verlag für Sozialwissenschaften 2008.

WEIDENKAFF, I.: Vom Reiz des Andersseins: Die Bedeutung von Subkulturen im Alltag junger Menschen. In: Grooper, E., Zim- 
mermann, H.-M. (Hrsg.): Raus aus Gewaltkreisläufen - Präventions- und Interventionskonzepte. 1. Aufl., Stuttgart: AJS-Jahrestagung 2000, S. 95.

WENDEL, C.: Mediale Idole von Grundschulkindern - untersucht an aktuellen Beispielen. Wiss. Hausarbeit. Universität Kassel 2000.

WIERTH-HEINING, M. (HRSG.): Filmrezeption und Mädchencliquen. Medienhandeln als sinnstiftender Prozess. München: kopaed 2004.

WINTER, R.: Medien und Fans. Zur Konstitution von Fan-Kulturen. In: SPoKK (Hrsg.): Kurbsuch Jugendkultur. Stile, Szenen und Identitäten vor der Jahrtausendwende. Mannheim: BollmannVerlag 1997, S. 40-53.

WITTE, M.D.; MÖLLER, R.; SANDER, U.: Die Bedeutung von Musik für Jugendliche: Eine Herausforderung für die Jugendforschung. In: Abel, J.; Möller, R.; Palentien, C. (Hrsg.): Jugend im Fokus empirischer Forschung: Klaus Peter Treumann zum 65. Geburtstag. Münster/New York: Waxmann. S. 177-198.

ZAREMBA, J.: Gender Non/Konform. Die produktive Uniformität von Heldinnen und Gamerinnen. In: Kaminski, W.; Lorber, M. (Hrsg.): Clash of Realities. Computerspiele und soziale Wirklichkeit. München: Kopaed 2006, S. 161-174.

ZINNECKER, J.: Selbstsozialisation - Essay über ein aktuelles Konzept. In: Zeitschrift für Soziologie der Erziehung und Sozialisation, 20. Jg. / 2000, Heft 3, S. 272-290.

\section{Internet}

Fan-Forschungsprojekt des Instituts für Soziologie der Freien Universität Berlin. URL: http://www.fanforschung.de/ - letzter Zugriff am 1.12.2009.

Gothic-City.de. Dresdens schwarze Seiten. URL: http://www.gothic-city.de/ - Zugriff am 10.4.200 
Iconkids \& youth (2007): Die Idole der Kids, Repräsentative Befragung von iconkids \& youth. URL: http://www.rankaholics.de/w/die+groessten+idole+deutscher+kids_1058 - Zugriff am 26.5.2009.

Lacrimosa - offizielle Homepage. URL: http://www.lacrimosa.ch letzter Zugriff am 05.10.2009.

Waldmann, Klaus (2000): Stars, Idole, Vorbilder. Was weiß die Jugendforschung? URL: http://www.step21.de/fileadmin/content-media/projekte/vorbilder_des_alltags/ PAEDAGOGIK_Stars_Idole_Vorbilder.pdf - Download vom 26.5.2009. 